Peter J.B. Hopkins Baring Asset Management

C. Hayes Miller, CFA Baring Asset Management

\title{
Country, Sector, and Company Factors in Global Equity Portfolios
}

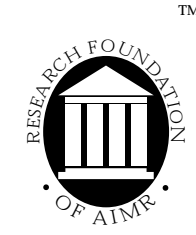




\section{Research Foundation Publications}

Active Currency Management

by Murali Ramaswami

Company Performance and Measures of

Value Added

by Pamela P. Peterson, CFA, and

David R. Peterson

Controlling Misfit Risk in Multiple-Manager Investment Programs

by Jeffery V. Bailey, CFA, and David E. Tierney

Corporate Governance and Firm Performance

by Jonathan M. Karpoff, M. Wayne Marr, Jr., and Morris G. Danielson

Country Risk in Global Financial Management by Claude B. Erb, CFA, Campbell R. Harvey, and Tadas E. Viskanta

Currency Management: Concepts and Practices by Roger G. Clarke and Mark P. Kritzman, CFA

Earnings: Measurement, Disclosure, and the Impact on Equity Valuation

by D. Eric Hirst and Patrick E. Hopkins

Economic Foundations of Capital

Market Returns

by Brian D. Singer, CFA, and

Kevin Terhaar, CFA

Emerging Stock Markets: Risk, Return, and Performance

by Christopher B. Barry, John W. Peavy III, $\mathrm{CFA}$, and Mauricio Rodriguez

The Founders of Modern Finance: Their PrizeWinning Concepts and 1990 Nobel Lectures

Franchise Value and the Price/Earnings Ratio by Martin L. Leibowitz and Stanley Kogelman

Global Asset Management and Performance Attribution

by Denis S. Karnosky and Brian D. Singer, CFA
Interest Rate and Currency Swaps: A Tutorial by Keith C. Brown, CFA, and Donald J. Smith

Interest Rate Modeling and the Risk Premiums in Interest Rate Swaps

by Robert Brooks, CFA

The International Equity Commitment

by Stephen A. Gorman, CFA

Investment Styles, Market Anomalies, and Global Stock Selection

by Richard O. Michaud

Long-Range Forecasting by William S. Gray, CFA

Managed Futures and Their Role in Investment Portfolios

by Don M. Chance, CFA

The Modern Role of Bond Covenants by Ileen B. Malitz

Options and Futures: A Tutorial

by Roger G. Clarke

Risk Management, Derivatives, and Financial Analysis under SFAS No. 133

by Gary L. Gastineau, Donald J. Smith, and Rebecca Todd, CFA

The Role of Monetary Policy in Investment Management

by Gerald R. Jensen, Robert R. Johnson, CFA, and Jeffrey M. Mercer

Sales-Driven Franchise Value

by Martin L. Leibowitz

Time Diversification Revisited

by William Reichenstein, CFA, and

Dovalee Dorsett

The Welfare Effects of Soft Dollar Brokerage:

Law and Ecomonics

by Stephen M. Horan, CFA, and

D. Bruce Johnsen 


\section{Country, Sector, and Company Factors in Global Equity Portfolios}


To obtain the AIMR Publications Catalog, contact: AIMR, P.O. Box 3668, Charlottesville, Virginia 22903, U.S.A. Phone 804-951-5499; Fax 804-951-5262; E-mail info@aimr.org or

visit AIMR's World Wide Web site at www.aimr.org to view the AIMR publications list.

The Research Foundation of The Association for Investment Management and Research ${ }^{\mathrm{TM}}$, the Research Foundation of AIMR ${ }^{\mathrm{TM}}$, and the Research Foundation logo are trademarks owned by the Research Foundation of the Association for Investment Management and Research. CFA ${ }^{\circledR}$, Chartered Financial Analyst ${ }^{\mathrm{TM}}$, AIMR-PPS ${ }^{\mathrm{TM}}$, and GIPS $^{\mathrm{TM}}$ are just a few of the trademarks owned by the Association for Investment Management and Research. To view a list of the Association for Investment Management and Research's trademarks and a Guide for the Use of AIMR's Marks, please visit our Web site at www.aimr.org.

(C) 2001 The Research Foundation of the Association for Investment Management and Research

All rights reserved. No part of this publication may be reproduced, stored in a retrieval system, or transmitted, in any form or by any means, electronic, mechanical, photocopying, recording, or otherwise, without the prior written permission of the copyright holder.

This publication is designed to provide accurate and authoritative information in regard to the subject matter covered. It is sold with the understanding that the publisher is not engaged in rendering legal, accounting, or other professional service. If legal advice or other expert assistance is required, the services of a competent professional should be sought.

ISBN-10: 1-934667-18-8 ISBN-13: 978-1-934667-18-7

Printed in the United States of America

August 2001

\section{Editorial Staff}

Bette Collins

Book Editor

Fiona D. Russell Cowen

Lisa S. Medders

Assistant Editors

Jaynee M. Dudley

Production Manager

Kelly T. Bruton/Lois A. Carrier

Composition 


\section{Mission}

The Research Foundation's mission is to identify, fund, and publish research that is relevant to the AIMR Global Body of Knowledge and useful for AIMR member investment practitioners and investors. 


\section{Biographies}

Peter J.B. Hopkins is a director of the Investment Management Group and head of the Quantitative Research Team (QRT) at Baring Asset Management. $\mathrm{He}$ is responsible for the quantitative stage of BAM's investment processes, including stock selection and market allocation modeling. As an investment manager, prior to setting up the QRT, Mr. Hopkins helped to develop BAM's process for evaluating Japanese equities. He holds an M.A. and D.Phil. in theoretical nuclear physics from Oxford University, where he was also a lecturer in physics and a research assistant in robotics.

C. Hayes Miller, CFA, is head of Baring Asset Management's Investment Management Team for North American clients and a member of BAM's Strategic Policy Group, which sets policy for global mandates. He is an asset allocation specialist and developed the country and sector screening models used by BAM. Before joining BAM as a portfolio manager in 1994, Mr. Miller worked at a leading European currency management firm and, previously, as director of research for a London-based international management firm. He holds a B.A. in economics and political science from Vanderbilt University and has conducted graduate studies at Temple University and Georgia State University. 


\section{Contents}

Foreword $\ldots \ldots \ldots \ldots \ldots \ldots \ldots \ldots \ldots \ldots \ldots \ldots$, viii

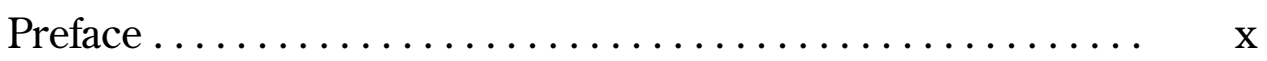

Chapter 1. Geography versus Sectors and Industries....... 1

Chapter 2. The Opportunity from Company and Stock Selection 41

Chapter 3. Countries, Sectors, and Stocks in Active Portfolio Management....................... 49

Chapter 4. Conclusions....................... 63

Appendix A. MSCI Global Industry Classification Standard . . 65

Appendix B. Regression Technique ................. 67

Appendix C. Explanatory Power Statistic .............. 69

Appendix D. Average Characteristics of Countries and

Sectors Used in Weighting .............. 71

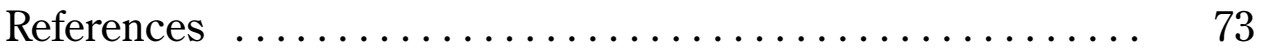

Selected AIMR Publications . . . . . . . . . . . . . . . . . . . . . $\quad 75$ 


\section{Foreword}

Successful management of equity portfolios requires a superior ability to efficiently combine forecasting of returns, risk estimation, and portfolio diversification. Before we can succeed at any of these activities, however, we must know how to stratify our opportunity set. Whereas in the past we may have achieved success by distinguishing among country returns, this skill may not serve us nearly as well in the future if differences in country returns shrink while differences in global sector returns grow. Moreover, efficient portfolio diversification depends critically on how we slice our investment universe. Should we focus on individual companies, industry groupings, economic sectors, or geographical regions? The answer to this question will determine, in large part, our chances of success.

Peter J.B. Hopkins and C. Hayes Miller, CFA, make an invaluable contribution to the resolution of this question. Several recent publications have addressed the stratification question, but Hopkins and Miller provide for the first time a comprehensive exploration of this issue by including four dimensions in their analysis-countries, sectors, industries, and companies-by applying a variety of innovative statistical methods, and by incorporating numerous permutations to address such issues as weighting schemes, classification rules, and investment constraints. Moreover, Hopkins and Miller address this critical topic, not from the idealized perspective of academics with a license to gloss over real-world complexities, but from the vantage point of professional portfolio managers who spend the largest part of their lives in the trenches of the world's most competitive and sophisticated financial markets. Yet, Hopkins and Miller neither bend in the slightest to commercial interests nor compromise on statistical rigor.

This monograph serves as a valuable resource for the investment community because it provides clear and thorough descriptions of a variety of statistical methods and, of course, provides an abundance of statistical results. Yet, Hopkins and Miller extend the value of this monograph beyond mere documentation by drawing on their considerable investment experience to gain an understanding of the underlying causes of the changes they observe, and these causes, of course, bear upon the durability of the changes. For example, not only do the authors document the statistical emergence of global sectors, but they also offer valuable insight into the degree to which the "new economy" and the attendant mercurial performance of technology stocks explain this phenomenon. 
This monograph is indispensable to anyone who is charged with the responsibility of forecasting returns, estimating risk, or structuring efficient portfolios in the global arena. The Research Foundation is pleased to present Country, Sector, and Company Factors in Global Equity Portfolios.

Mark P. Kritzman, CFA Research Director The Research Foundation of the Association for Investment Management and Research 


\section{Preface}

We address two fundamental questions for active managers of international equity portfolios. First, how important have sectors and industries become relative to countries? Second, how much scope does stock selection provide relative to top-down country and sector selection for adding value to global equity portfolios?

These issues are relevant to plan sponsors, consultants, fund managers, and research teams for a variety of reasons. Plan sponsors and their consultants frequently try to find optimal ways to diversify within their international equity strategies. Strategies that distinguish between bottom-up versus topdown methods, together with diversifying by value versus growth, are generally considered the predominant methods. For international strategies, diversification has historically been based on geography. But processes that allocate among sectors may offer better diversification benefits than those that are geographically based. Moreover, managers must make critical decisions about allocating their own resources for research-whether to focus on stock selection or asset classes, on geography or industry.

Chapter 1 of this monograph deals with the relative importance of countries, sectors, and industries in the developed markets. It contains tests for what drives the average stock return and the homogeneity of each class of asset. This ground has been fairly well covered in recent years, as the References list will attest. We have not unearthed any clever new ways to ascertain the changing structure of markets, but we do provide a comprehensive set of tests that offers multiple angles on the recent data. This chapter also tries to identify those industries and countries that are more important to forecast. If asset managers can identify the degree to which country, sector, and industry factors drive stock returns on average and which countries, sectors, and industries are the more homogenous, they will have a good guide for how to apply research.

Chapter 2 examines the opportunities available for stock selection within countries and sectors and attempts to relate these opportunities to those available to top-down decision makers. Relatively little research has been published in this area, which is a surprise in light of the vociferous debates between top-down and bottom-up devotees. This topic is more challenging than the well-worn ground in Chapter 1, however, and is less accessible through quantitative tests.

By synthesizing data from a variety of sources, Chapter 3 turns the reader's attention to our findings about countries, sectors, and stocks in the "active portfolio management" framework of Grinold and Kahn (1995). We 
discuss the implications for the differences in breadth of decisions across countries, sectors, and stocks as well as the possibility that the information coefficients (thus, the rewards to research) may be different for these decisions. Chapter 3 closes with a discussion of ideas for further research related to implications for the information coefficients of stock selection versus those of country selection.

In our tests reported in this monograph, one of the ways we tried to add value to the existing literature was to use the Morgan Stanley Capital International standard for country, sector, and industry classifications. We believe that the general industry preference for MSCI indexes-in North America, especially for the Europe/Australasia/Far East Index-demands that the MSCI Global Industry Classification Standard, which began in late 1998, form the basis for sector and industry analysis. To use this system for the sample period we studied (December 1992 through December 2000), we manually "backfilled" the indexes according to a method described in Chapter 1 . This approach, we believe, makes the conclusions particularly appropriate for asset managers or plans that are benchmarked to an MSCI index. We also performed tests through the year 2000, which helps bring some previous work up to date.

We would like to thank Wenling Lin for sharing her updated research, Intersec Research Corporation for accommodating numerous special data requests, and Amy Chong for extensive production assistance. 



\section{Geography versus Sectors and Industries}

The study of the relative importance of country factors, sector factors, and industry factors blossomed in the 1990s as data vendors began to improve their approach to global sector classification. Study was enhanced as the heralding of the single currency in Europe prompted researchers to analyze intra-European stock-price drivers. Although trends in continental Europe are important to global integration by virtue of Europe's size in the indexes, we are concerned with the global implications of sector importance rather than the European focus of many previous researchers. It is not yet totally clear that geographical importance has permanently diminished on a global basis or that sectoral importance has increased globally.

Exhibit 1.1 lists the key publicly available studies relevant to this monograph and indicates the universe, sample period and size, and other characteristics of each study. These studies differ materially, sometimes substantially, from each other. In this chapter, we describe the cross-sectional dummy tests, time-series tests, and cluster tests we carried out. In each section, we briefly review the key modeling methods used in previous work and discuss how our approach and findings relate to those studies.

An important design question has revolved around the various data vendors' industry classifications. Country designations have been fairly straightforward, but each vendor seems to have arrived at a different set of industry and sector groups. 1 We chose to use the Global Industry Classification Standard developed by Morgan Stanley Capital International, primarily because of the standard's acceptance by the market. MSCI recently changed its classification system to correct some well-known deficiencies. The new system, formed in conjunction with Standard \& Poor's, contains 10 sectors, 23 industry groups, 59 industries, and 144 subindustries. Exhibit 1.2 shows the new industry groups by sector. The complete classification system is in Appendix A.

MSCI formed these classes in late 1998 and began keeping class-level data as of January 1999. It has not yet created historical series based on the new

1 With respect to country designations, we do not wish to understate the importance of multinational companies, foreign listings, or the trend toward convergence of stock exchanges across borders. Certainly, index providers will have to grapple with these issues in the future. 


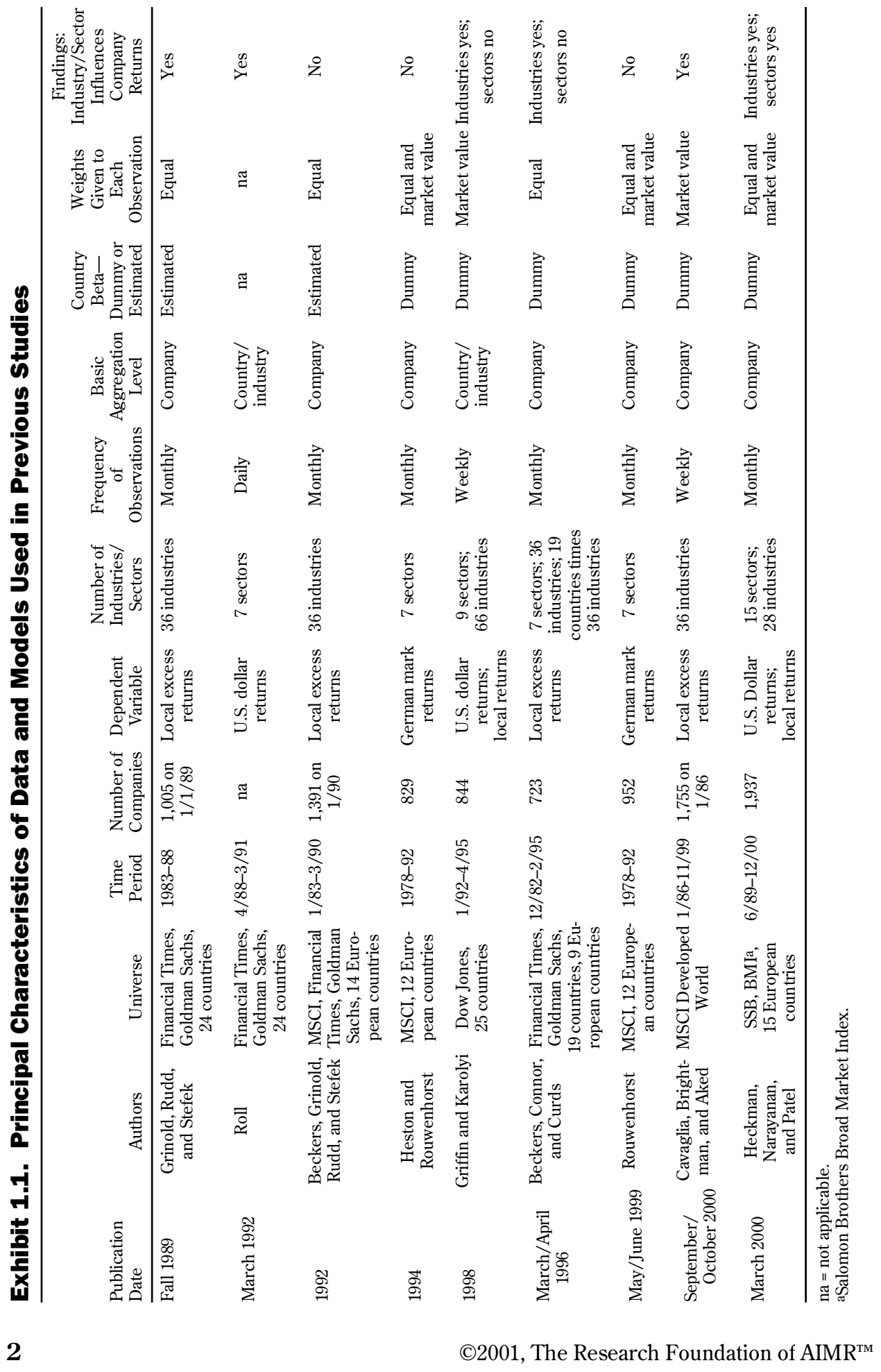




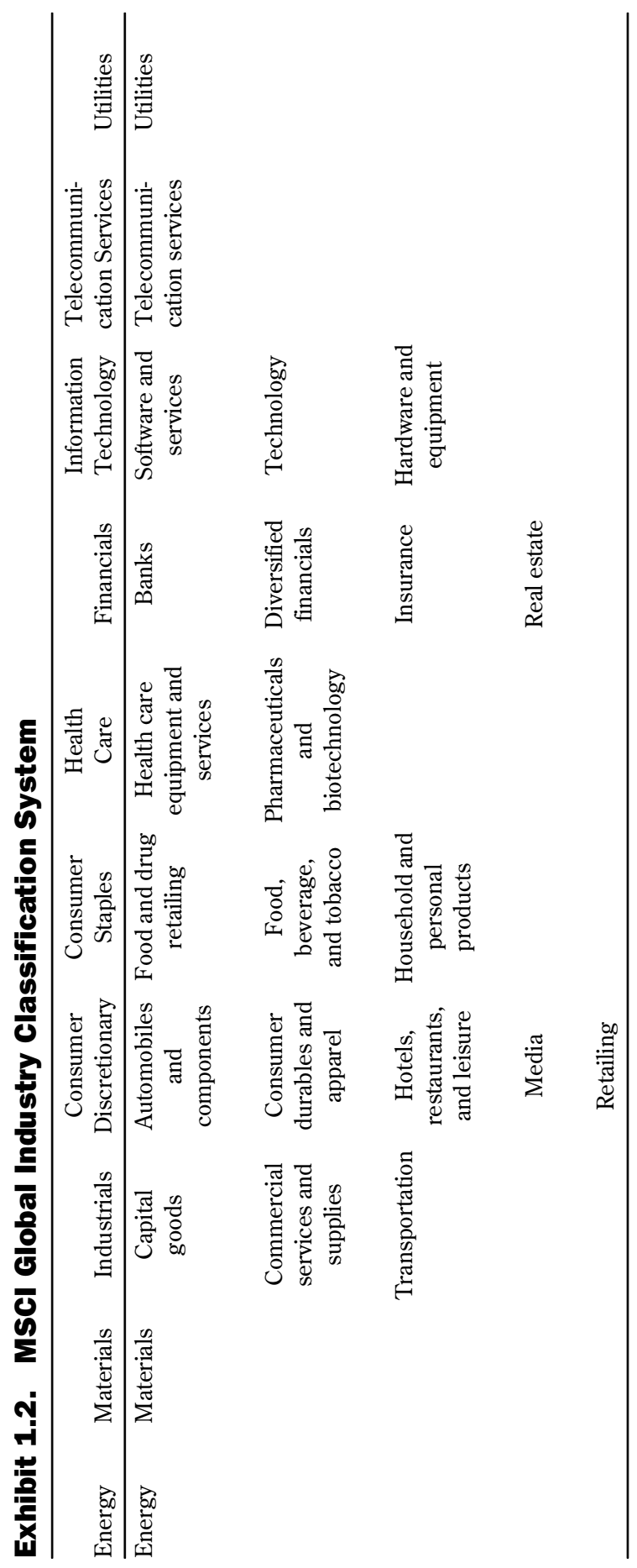


system. Thus, for the study reported here, we manually created historical series by mapping the old MSCI classes into the new. In certain cases, we had to assign a company to an industry based on its revenue source. Most of the mapping uncertainties occurred at the industry level, so we feel confident that the more generalized "industry group" and "sector" levels are cleanly defined. We conducted this exercise for all MSCI constituents back to December 1992, giving us eight years of data ending December 2000. To test our classification, we regressed our performance time series at the sector level with the subsequently released five-year history from MSCI for the 1996-2000 period. In each sector except in utilities, we achieved correlations of 99.5 percent or better; for the utilities sector, the correlation was closer to 99 percent. These results suggest that our conclusions should not be materially altered because of the stock classifications.

\section{Cross-Sectional Dummy Tests}

We found the methodology first used by Heston and Rouwenhorst (1994) to be one of the best ways to gauge the impact of country-specific factors versus the impact of sector/industry-specific factors. Their method, which relies on the regression techniques summarized in Appendix B, uses individual returns for each stock in the universe for each period reviewed. For our purposes, we used every stock in the MSCI World Index for monthly periods going back eight years. For each month, we disaggregated the full set of stock returns into a global market return (the alpha variable) and a set of country and industry or sector returns (the factor coefficients for each country, industry, or sector). Additionally, a residual exists for each stock that might be regarded as the stock-specific information. We were able to use the country, sector, and industry coefficients for each month to evaluate the relative importance of the country or sector. We could also watch them through time to see trends.

A benefit of using this technique is that each sector coefficient can be thought of as country neutral and each country coefficient can be thought of as sector neutral. The factor return for the Netherlands, for example, was determined independently of the fact that the Dutch index is heavily weighted by the Royal Dutch/Shell Group and is, therefore, substantially exposed to the energy sector. Similarly, the factor return for the information technology sector was determined independently of the influence that the U.S. market has on that sector.

Beckers, Connor, and Curds (1996) used the same methodology but added two interesting twists. First, they added a statistic that measures the explanatory power of the regressions better than the usual $R^{2}$ statistic. Their explanatory power (EP) statistic explained the causality of the regression 
better than $R^{2}$ by adjusting for the global market, or alpha parameter, of the regressions. Second, by performing the regressions on countries only, industries only, sectors only, and then on combinations thereof, they measured the relative increase in explanatory power of the regressions from the addition of each element-which gives a good indication of the relative importance of each. Calculation of the EP statistic is explained in Appendix C.

Previous researchers differed in their approach to currency. We chose to focus on hedged returns from the standpoint of a U.S.-based investor (i.e., the local-currency equity return less the U.S. risk-free rate as measured by the U.S. Treasury bill). Hedged returns have the benefit of isolating the equity return effects from the currency effects. For example, one would not want to find in the tests that energy stocks globally reacted to a significant oil price move but that the energy sector's factor return was diminished because of significant divergences between the U.S. dollar, European currencies, and Asian currencies. ${ }^{2}$ At the same time, hedged returns are achievable by U.S.based international investors, which makes them preferable to simple localcurrency returns.

We ran regressions on both equal-weighted and value-weighted bases. In the equal-weighted tests, each stock's return counted for the same weight for the regression's result. To value-weight the regressions, we carried out a weighted least-squares approach (because in an ordinary least-squares regression technique, market capitalization is not taken into consideration). In the weighted least-squares method, the regression outcome is weighted by the market capitalization of each stock. Intuitively, the importance of any differences in the results depends on the importance of capitalization (thus liquidity) in the investment program. The manager of a concentrated stock program with a small asset base need not be too concerned about capitalization, so the equal-weighted results might be more applicable for such a program. The relative importance of countries, sectors, and stocks is different for such a manager from their importance for the manager of a large pension fund, for example, simply because the first manager has no capitalization constraints. A program that buys and sells country or sector baskets will care more about the relative importance of countries and sectors in a value-weighted context.

The regressions provided coefficients for each month. The coefficients were quite volatile, however, from month to month. For example, in March 1999 , when the price of a barrel of oil rose from $\$ 9.50$ to $\$ 15.50$, the energy

\footnotetext{
2 Currency movements are exogenous drivers of stocks because a foreign exchange movement indicates, among other things, import and export shifts as well as inflationary considerations. Currency movements, therefore, are one driver of country factor returns; the movements tend to affect many companies within a country in the same way.
} 
sector factor coefficient spiked dramatically. The following months, it settled down to more normal levels. Therefore, to clearly compare factor returns, we had to take averages through time. We chose to compare 36-month moving averages, so in this discussion, the factor returns at any point are records of the previous three years.

Finally, all the factor returns shown are positive (even though for a country or sector factor coefficient to be negative is perfectly normal) because we used the absolute value of the coefficients. The reason for using absolute values is that we were trying to compare the strength of the country or industry effect, not the direction. Large negative coefficients and positive coefficients both signal a strong effect.

Factor Returns. We began with calculating rolling 36-month factor returns, in absolute value terms, for each of the 21 countries from the valueweighted combined country plus sector $(\mathrm{C}+\mathrm{S})$ regressions. ${ }^{3}$ Figure $\mathbf{1 . 1}$ shows the country factor results, with selected countries highlighted and the rest of the index in a shaded band. 4 The most obvious feature of Figure 1.1 is the recent upward trend of the coefficients as measured against the global average. This trend indicates either more-extreme country returns around the global average or, possibly, greater importance of countries as a driver. Hong Kong and Singapore factor returns began an impressive rise in the summer of 1997, just as the Asian currency crisis got into full swing. Keep in mind that these results are based on hedged currency returns, so currency movements did not directly affect the results. Finland and Italy, which lie at the top of the band, have shown persistently high factor coefficients, and these coefficients rose even more beginning at the end of 1998. Conversely, the United States, Canada, and the United Kingdom had persistently low factor returns in the period.

The countries with the strongest factor returns are apparently those with smaller, less diversified markets; the larger markets have more modest factor returns. As mentioned previously, these factor coefficients for the countries should be interpreted as "sector neutral," so industry composition should not be the reason for this difference. 5 Moreover, Australia, which had a low

3 The countries in our study were Australia, Austria, Belgium, Canada, Denmark, Finland, France, Germany, Hong Kong, Ireland, Italy, Japan, the Netherlands, New Zealand, Norway, Singapore, Spain, Sweden, Switzerland, the United Kingdom, and the United States. Portugal was left out for lack of data in the early part of the time period.

4 Complete color versions of Figures 1.1-1.3 and 1.11-1.13 are available for a limited time on the Web at aimrpubs.org, or contact info@aimr.org.

5 Since Roll (1992), a debate has been running about the importance of industry composition in explaining cross-border returns. Our tests did not address this question. 
Figure 1.1. Selected Cap-Weighted Country Factor Returns, December 1992-December 2000 Data

(36-month moving average)

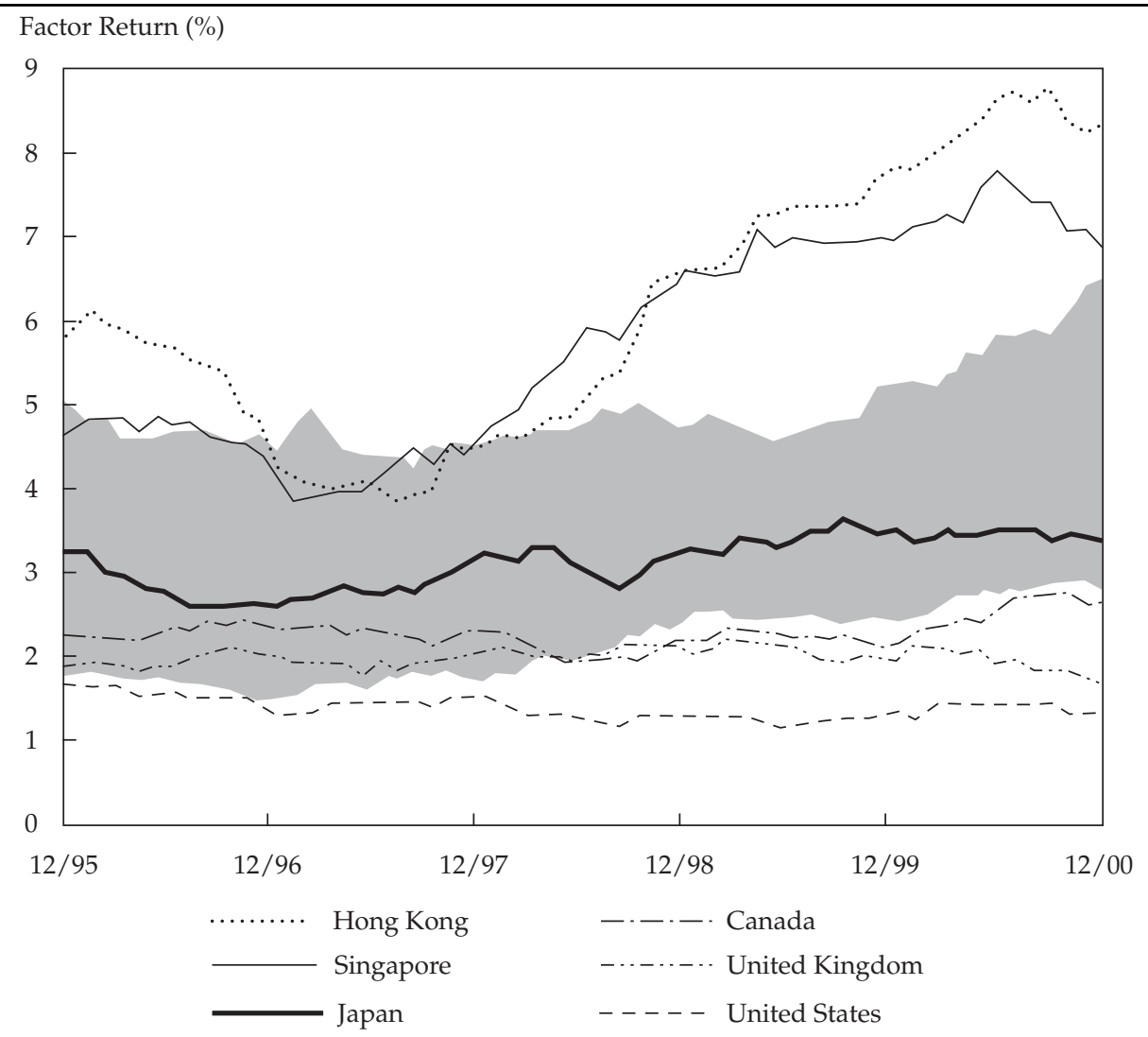

Note: The gray band encompasses the remaining countries.

coefficient in the period, is not as diverse as Japan or France, which had somewhat higher factor coefficients. ${ }^{6}$ But although industrial diversity does not explain all of the factor differences, a more diversified market is less likely to generate extreme returns around the global average and thus less likely to generate high country factor returns. Additionally, large markets, such as the United States, contribute more to the global market average and may have difficulty generating excess country factor returns around a market-weighted global mean, which was expressed by the regression's alpha.

6 "Diversity" was measured by the Concentration Index in Roll. 
As shown in Figure 1.2, factor returns for the 10 MSCI sectors also increased in the 1996-2000 period and increased much more steeply than they did for countries. The increase indicates either more-extreme sector returns around the global average or a rising importance of sectors as drivers. The persistent rise in information technology is not surprising in light of the

Figure 1.2. Selected Cap-Weighted Sector Factor Returns, December 1992-December 2000 Data

(36-month moving average)

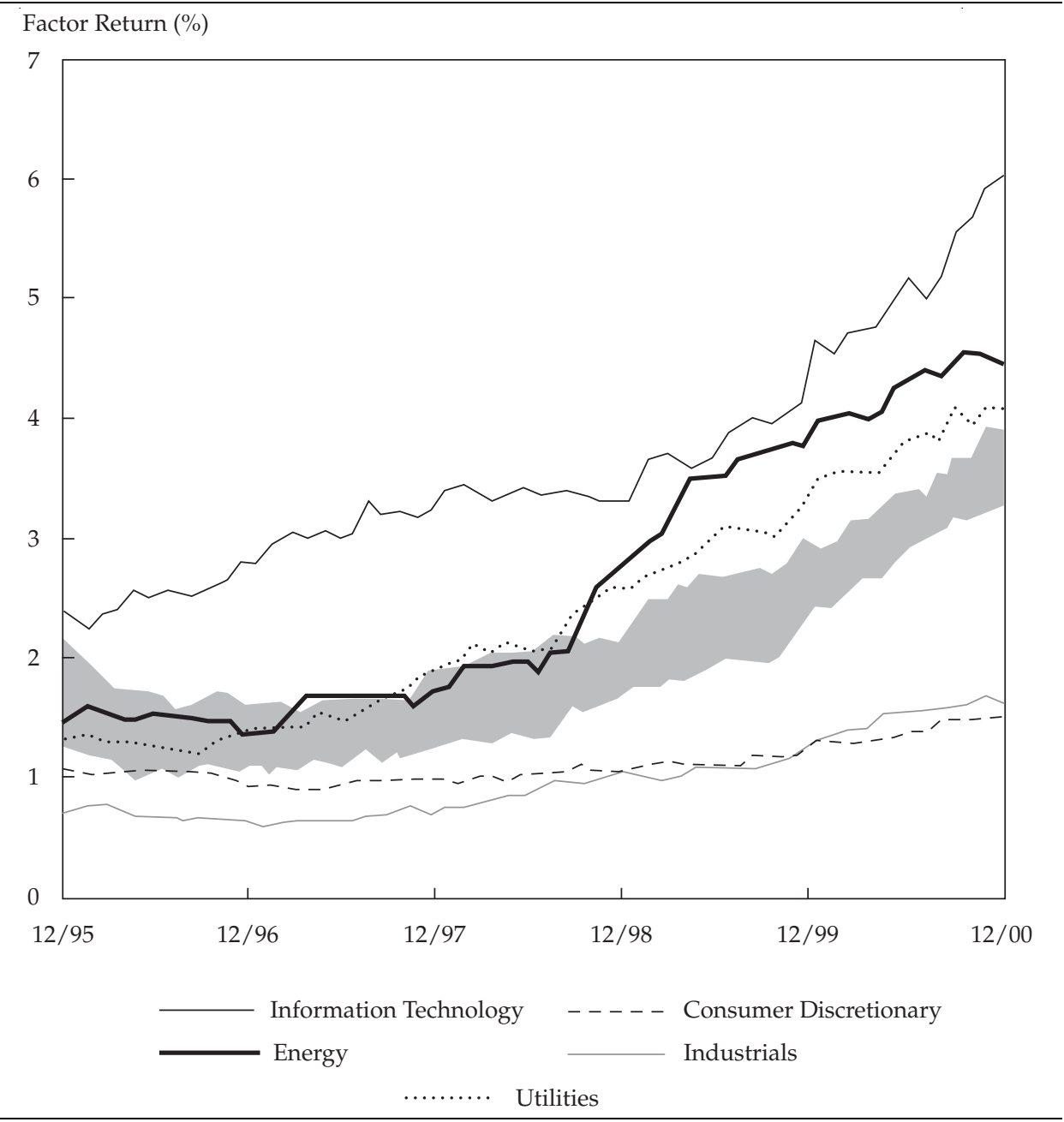

Note: The gray band encompasses the remaining sectors. 
extreme returns and global nature of the IT revolution. Equally interesting is the rise in the energy sector coefficient, probably a result of the extreme price movements of oil and gas in the period and the similar reactions of global energy stock prices. Perhaps most interesting of all is the strength of the factor returns for the utilities sector since 1999. This sector has been generally perceived to be composed of domestic industry groups subject to local interest rates and regulatory environments. The strong factor returns might be explained by returns that were persistently lower than average for utilities around the globe through 1999 rather than by a globalization of utilities.

To ascertain the relative importance of the 23 more refined industry groups, we calculated the factor returns for the regressions incorporating countries and industry groups $(\mathrm{C}+\mathrm{IG}) .{ }^{7}$ Results for the industry groups, shown in Figure 1.3, tell a story very similar to that of the sector results but with more precision. Both of the industry groups contained by the IT sector (the technology hardware and equipment group and the software and services group) had very high and rising coefficients in the period. The hardware side was much more prominent in the last five years than earlier. These results also differ for the cap- and equal-weighted regressions because these industry groups have been dominated by some enormous companies that have been propelled into even larger entities by the "winner-take-all" mentality of the late 1990s' technology boom. When returns were equal-weighted, the results for hardware and (especially) software were more muted in absolute and relative terms.

Comparing Countries with Sectors and Industry Groups. To derive the relative importance of countries versus sectors and industry groups, we had to compare the factor returns directly. To do so, we calculated average country factor coefficients over the rolling 36-month periods. We carried out the factor return comparisons with the United States included in the analysis and excluded from the analysis.

Results with U.S. stocks included. The averages were calculated both on a country-weighted basis (where the United States represented about 50 percent of the weight in 2000) and on an equal-weighted basis. We then did the same for the sector and industry groups, with the $\mathrm{C}+\mathrm{S}$ and $\mathrm{C}+\mathrm{IG}$ coefficients, respectively.

Figure 1.4 and Figure 1.5 show, respectively, the average country versus sector and country versus industry group coefficients in countryweighted (i.e., market-weighted) terms. The results clearly show that both sector and industry group effects have become more pronounced than country

7 The country coefficients were broadly similar to those for the $\mathrm{C}+\mathrm{S}$ regressions. 
Figure 1.3. Selected Cap-Weighted Industry Group Factor Returns, December 1992-December 2000 Data

(36-month moving average)

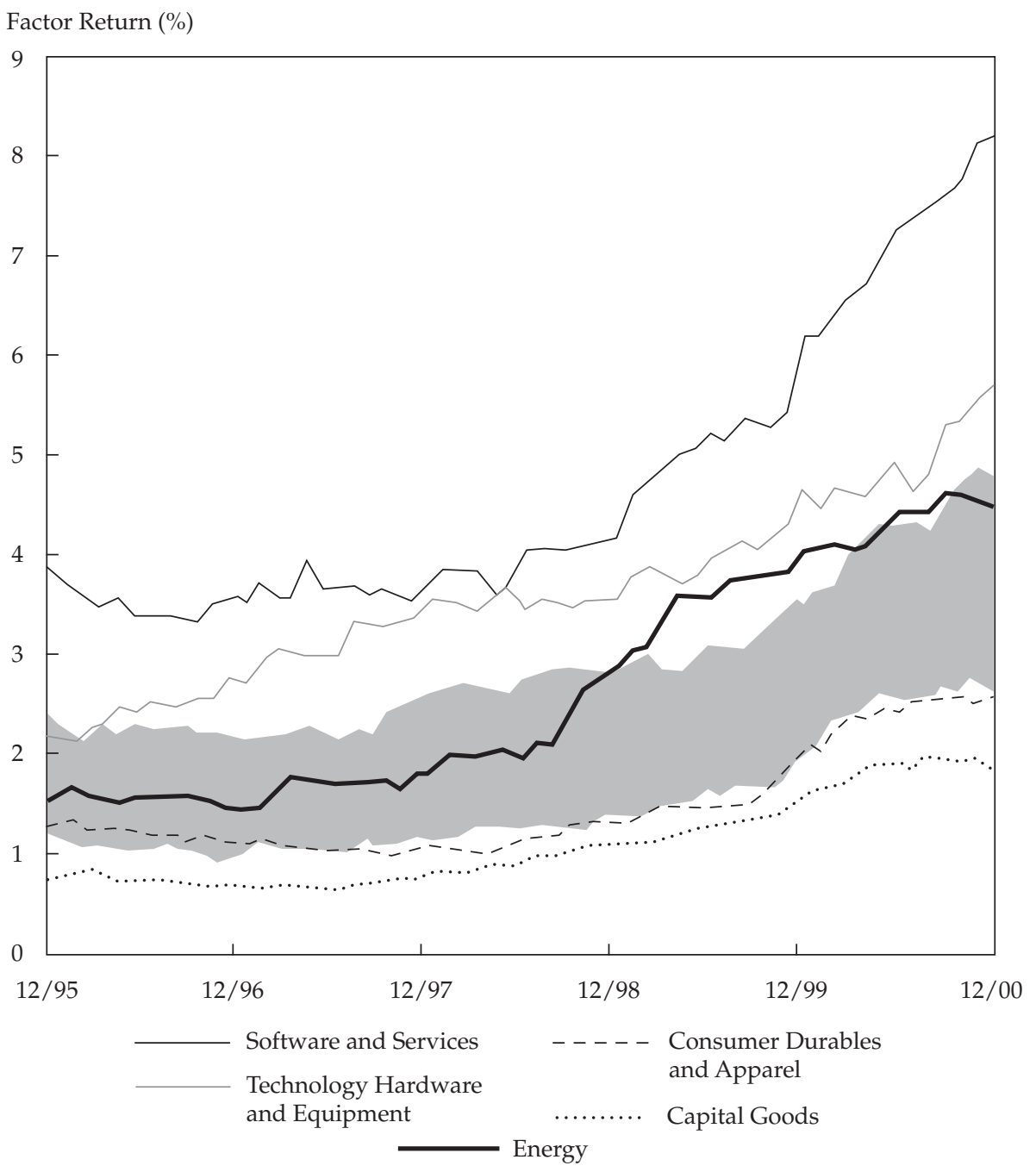

Note: The gray band encompasses the remaining sectors.

effects in the past few years. Overall, industry group effects are stronger than those for sectors but not by a substantial margin. 
Figure 1.4. Market-Weighted Average Country and Sector Factor Returns, December 1992-December 2000 Data

(36-month moving average)

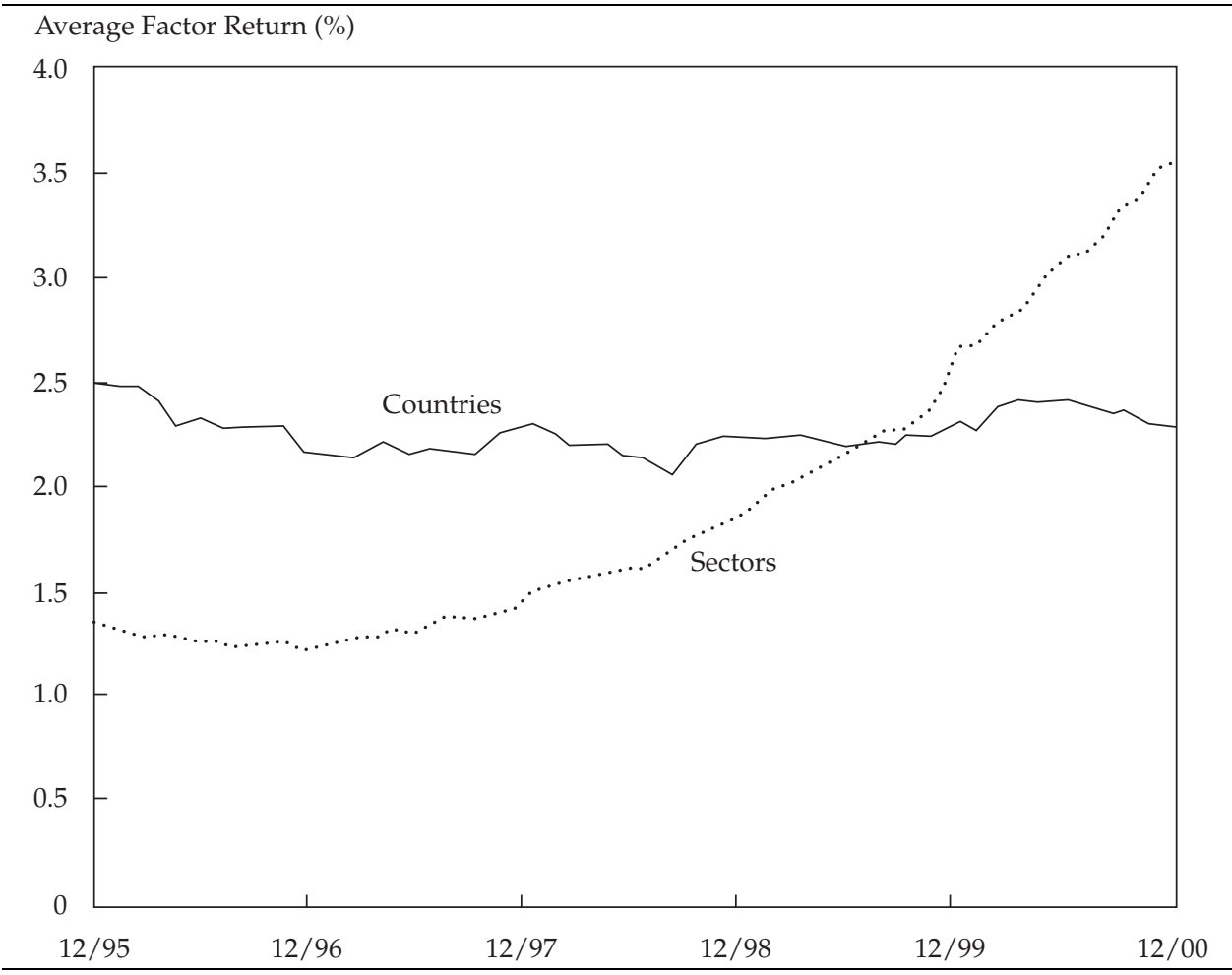

When equal weighting was used to compute the average country, sector, and industry group coefficients, however, a different story emerged. 8 As can be seen in Figure 1.6 and Figure 1.7, country factors remained dominant in an equal-weighting context, although by a decreasing margin.

This dichotomy between the country- and equal-weighted results might be explained by the fact that the strongest country factor coefficients come from the smaller countries whereas the strongest sector/industry group factor coefficients come from large sectors/industry groups. Furthermore, many of the largest country markets (the United States, France, and the United Kingdom) are highly diversified by sector whereas the largest sector (IT) is not so diversified among countries.

8 These results still apply to capitalization-weighted regressions, where stocks were weighted to arrive at monthly cross-sectional factors. The equal weighting referred to here has to do with weights on countries, sectors, and industries to arrive at the average coefficients each month. 
Figure 1.5. Market-Weighted Average Country and Industry Group Factor Returns, December 1992-December 2000 Data (36-month moving average)

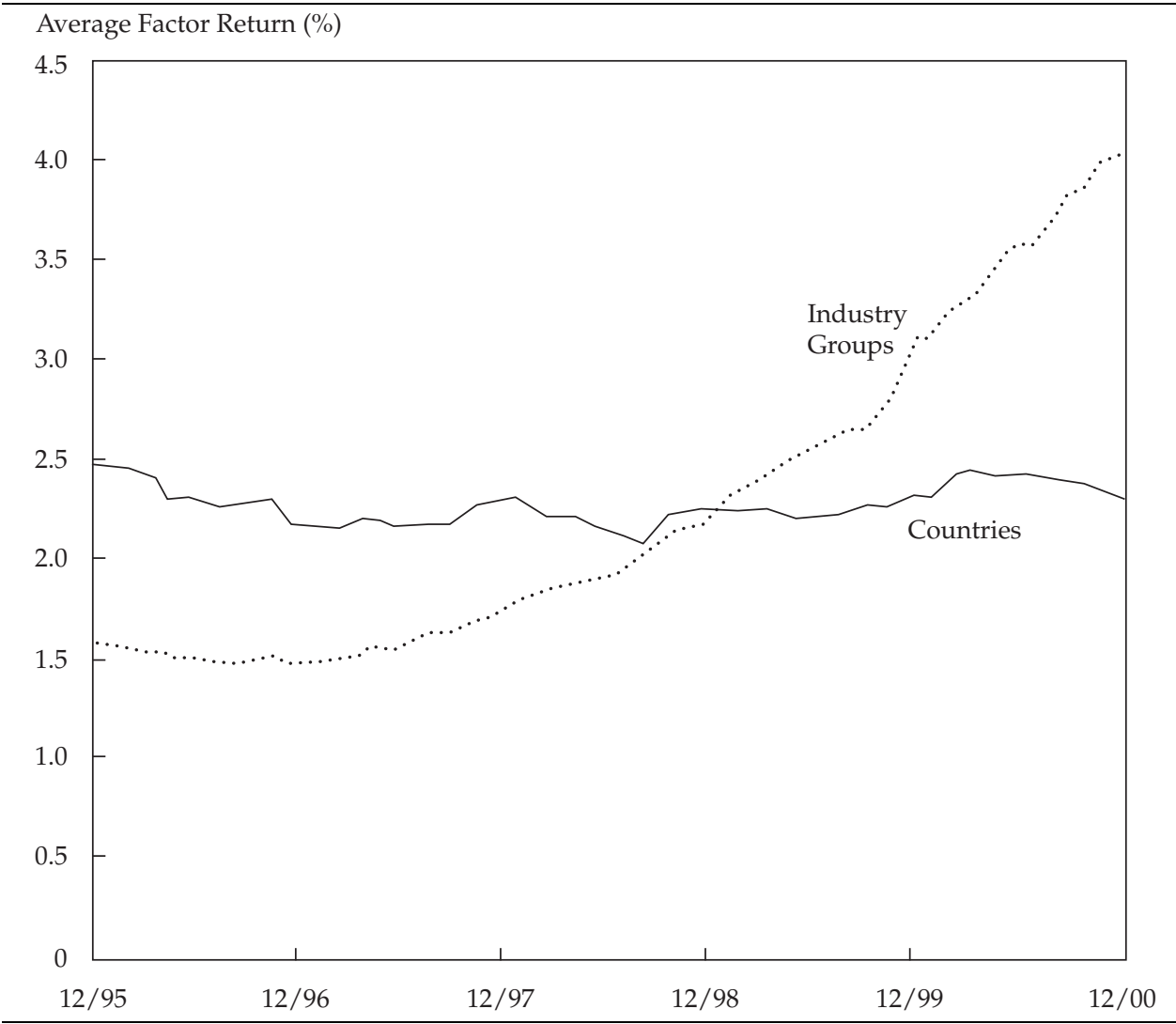

Results with U.S. stocks excluded. A large amount of international assets is managed on a non-U.S. basis with the Europe/Australasia/Far East (EAFE) Index of developed countries as the benchmark. Because the marketweighted regression results reported in the preceding section were heavily influenced by the large weight of the United States, which has a low country factor return, we were interested in results that excluded the United States. As demonstrated by a comparison of Panel A in Figure 1.8 with Figure 1.5, for these tests, sector prominence is markedly lower and the country effect is stronger.

Two conclusions are possible. First, the country effect increases because the United States, the largest country, has the lowest factor returns. Second, because the United States is home to such a significant portion of the IT sector "high flyers," taking these companies out reduces the IT sector factor returns. 
Figure 1.6. Equal-Weighted Average Country and Sector Factor Returns, December 1992-December 2000 Data

(36-month moving average)

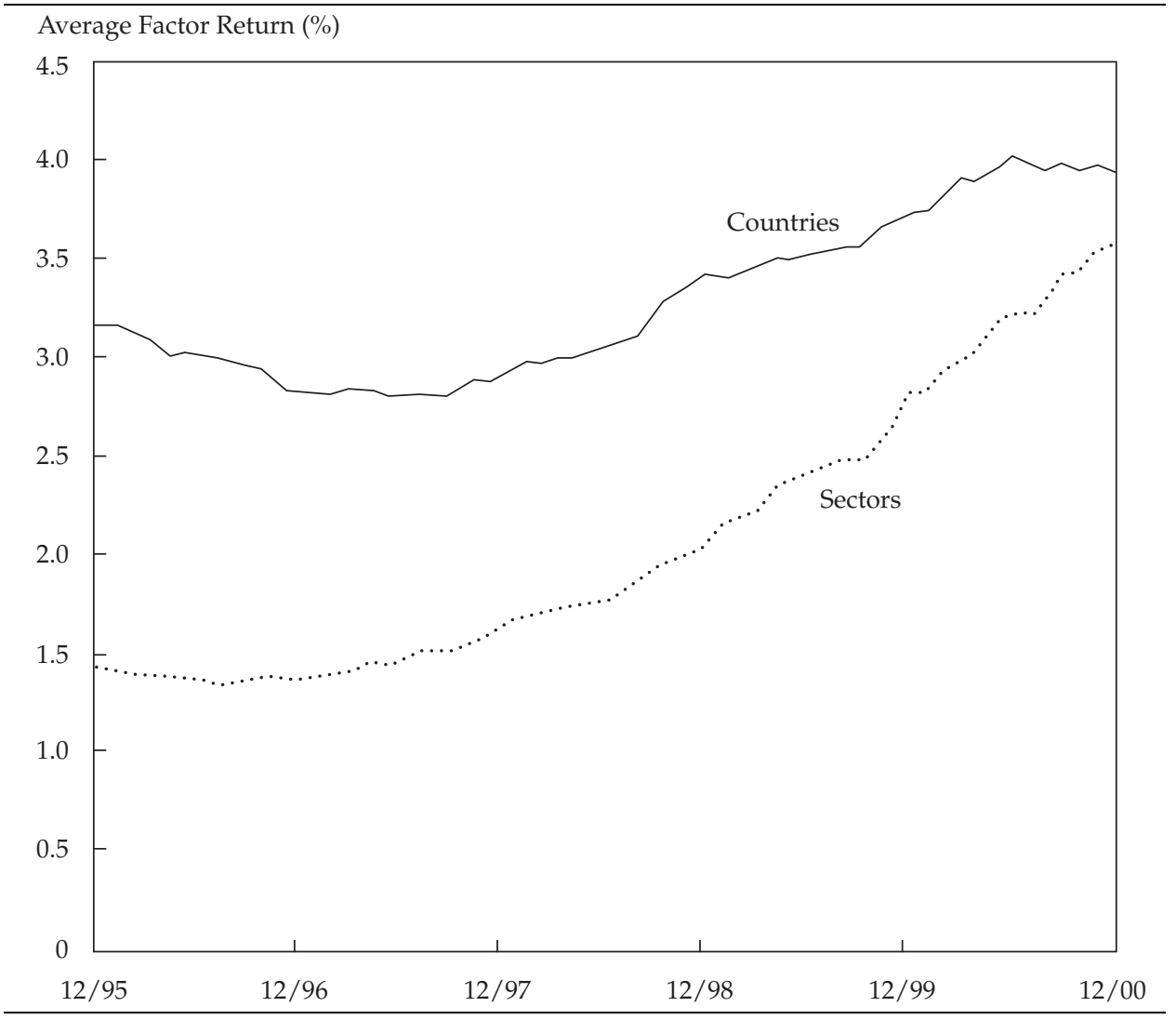

Panel B of Figure 1.8 shows the results of computing the factor returns for the non-U.S. universe on an equal-weighted basis. Comparing the graph in this panel with Figure 1.6, the global equal-weighted results, reveals little difference in results when the United States is removed and markets are equalweighted, precisely because the United States does not account for a large portion of the global equal-weighted results.

For the average institutional investor, the most meaningful scenario lies somewhere between the market- and equal-weighted results. Neither method alone is truly representative of a world where investors of significant size have choices that are constrained by market capitalization (liquidity) issues. Thus, for most institutional investors, countries continue to prevail in importance. But industry groups and, to a slightly lesser degree, sectors have now caught up and seem to be strengthening. For structured programs, the bias should 
Figure 1.7. Equal-Weighted Average Country and Industry Group Factor Returns, December 1992-December 2000 Data (36-month moving average)

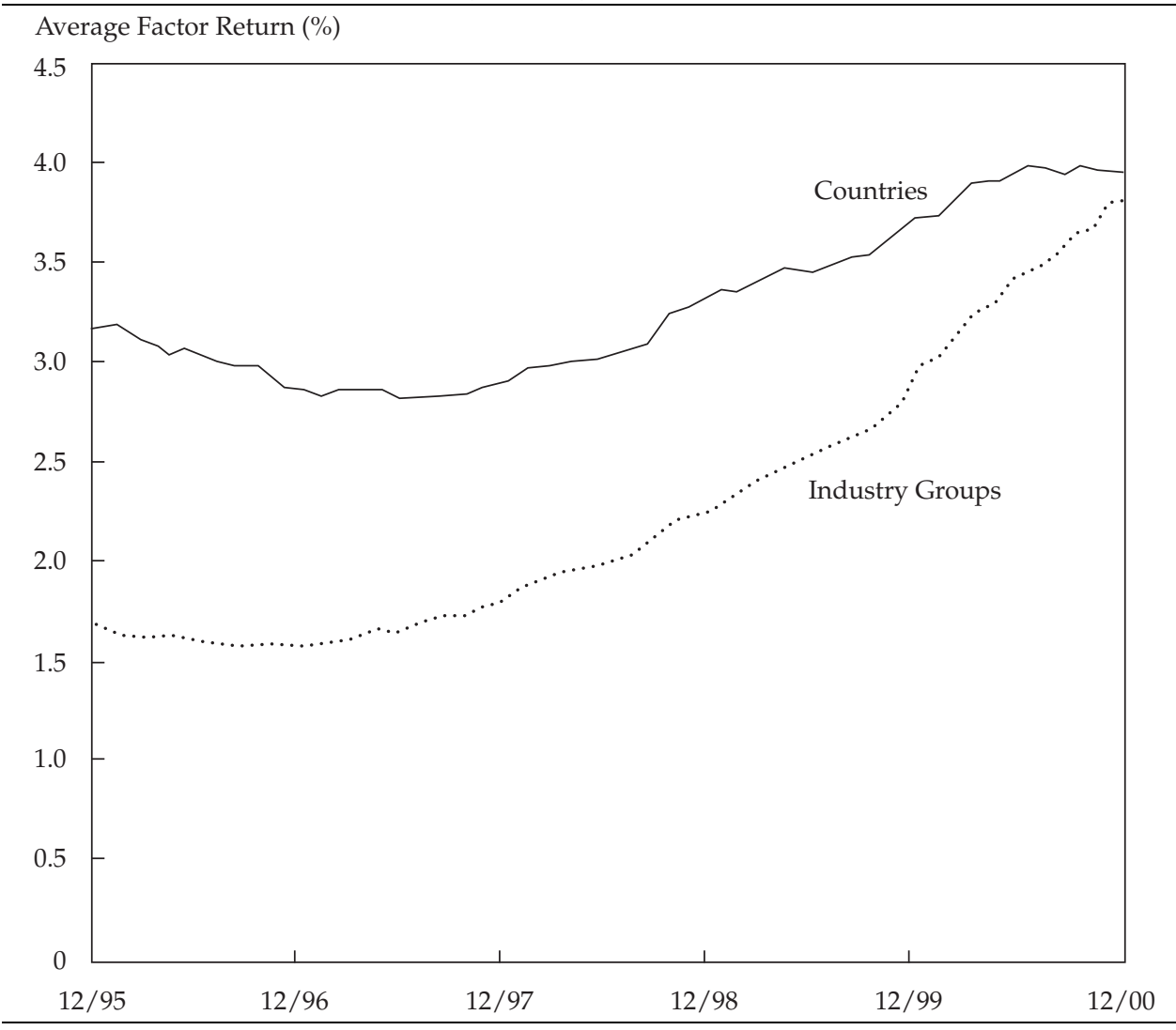

be toward the market-weighted results, which favor the strength in sectors and industry groups because of the size of the "new economy" sectors.

Equal-Weighted Regressions. We also ran all of the original regressions with each stock equally weighted rather than cap weighted. In Figure 1.9, we show the results for the country and sector averages (we also used equal weighting for these averages). As can be seen, country factors are significantly greater than sector factors in this context. These results are particularly relevant for a concentrated stock portfolio, where liquidity is of no concern so every stock in the universe is equally eligible for the portfolio. In such a portfolio, these results suggest that the country factor is, on average, more important than the sector or industry factor. 
Figure 1.8. Weighted Average Country and Sector Factor Returns: NonNorth America, December 1992-December 2000 Data (36-month moving average)

A. Market-Weighted Returns

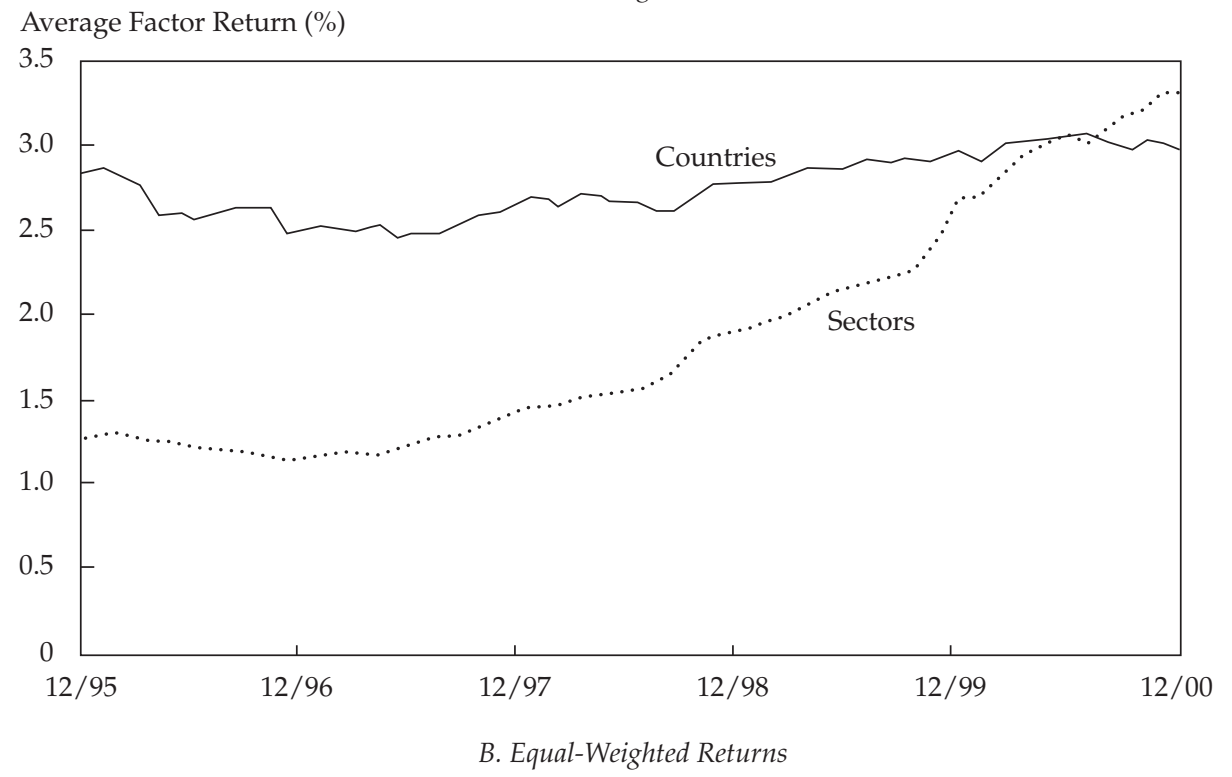

Average Factor Return (\%)

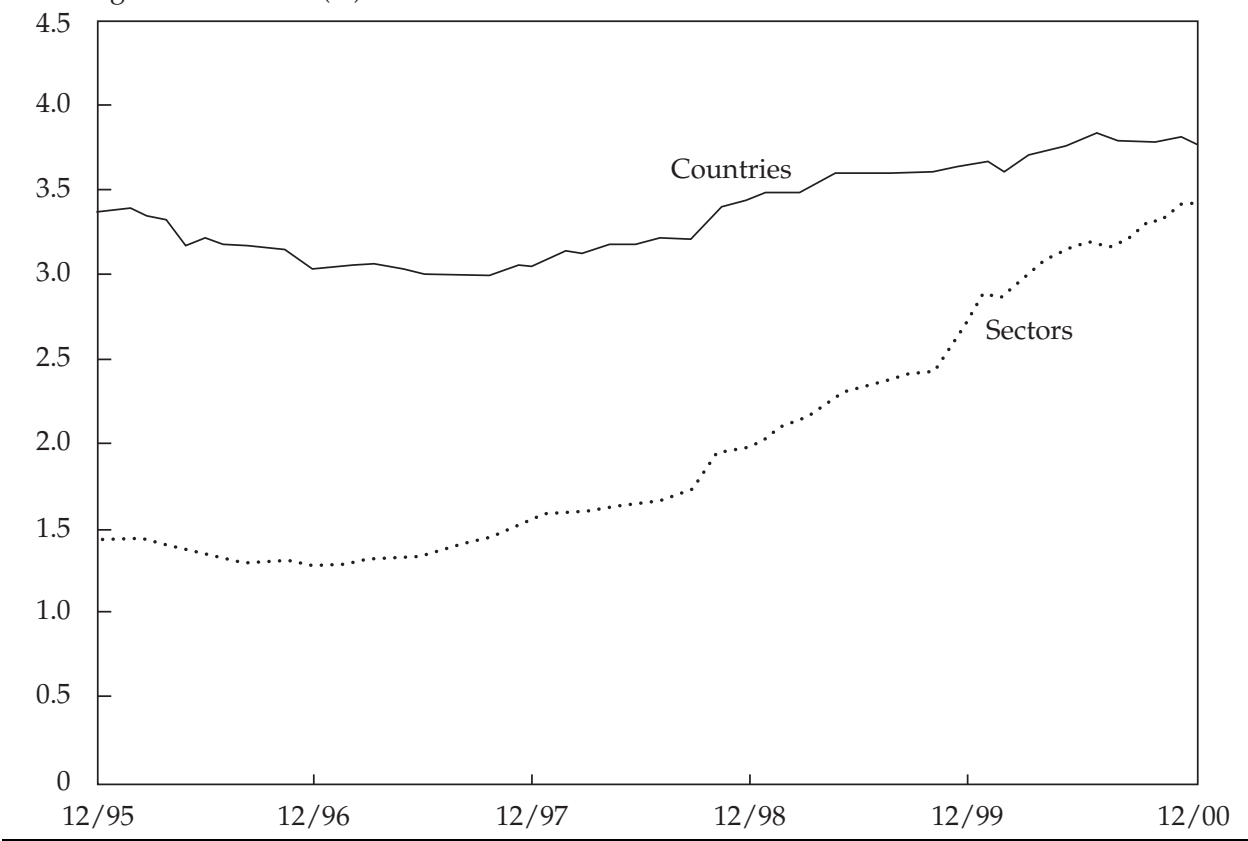


Figure 1.9. Equal-Weighted Average Country and Sector Factor Returns Based on Equal-Weighted Regression Coefficients, December 1992-December 2000 Data

(36-month moving average)

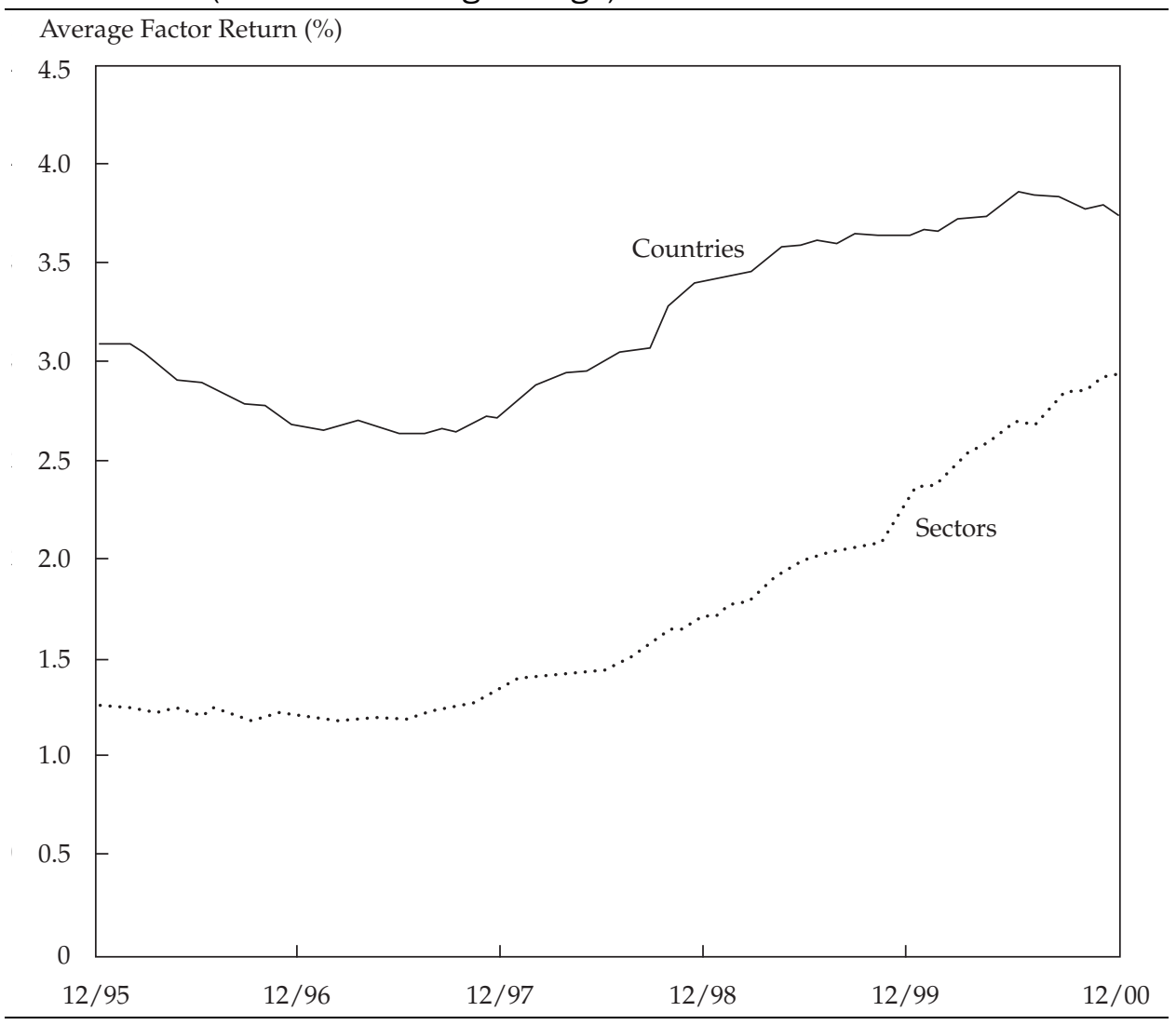

Explanatory Power of the Regressions. The regressions we performed contain more useful information. Every regression has a statistic, the $R^{2}$, that connotes the degree to which the dependent variable-in this case, stock returns each month-is "explained" by the independent variable(s) in this case, inclusion in a country, sector, and/or industry group. Remember also that these regressions have an alpha variable that equates to the global market return each month and is thus contained outside the country or industry coefficients. Beckers, Connor, and Curds showed that for these regressions, a modification to the $R^{2}$ must be made to adjust for the global market return in alpha. A technical explanation of their EP statistic, which makes the adjustment, is in Appendix C. 
To determine the relative importance of countries, sectors, and industry groups, we performed the regressions, cap-weighted, on countries only (C), sectors only $(\mathrm{S})$, industry groups only $(\mathrm{IG})$, countries plus sectors $(\mathrm{C}+\mathrm{S})$, and countries plus industry groups $(\mathrm{C}+\mathrm{IG})$. Figure $\mathbf{1 . 1 0}$ provides the rolling EP statistics with adjustment for the global market factor. The relative increase in sectors and industry groups versus countries since late 1997 can again be seen. As expected, the combined C + IG statistic has a modest edge over the $\mathrm{C}+\mathrm{S}$ statistic. The significance of these values is discussed further in the next sections.

\section{Time-Series Tests}

In the previous section, we used cross-sectional regressions, which yielded monthly factor returns. We then averaged the monthly data to establish trends in three-year characteristics. In the tests described next, we examined each stock relative to its relevant country and sector index in time-series comparisons, and we then averaged the time-series results across countries, sectors, and industry groups. These time-series results provide a slightly different slant on the data.

\section{Figure 1.10. Moving 36-Month Average EP Statistics for Regression Combinations, December 1992-December 2000 Data}

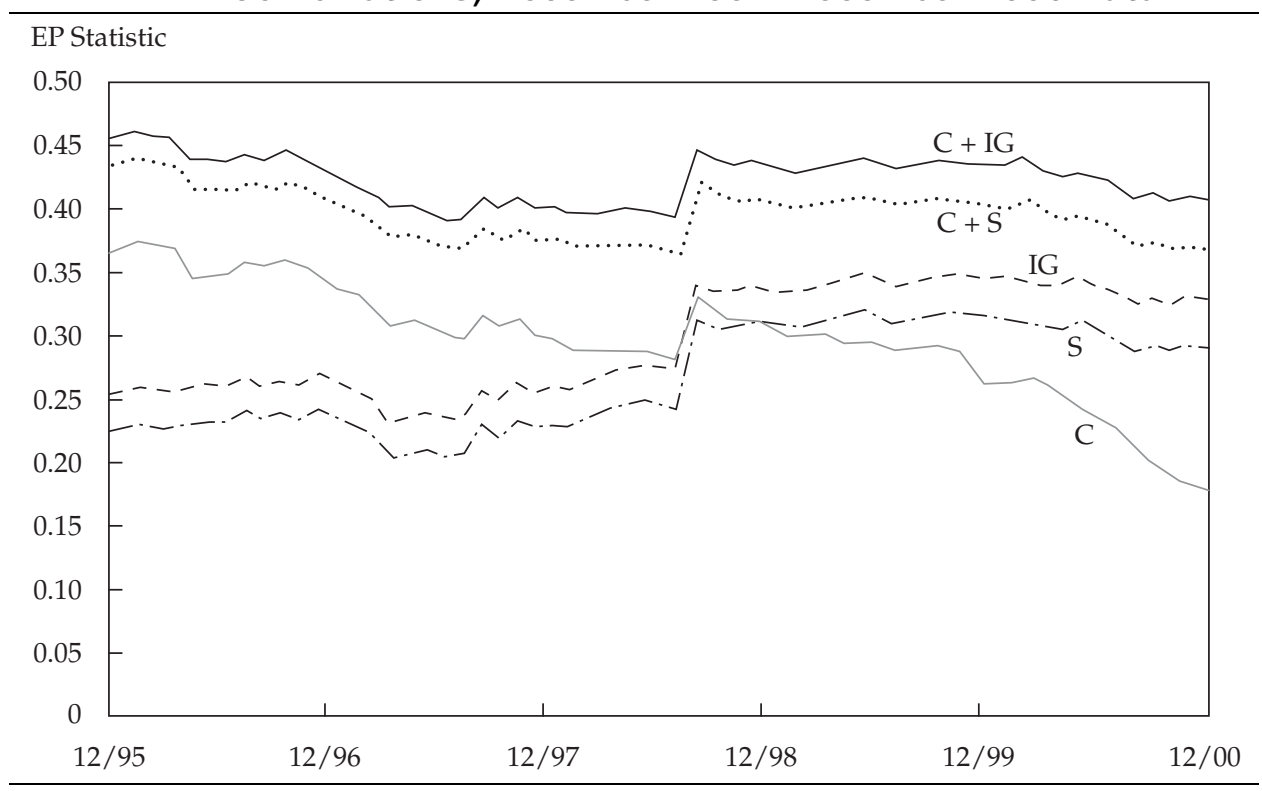


We used the same stock-level data as for the cross-sectional dummy tests, for which we again relied on the MSCI constituents and classification system. Recall that we backfilled the MSCI global industry classification system to create sector and industry groups for eight years ending December 2000. For these tests, we then subtracted the monthly global cap-weighted index return series (the MSCI World Index) from each of the stock series. All of the data were then on a "net of global" basis, so we were working with excess returns. 9

Next, we created country, sector, and industry group index time series on a cap-weighted basis. Allowing stocks to be correlated with indexes that contain those stocks introduces biases, however, which can produce misleading results. For instance, at the extreme, the correlation of Nokia with the capweighted Finnish index is quite high because Nokia has a roughly 70 percent weight in that index. When analysts then look at the Finnish averages (especially market-weighted averages, which weight Nokia at 70 percent of the country result), those averages would appear quite high. Thus, we created indexes that excluded each constituent stock.

We regressed each stock in the universe against its own country, sector, and industry group index, excluding itself, over rolling 36-month time periods. 10 The resulting equations provided coefficients for each stock along the lines of the traditional capital asset pricing model's alpha and beta, with a set of residuals. We used the $r$-statistic, or correlation coefficient (commonly called the correlation), of each regression to approximate the degree to which any stock's excess return is explained by its country, sector, or global industry group excess returns. We then averaged these stock correlations within each country, sector, and industry group on both market-weighted and equalweighted bases. The result was an indicator of how much of the return of the average stock is explained by its inclusion in the index.

Before reviewing the results, we will consider the possible reasons for any differences between the cross-sectional dummy tests and these tests. In the case of the factor returns in the cross-sectional tests, both magnitude and direction were important. Although country factor returns are theoretically neutral from sector influences and vice versa, strong upward or downward activity will generally result in larger factor returns. In these correlation tests, the similarity of direction is the key issue; magnitudes are not as relevant. Also, secular trends within sectors that last more than three years will show up in the factor returns, whereas they are less likely to affect correlation tests. For

9 The correlation of excess returns is more instructional than the correlation of raw data.

10 We excluded stocks for which we had fewer than 24 months of returns in any 36-month period. 
both these reasons, one would expect, assuming strong secular effects have been at work within the sector, the recent rapid rise of IT to have a more muted effect in the correlation results.

The average market-weighted correlations for each country, shown in Figure 1.11 for selected countries with the rest in a band, have some significant similarities to the cross-sectional results. For example, note the relative homogeneity of Hong Kong and Singapore in Asia. Italy, Norway, and Spain showed similar homogeneity in Europe. The relative breadth of the U.S. market is again apparent from its low average level of correlation. 11

\section{Figure 1.11. Selected Average Correlations of Excess Returns within Countries, ex Stock, December 1992-December 2000 Data (rolling 36 months)}

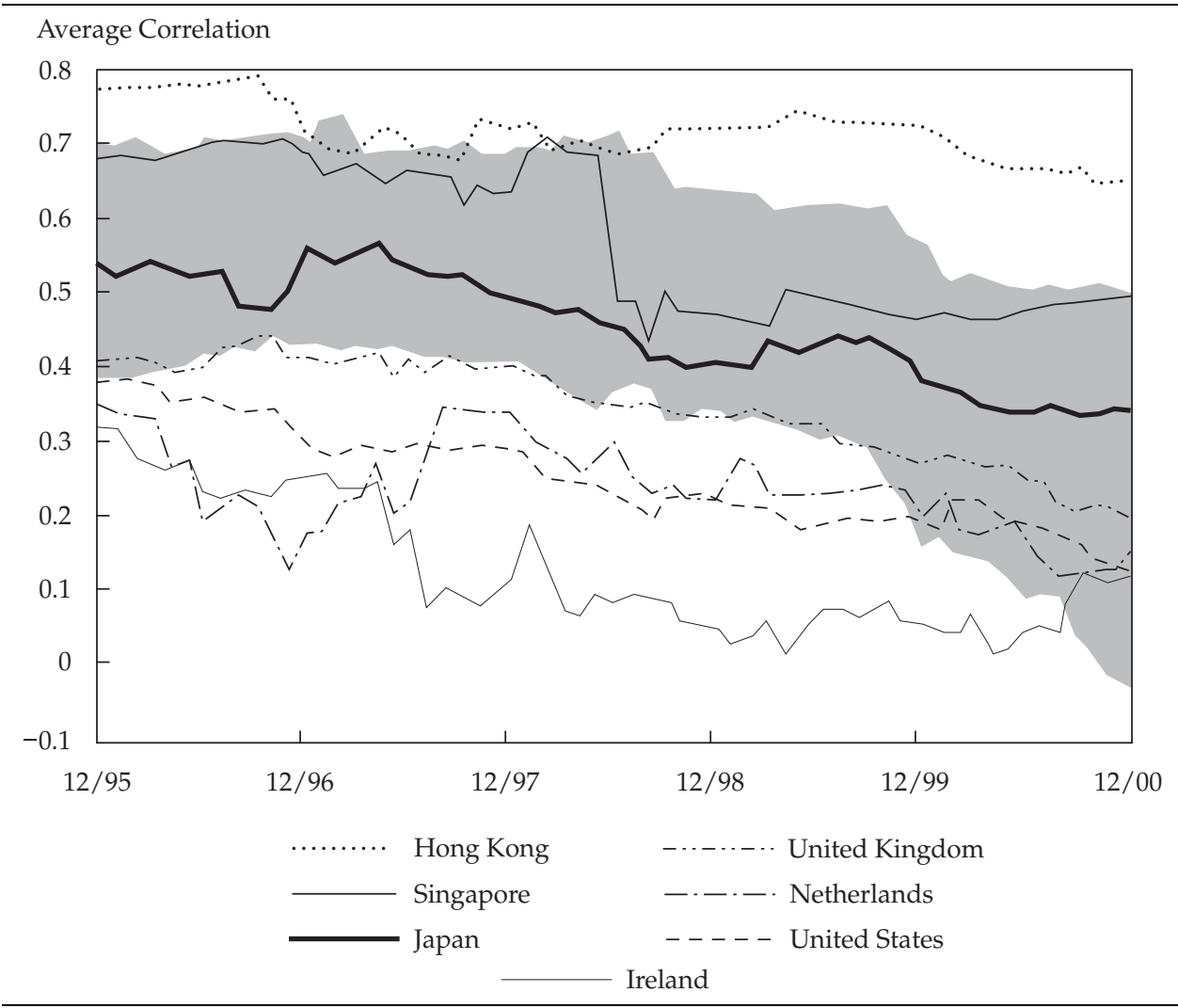

Note: The gray band encompasses the remaining countries.

11 The notion of "breadth" comes from Grinold and Kahn (1995) and is explored in Chapter 3. 
Some significant differences appear, however, between the time-series and cross-sectional results. Ireland had a surprisingly low average correlation. The Netherlands' average correlation was lower than its position in the factor model, indicating lower homogeneity. This difference may be a result of the significance of the Royal Dutch/Shell Group in the market-weighted average, whereas its correlation with the Dutch index (ex itself) was low because of its energy orientation. Japan and the United Kingdom appear to be more correlated with their country indexes than the cross-sectional results suggest.

The results for selected sectors are shown in Figure 1.12. In contrast to the cross-sectional results, IT (with an internal correlation of excess returns ending about 0.4 by December 2000) did not have the most significant average correlation in these results. The telecommunications sector also had a lower

\section{Figure 1.12. Selected Average Correlations of Excess Returns within Sectors, ex Stock, December 1992-December 2000 Data} (rolling 36 months)

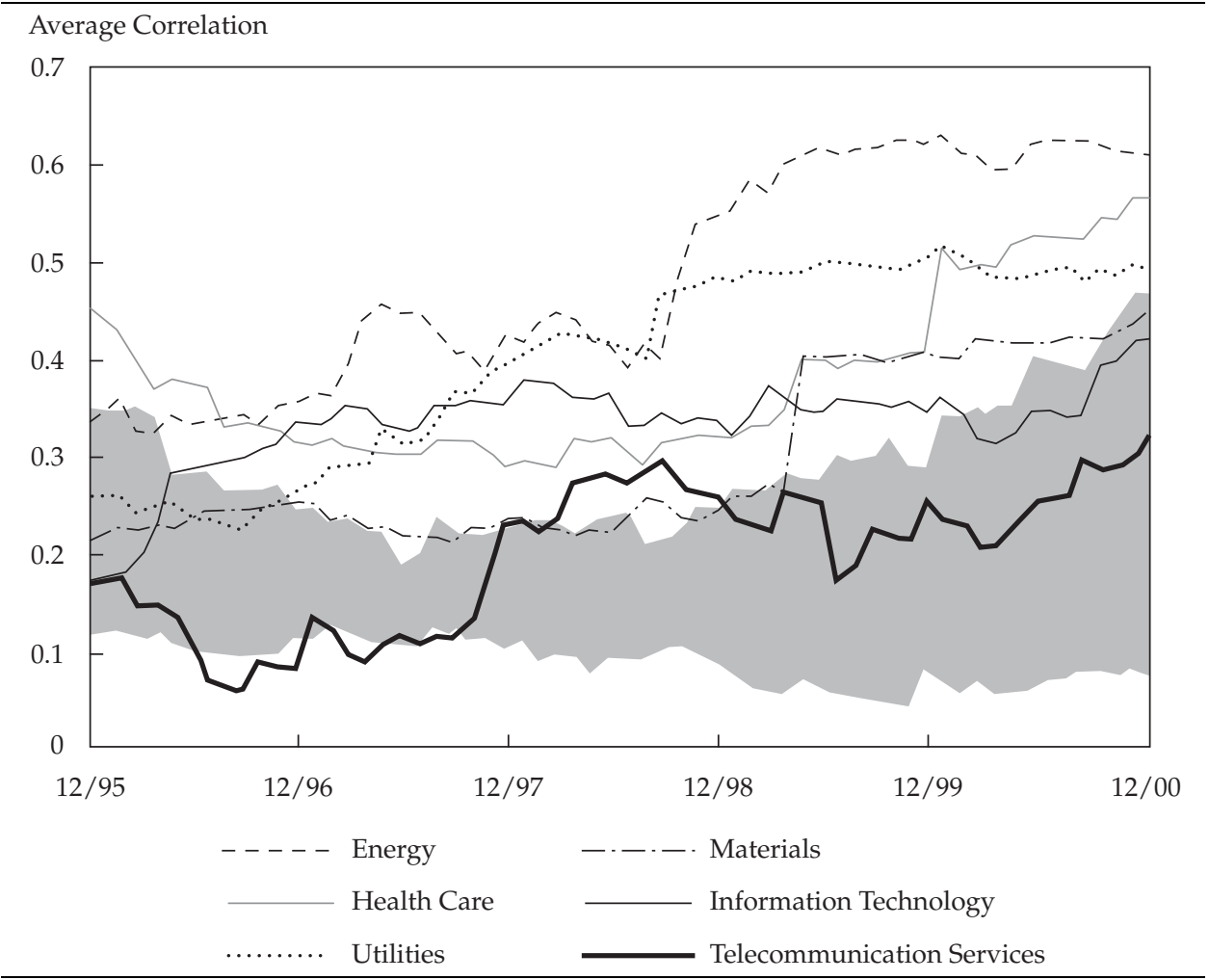

Note: The gray band encompasses the remaining sectors. 
average correlation (at about 0.32 by December 2000) than in the crosssectional tests. Energy, with a correlation that climbed from about 0.35 to 0.60 during the period, had strong cohesiveness as a group throughout the period examined, as one might expect because of oil price moves in the period. Utilities also showed strong correlations, perhaps as a result of their uniform underperformance through 1999 followed by recent outperformance. Health care appeared to be more homogeneous in these results than in the crosssectional results, as did materials. The disparate nature of the consumer discretionary sector and industrials sector, which make up the lower edge of the shaded band, was confirmed by their low average correlations throughout the period.

The data for the industry groups, shown in Figure 1.13, indicate that the reason for the drop in IT correlations came from the dramatically lower software and services industry group correlations in the period. The hardware industry group was relatively correlated globally. The difference between the hardware IG and the software IG indicates some potential value added from breaking down the IT sector along those lines. The other sector that offers such distinct subgroups is health care; a significant difference was found between the relatively cohesive pharmaceuticals and biotechnology IG and the more diverse health care equipment and services IG. Within the industrials sector, the transportation IG had average correlations whereas the more cyclical segments of the sector (capital goods and commercial services and supplies) form the bottom of the band, with almost no correlation within their groups at all.

As in the cross-sectional tests, we created global average correlations for countries, sectors, and industry groups using a number of weighting methods. All of our results are based on regressions of stocks against market-weighted, ex stock, indexes. Once the correlations for the regressions were calculated, however, we weighted them within countries either equally or by market cap. Moreover, we could then weight these correlations across countries or sectors, either on a market-cap or equal basis. The most instructive pair of methods are for the pure market-weighted and equal-weighted averages, which are shown in, respectively, Figure 1.14 and Figure 1.15.

The conclusions we can draw from these graphs with respect to the relative importance of countries versus sectors are nearly identical to those drawn for the cross-sectional tests. In the market-weighted environment, the sector and industry group effects have surpassed the country effects in recent years because of higher correlations in the large sectors but not in the large countries. Moreover, the average industry group correlations are higher than those 


\section{Figure 1.13. Selected Average Correlations of Excess Returns within Industry Groups, ex Stock, December 1992-December 2000 Data \\ (rolling 36 months)}

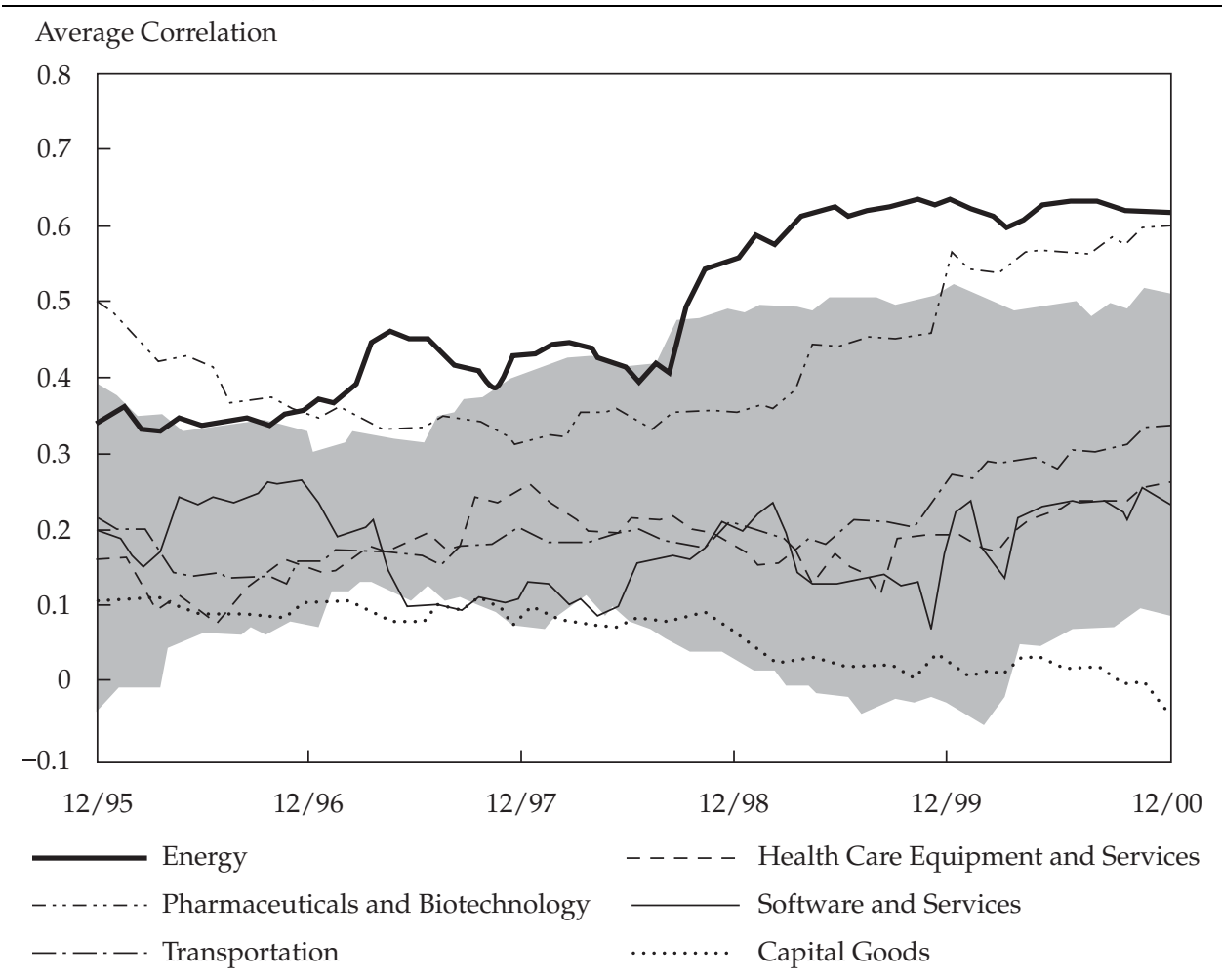

Note: The gray band encompasses the remaining industry groups.

for the sectors. This outcome is intuitively satisfying in light of the presumed higher cohesiveness on the smaller, more refined classification level.

Results for the equal-weighted sector and industry groups are weaker. It is interesting, however, that in the purely equal-weighted context, the average sector correlations are actually higher than those for the more focused industry groups. The reasons are unclear, although the effect seems to emanate from the smaller sectors having higher correlations than the larger ones and their contribution being exaggerated in the equal-weighted context.

Nevertheless, these results have implications for the question of whether analysis at the sector level has advantages over analysis at the level of industry groups. We regard higher correlations of excess return as being positive for allocation among asset classes and negative for selection of securities within each asset class. If the average correlation of excess returns within industry 
Figure 1.14. Global Average Correlations of Excess Returns: MarketWeighted Methodology, December 1992-December 2000 Data

(rolling 36 months)

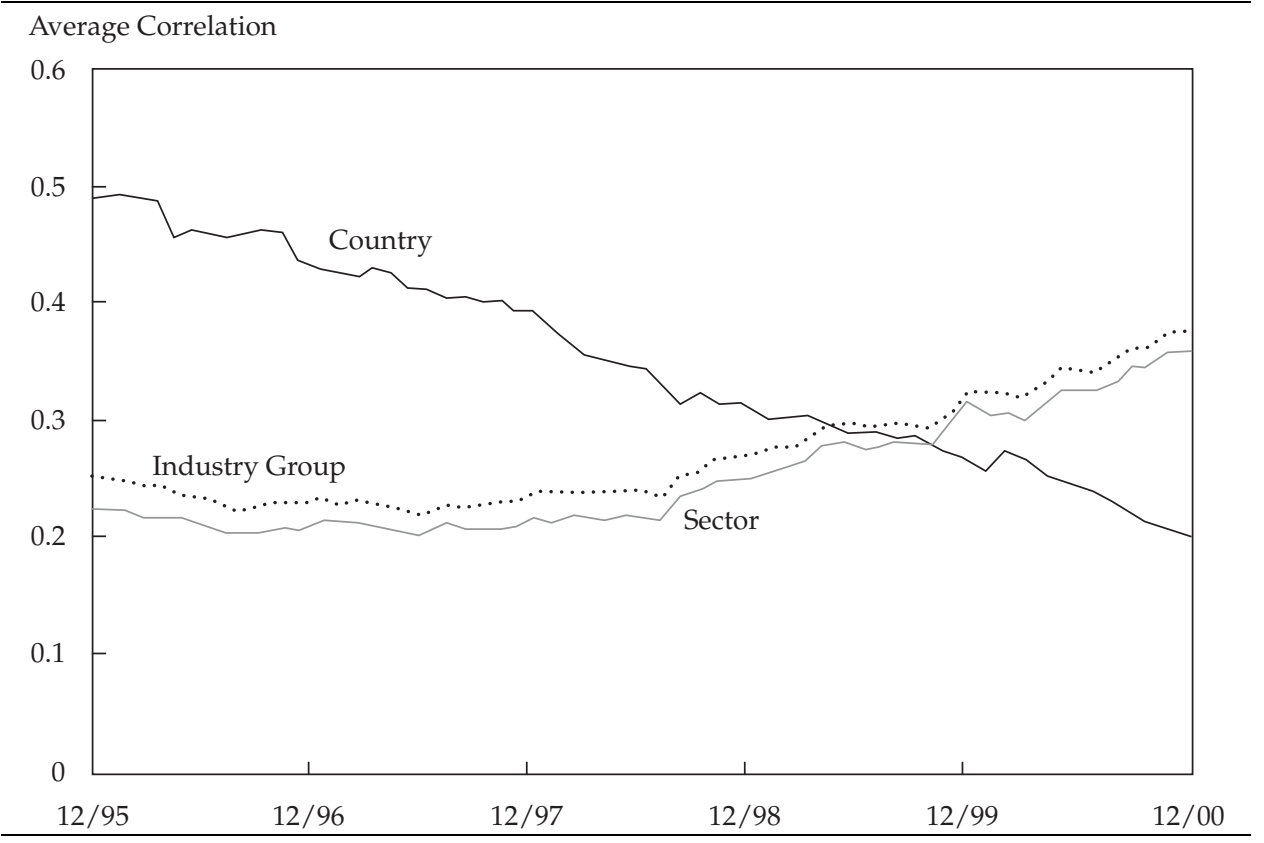

groups were, say, 50 percent greater than the average correlation within sectors, selecting stocks within these small industry groups would be more difficult because of the few unrelated options from which to select.12 But the greater number of asset classes with more-homogeneous stock groups should be a boon to an allocator across industry groups. The central insight from these results, however, is that for investors operating somewhere in between a market- and equal-weighted world, sectors and industry groups are not different enough to make a huge impact on how investors do their jobs. The choice may be more sensibly made on the basis of resources required to cover each; in that case, the advantage clearly goes to the sector approach.

\section{Cluster Tests}

Yet another way to assess homogeneity of stock groups is through cluster analysis. One choice within such analysis revolves around the correlations between assets, and we chose the case in which the assets are the intersection

12 This concept also is related to the Grinold and Kahn notion of breadth, which is explored in Chapter 3. 


\section{Figure 1.15. Global Average Correlations of Excess Returns: Equal- Weighted Methodology, December 1992-December 2000 Data}

(rolling 36 months)

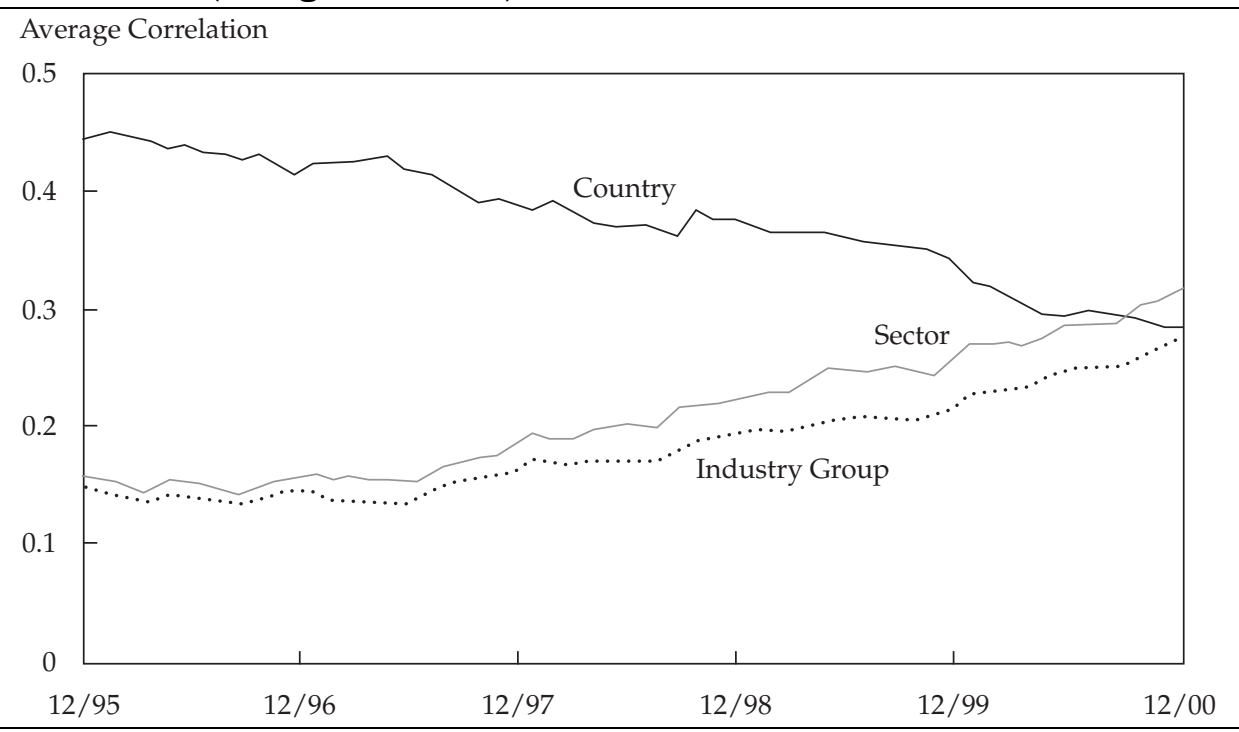

of countries and industry groups. We refer to the intersection of a country and sector as a "cell."With 21 (MSCI World ex Portugal) countries and 23 industry groups, we had, theoretically, 483 cells-such as French real estate, Japanese energy, and Australian information technology hardware and equipment. We had many empty cells, however, resulting from lack of constituents. For example, no cells existed for Singapore energy, German real estate, or Spanish food and drug retailing companies in the MSCI indexes.

In these tests, we formed clusters of country/sector cells by merging those that had the highest correlation first. By seeing how the clusters formed, we could get a better sense of the relative importance of countries versus sectors.

The time-series tests in the previous section were based on correlations over rolling periods and thus showed trends through time. The benefits of using cluster tests lie in (1) looking at correlations across sectors and countries simultaneously, rather than solely within countries and within sectors, and (2) working at the aggregated cell level rather than the stock level.

We used the same hedged stock data from the previous two tests aggregated into country and industry group cells to generate a market-weighted return series for each possible cell. Some cells were empty, and for some cells, we did not have data for the complete time period analyzed (because companies were either added to or deleted from the MSCI World Index). In the end, 
we had 251 cells for the complete December 1992 to December 2000 period. The global return was subtracted from each cell's return to form cell return series in excess of the world index.

Cluster analysis can be performed in many ways. We chose a method that has the following characteristics. First, a cluster is formed by merging the two most highly correlated cells. That cluster is treated as a new cell, and then the process repeats by merging the next highest correlated cells. That is, in this method, one cluster is formed at a time. Clusters may merge together with other clusters or simply have a new cell appended. The method works essentially from the highest correlation down to the lowest. We also decided to terminate the analysis after 212 iterations, at which point the marginal correlation is around 0.30 or below and combinations no longer assist in the analysis. We show the clusters at the point where correlations are around 0.50 and 0.30 .

In addition, because the other tests strongly suggested an increase in the importance of industries over countries since 1997, we conducted cluster analysis for the period January 1997 through December 2000 alone. Comparing the clusters formed solely for the later period was expected to help confirm the shift in importance.

Exhibit 1.3 shows the clusters formed for the full time period; Panel A contains the results after 118 iterations with correlations greater than 0.50 , and Panel B contains the results after 212 iterations with correlations greater than 0.30. The clusters rank from those formed earliest to those formed latest, so Cluster $1 \mathrm{had}$, generally, the highest correlations. The clustering when correlations were greater than 0.50 shows that geography dominated industry, although pockets of industry influence did form. For example, North America generated distinct energy and financial clusters; Japan divided into what appears to be cyclicals and a technology, media, and telecom (TMT) group; and a European TMT cluster also formed. The existence of Spain, Italy, and U.K. clusters strongly supports the geographical influence at the higher correlations.

After 212 iterations when the marginal cluster correlation was about 0.30 and some of the previous clusters had merged together, the geographical influence appeared even stronger. Clear Southeast Asia and Japan groups formed, and a strange "Scandi-terranean" bloc even appeared in Europe. Generally, Europe fell into TMT and financials groups, however, and the cyclical elements merged into a more global materials and capital goods group.

Exhibit 1.4 shows the results for the more recent (1997-2000) period, with results after 142 iterations with correlations greater than 0.50 in Panel A and results after 213 iterations with correlations greater than 0.30 in Panel B. The initial clustering, when the screen was correlations of above 0.50 , 


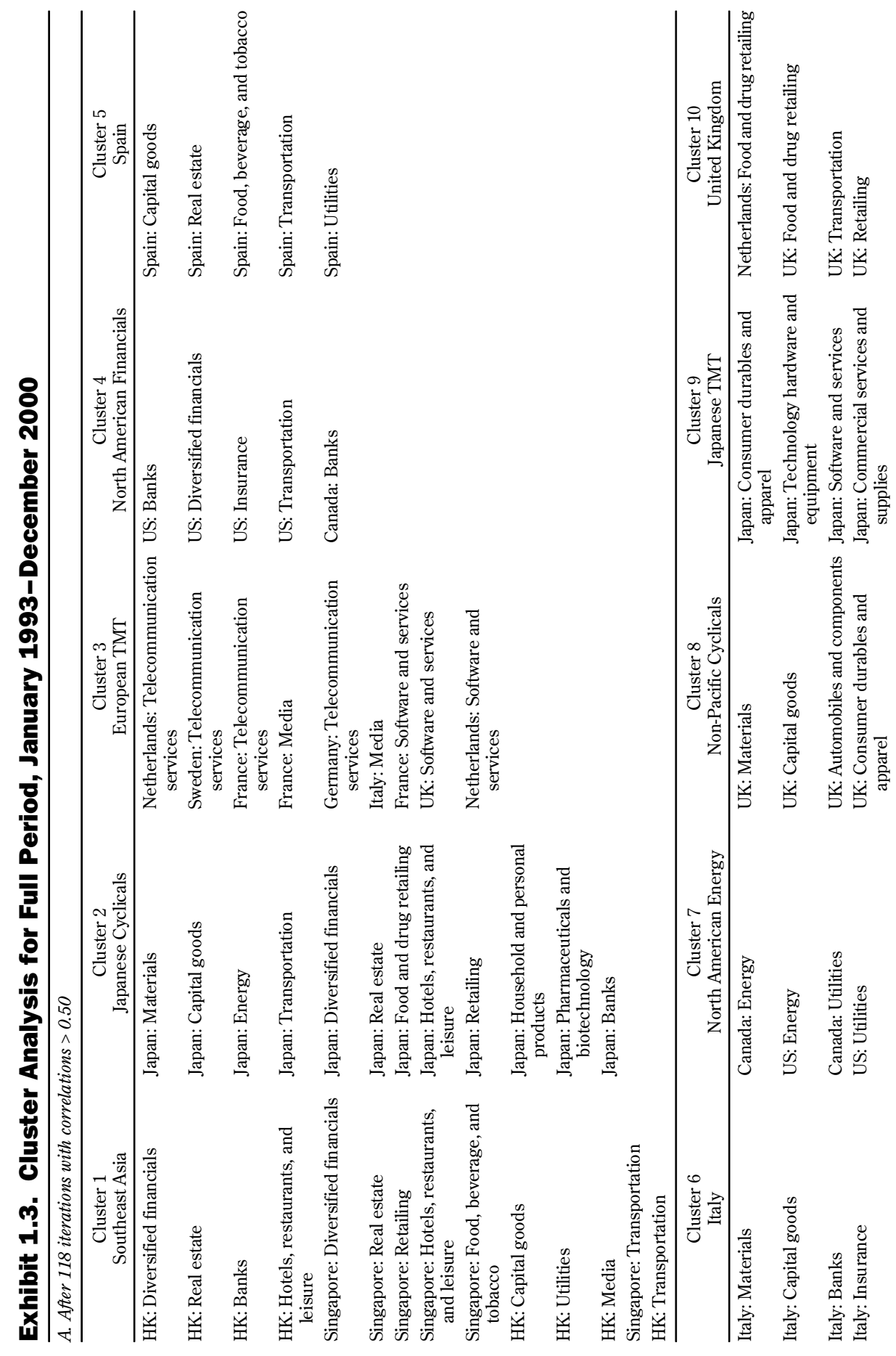




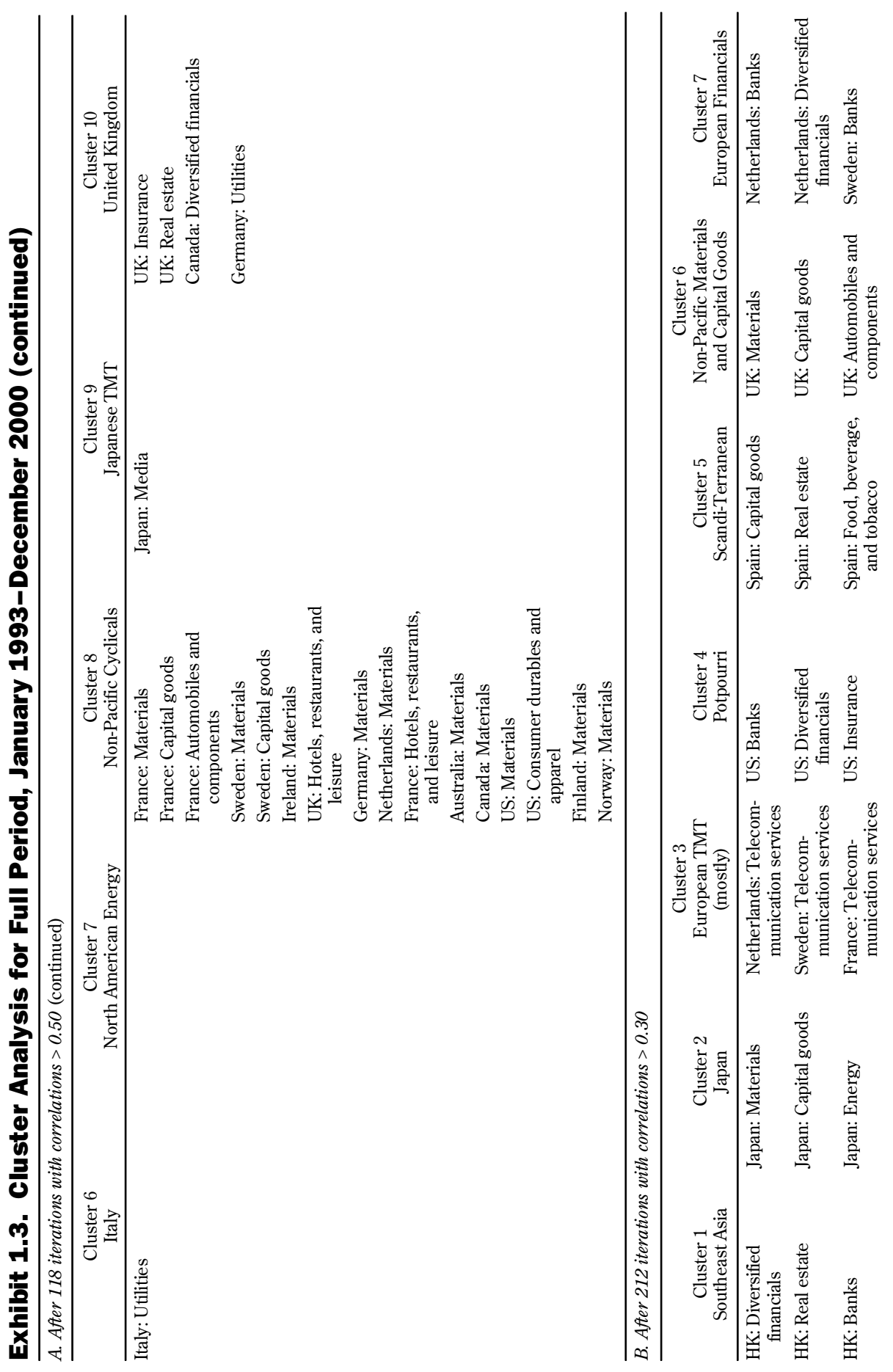




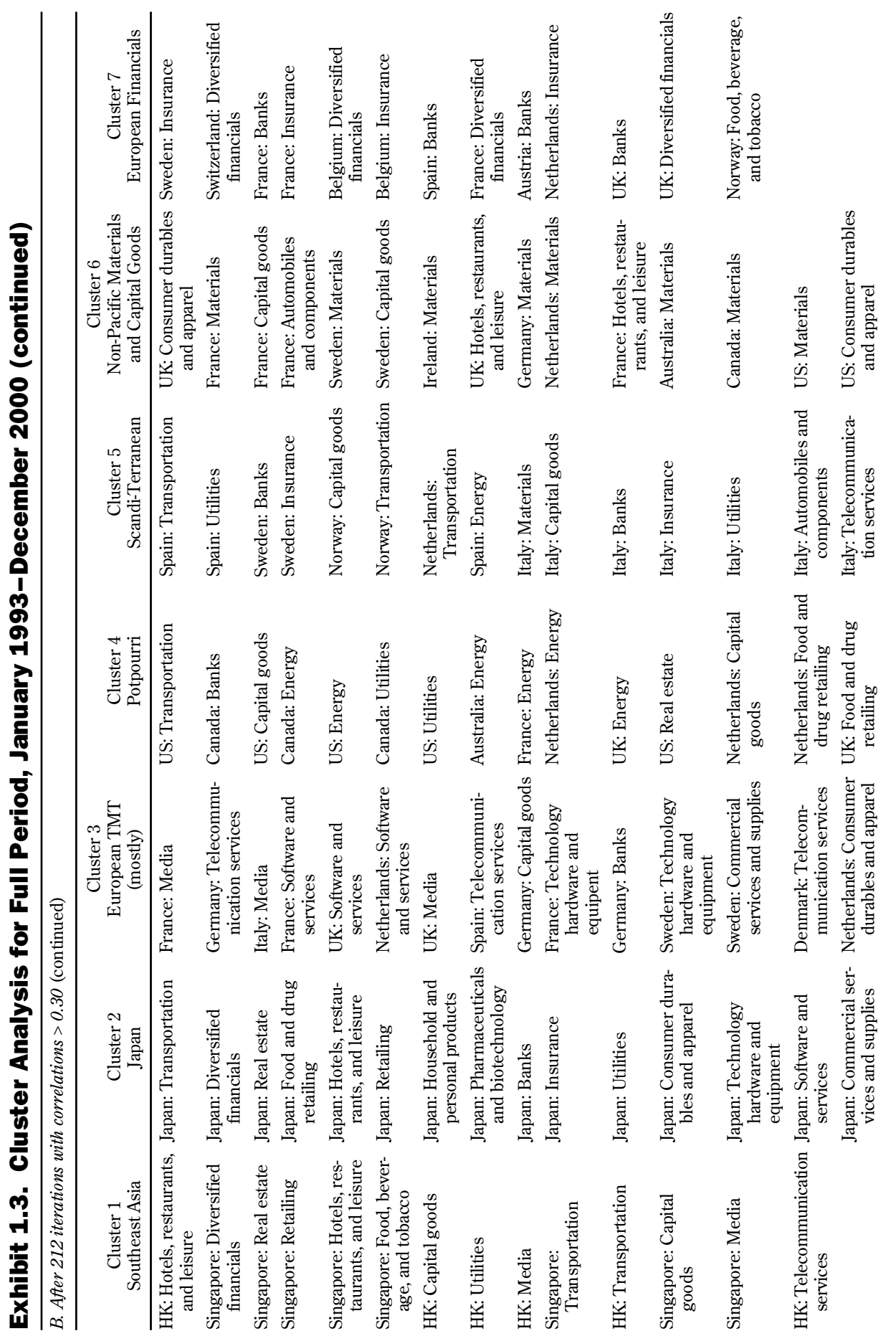




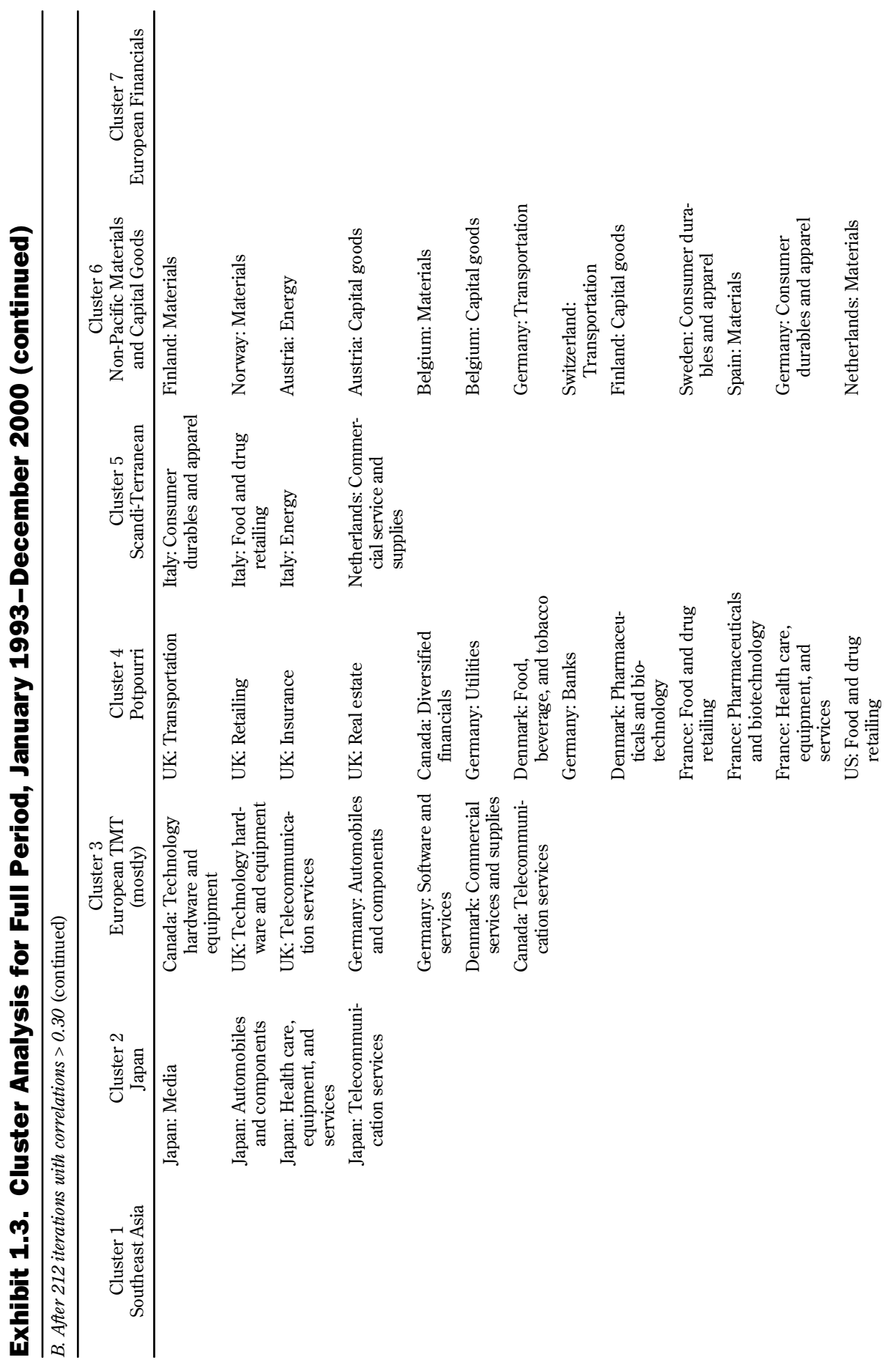




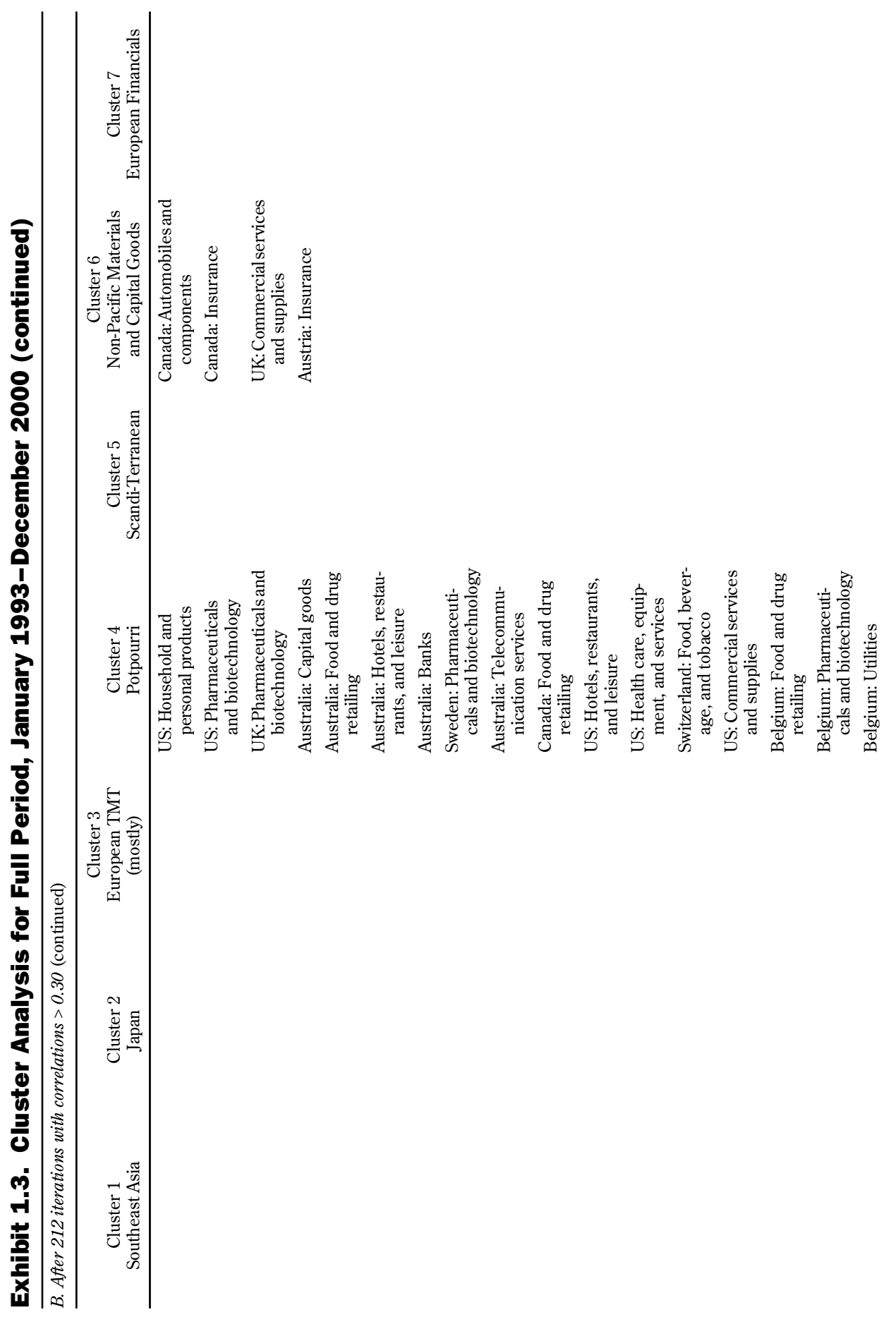




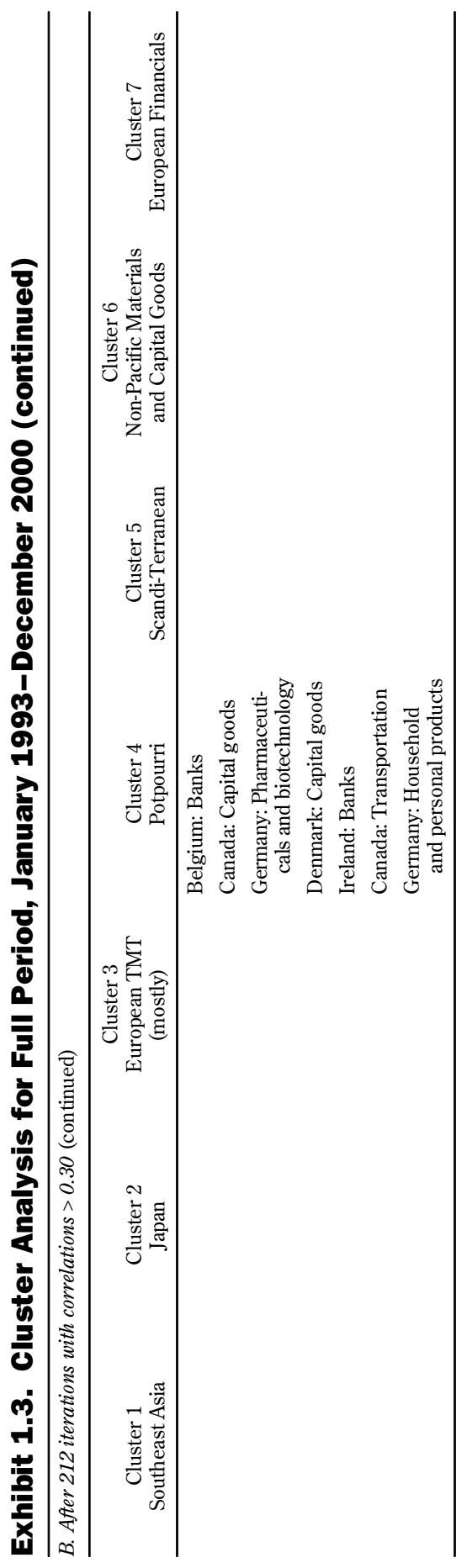




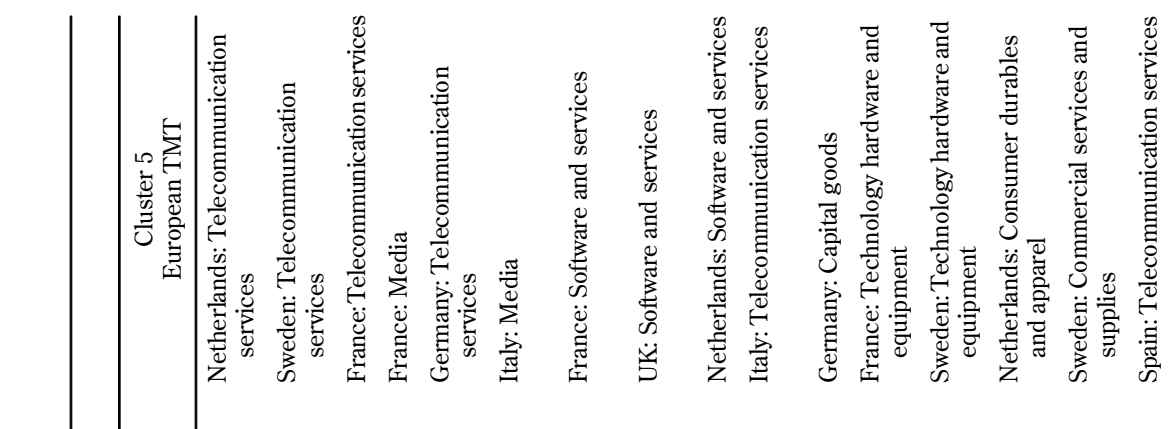

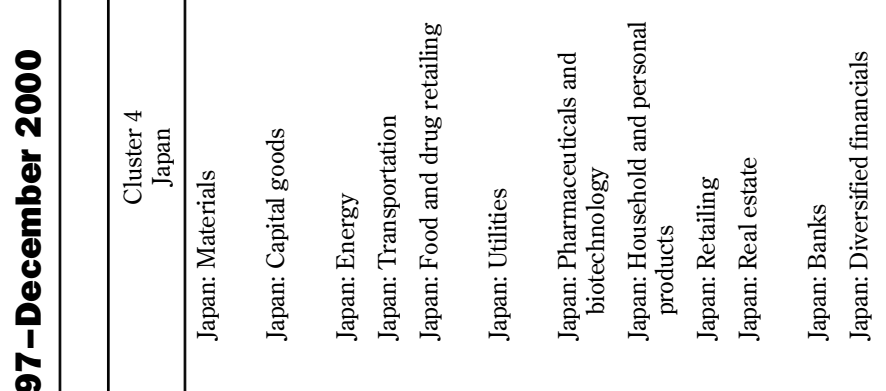

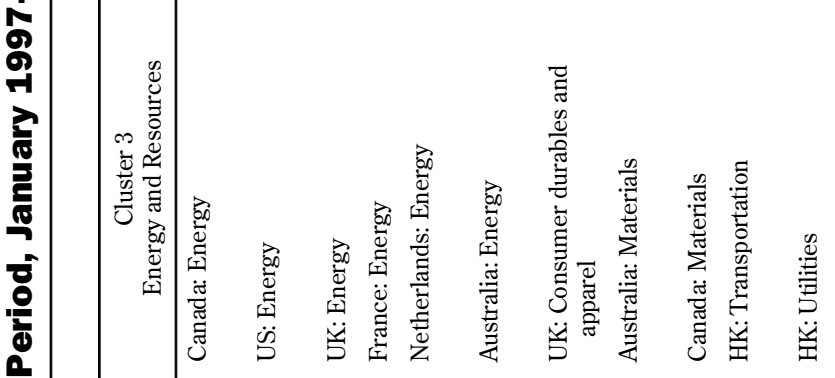

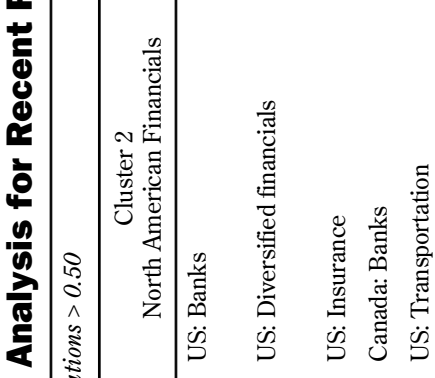

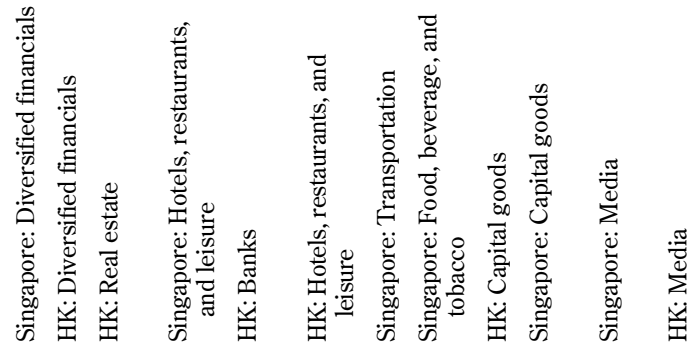




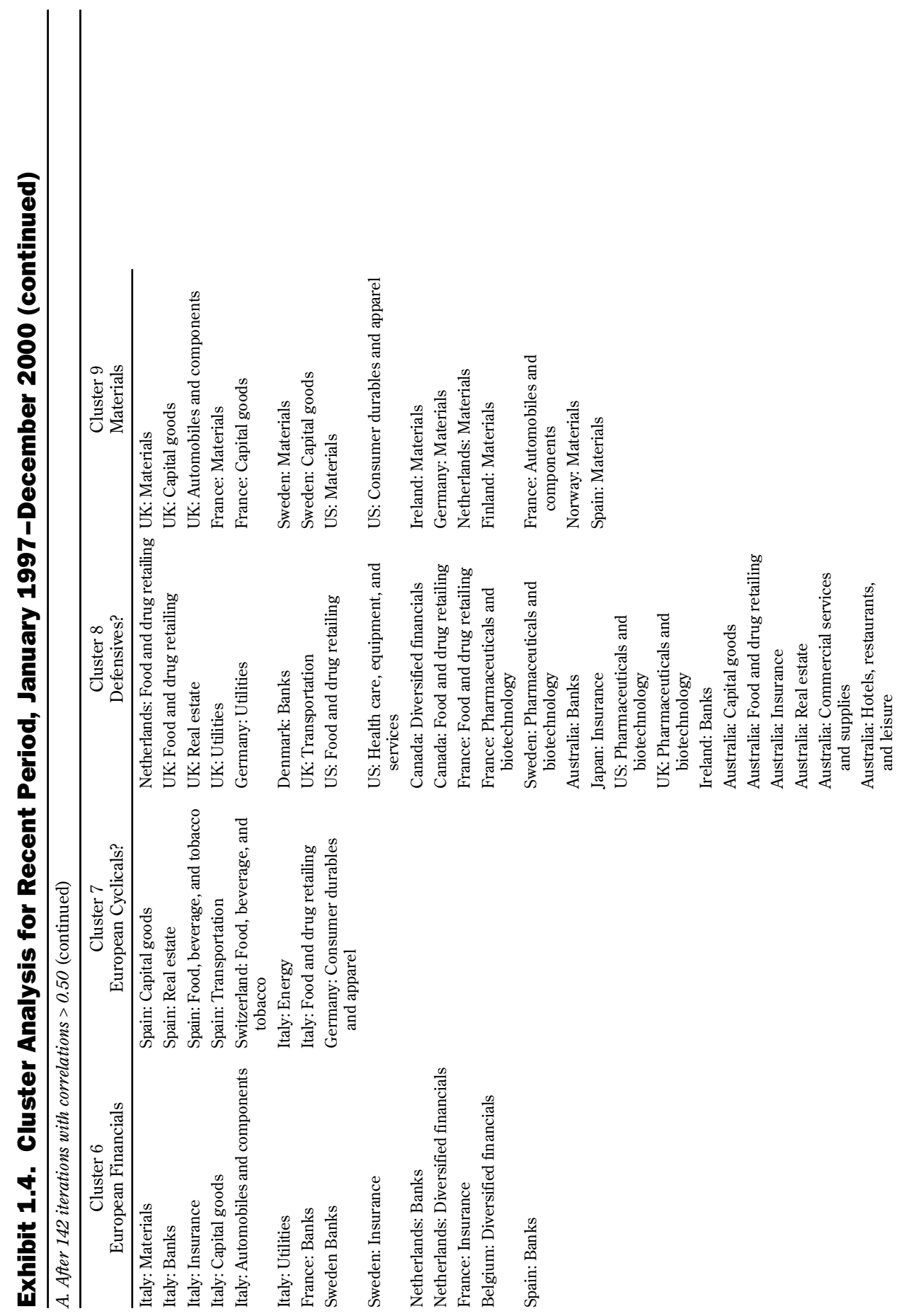




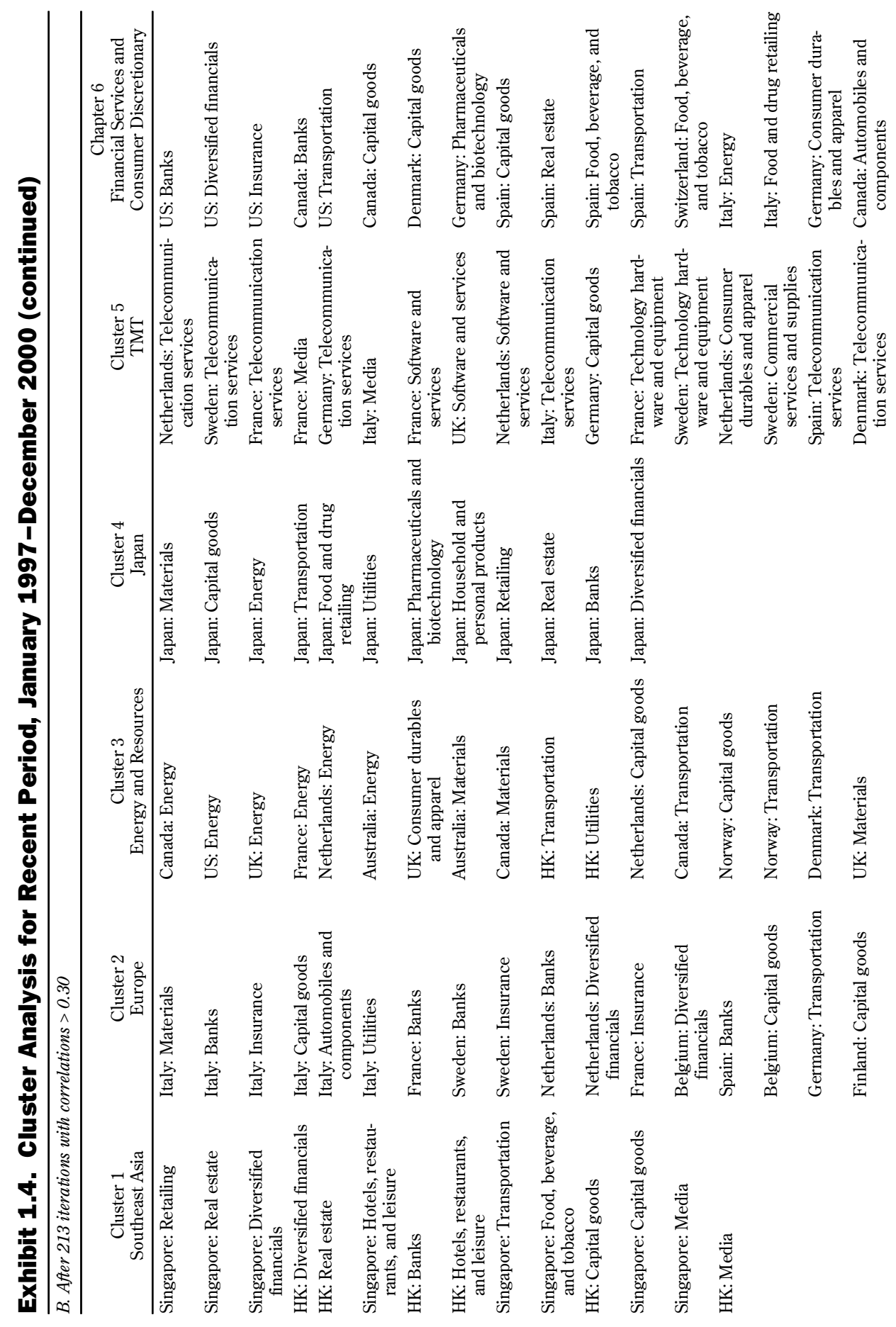




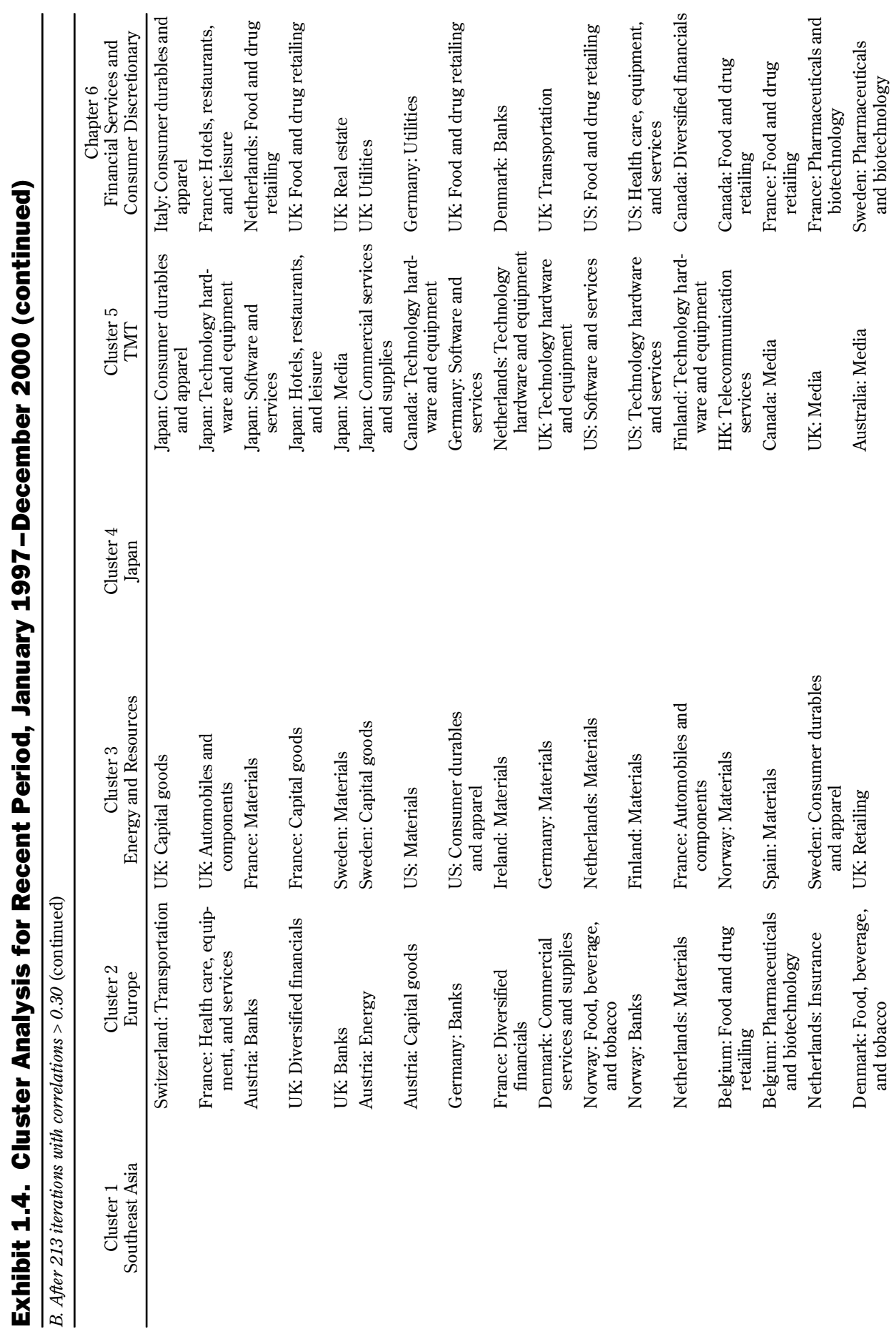




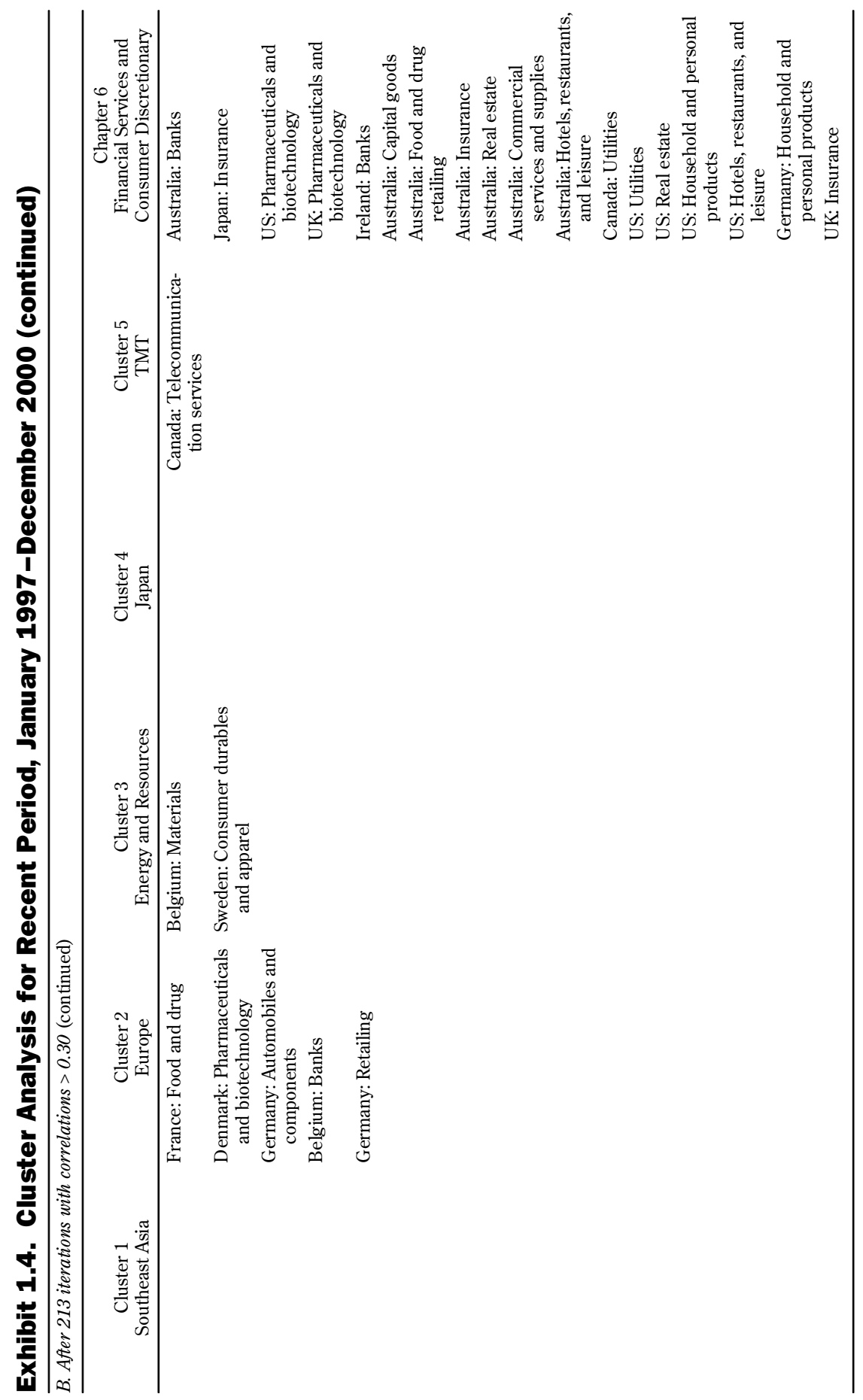


reflected an industry emphasis more than was present for the overall period. Although Southeast Asia still formed the strongest group, energy was a strong influence at Cluster 3. Even more relevant is the finding that Europe tended to fall into industrial blocs rather than the more fragmented geographical blocs of the longer time frame. This result is consistent with the notion that the single-currency zone should have a homogeneous Europe as a region. But evidence in Clusters 8 and 9 indicates that parts of Europe are aligning with global sectoral themes, especially in the materials sector.

For the more recent period, Clusters 2, 5, and 6 formed with the marginal correlation as low as 0.30 , which indicates strong global industry cohesiveness in the energy, TMT, and financial sectors. What appears to be the union of financials and segments of the consumer sectors in Cluster 6 is interesting. A strong geographical influence is still evident in Japan, Southeast Asia, and Europe as a whole for the recent period in Panel B. Perhaps the best description of this period is a good blend of key geographical and industry factors.

\section{Summary}

These tests suggest that from 1992 through 1995, country effects were between one-and-a-half to two times as important as industry effects, 13 but now the importance of country and the importance of sector or industry group are about equal. This change is especially relevant for practitioners managing structured investment products or enhanced index tilts, for which capitalization is important. For investors who are free of capitalization constraints, country effects are still dominant but not to the same degree as previously.

The geopolitical backdrop during this period included harmonization in Europe, the steady dissipation of the "Japan premium" associated with its 1989 bubble collapse, and the Asian crisis. The Asian crisis had a limited impact on these results because, in the context of the developed markets, only Hong Kong and Singapore were truly affected, and in terms of market capitalization, Hong Kong and Singapore are small countries. Moreover, as Japan's market capitalization shrank throughout the 1990s, the importance of the Japan premium shrank in the results. Within a number of countries, such as Norway, Italy, Singapore, and Hong Kong, stable homogeneity of stocks seems to have been the environment, which implies a steady country effect. Most of the other markets have experienced a steady decline in internal correlations. The 1998 period running up to the implementation of the single euro currency was a particularly good period for the small European markets, which experienced

13 Although we do not have strong evidence for support, we believe country effect dominated throughout the 1980 s as well. 
dramatically falling interest rates. This environment had a broad and general effect on stocks within some of the small European markets. The events of the 1997 Asian currency crisis had a similar, but negative, effect on Southeast Asian markets.

The sector/industry environment in the 1995-2000 period included unprecedented (in recent history) sector-oriented themes as the new economy engendered market euphoria relative to the old economy. The dramatic and persistent outperformance of the IT and telecom sectors up to March 2000 , combined with the large and increasing market capitalization of these sectors, augmented the importance of sectors and industry groups in these results. The ensuing reversal of fortunes in these sectors since March 2000 has simply extended the significance of sector influence. The energy sector, although somewhat smaller than the technology sectors, has been similarly cohesive, as one would expect because of oil prices in the period. Most of the other sectors and industry groups experienced a gradual increase in their factor returns over the past five years.

The time-series results were less conclusive for the IT sector than the cross-sectional results were. We believe the reason is that time-series correlations are less sensitive to magnitude than cross-sectional factor returns; the IT sector had persistently high returns up to March 2000 and has had significantly lower returns since then. Correlations are highly affected by directional movements and the similarity that stocks in a group display with respect to directional movements. The IT sector group has had a wide dispersion around the index return, even though the general direction has been upward.

The cluster results, especially for the most recent period, confirm the practicality of investing with a dual emphasis on geographical and sectoral factors. The clusters vividly display the efficiency in organizing research around regions. Europe has become more homogeneous, and Hong Kong and Singapore have tended to behave similarly. Australia (and we suspect New Zealand) tends to group with other Anglo countries. This grouping also confirms the notion that managers with pan-Pacific mandates-when they are worried about the risk in Hong Kong, Singapore, South Korea, and so ontend to park assets in Australia as a defensive measure. Moreover, patterns of country-specific returns within regions suggest that if one is willing to invest in the added research, a focus on some specific countries could pay off, although such detailed effort would probably have diminishing returns.

The clusters also vividly show that organizing one's research around certain industry groups or sectors would be effective. Although the past five years may not represent a permanent landscape, great advantages are appar- 
ently available by dividing global research into TMT (new economy), cyclicals (old economy), energy, and financials. Some readers will identify this prescription as making growth versus value distinctions. We do not believe that the growth sectors are necessarily the most homogeneous, but the recent history in TMT has certainly been built on growth expectations. Finally, as in the results for specific countries, some benefits may be gained from applying resources to the more refined industry levels, but diminishing returns should be expected. 



\section{The Opportunity from Company and Stock Selection}

Thus far, we have dealt only with the importance of geography versus sectors and industry groups. We are also interested, however, in the importance of stock selection, especially relative to these other sources of adding value. This issue is vicariously raised in Figure 1.10: If the combination of country and industry group factors explains about 40 percent of cross-sectional stock returns through time, then stock-specific issues should be responsible for the remaining 60 percent. Figure 1.10 also clearly indicates that the reduction in the portion of stock returns explained by country movements has been mostly, but not fully, compensated for by industry group activity in the eight-year period of our study. The inference is that stock-specific issues have modestly increased in importance. Unfortunately, the answer to the question of stock selection's importance is not so simple as that inference and needs a fair degree of qualification.

The first thing to remember about Figure 1.10 is that country and sector/ industry group factors were the independent variables in the regressions. Therefore, the explanatory power (EP) statistics (which are similar to $R^{2}$ ) are quite defined for the relationship between stocks and their country/industry groups. In fact, many would agree that for country and industry factors alone to explain 40 percent of a noisy, chaotic system is a pretty good job. The remaining 60 percent contains all of the undefined "information," which includes, of course, stock-specific information. But this 60 percent also includes all of the randomness in the stock-return data. Given that equity returns exhibit a great deal of randomness, we believe that the 60 percent of returns not "explained" by country and industry exposure can hardly be completely chalked up to company-specific information.

To measure the opportunity available from stock selection directly required a precise definition of "stock selection." In particular, we wanted our definition of stock selection to be free of what we may have previously defined as sector or country selection. In today's institutional markets, the common attribution systems divide performance into currency, country, and stock selection. Such systems, as the value added by currency and country are defined, relegate sector selection to the stock selection category. If an attribution system were to correctly isolate and account for currency, country, and 
sector allocation, however, the concept of stock selection would be redefined to be the sum of selection within each country/sector cell, such as Japanese financials or Australian industrials.

\section{Perfect-Foresight Tests}

To ascertain the opportunity available to stock selection relative to industry/ sector or country selection, we assessed the potential for portfolio return generation for an investor with perfect foresight. Although this approach is clearly idealized, it did provide insight into the limits of performance, and in doing so, we believe, scaled the potential returns from the three sources of return.

We used the same hedged monthly stock and index data for the period December 1992 to December 2000 as we used for all the previous tests. Using hedged returns obviated the requirement to deal with currency attribution. We created a series of portfolios based on a long-short method whereby we assumed we could own the best-performing half of each universe and not own ("sell") the worst-performing half. We rebalanced monthly, under the assumption of no transaction costs. Thus, the portfolio return we report for each month is the return for the best half of the universe minus the return for the worst half. We show average bottom-up results on both market- and equalweighted bases. Appendix D shows the average characteristics for each country and sector for purposes of our weighting method.

The construction universes we used are as follows.

- Top-down (TD). We divided country index returns (TD-C) into the best and worst halves. We did the same for sector index returns (TD-S) and industry group index returns (TD-IG).

- Bottom-up (BU). We divided each country's stocks into their best- and worst-performing halves and then summed the countries' results (to produce the BU-C portfolio). We did the same for the sectors (to produce the BU-S portfolio). Each summation was carried out on a market-cap and an equal-weighted basis.

- Neutralized bottom-up (NBU). We performed the bottom-up tests but neutralized the sector exposure within each BU-C portfolio (producing the NBU-C portfolio) and neutralized the country weights within each BU-S portfolio (producing the NBU-S portfolio).

- Unconstrained bottom-up (pure BU). We selected the best-performing half of stocks globally. (We also ran some permutations on this strategy to gauge the impact of holding fewer stocks.)

- Cell-based bottom-up (CELLS). We took the best-performing halves minus the worst-performing halves within each country/sector cell and then 
both market-cap-weighted and equal-weighted the results. Fewer than 210 cells were included in this method because not all cells had a company and some cells had only one company, which prevented formation of longshort portfolios.

The CELLS and NBU methods are similar, and the small difference in results is insignificant, a result of the distribution of companies across countries and sectors. We report the results of both purely for the sake of completeness.

The average monthly returns for each test, both market-cap and equalweighted where available, are in Table 2.1. The most obvious feature is the higher returns for the bottom-up strategies. This result is not a surprise.

Table 2.2 shows the average monthly returns from the bottom-up perfectforesight tests for each country and sector. These results show fairly clearly that a number of factors affect available opportunity. The first factor is the number of stocks in the index. Large countries tend to provide higher-return opportunities than small countries (e.g., Canada versus Belgium), and the same is true of sectors (e.g., financials versus utilities). Thus, one might conclude that the larger countries or sectors offer better stock selection opportunities. Second, the magnitude and volatility of returns has an impact (as can be seen in the high information technology returns) that echoes the factor returns reported in the cross-sectional dummy tests. Finally, the correlation of stocks within an index also matters. An example is the case of Canada and consumer discretionary stocks, which had low covariance across stocks and correspondingly higher perfect-foresight returns. Issues of number and

\section{Table 2.1. Average Monthly Returns for Perfect- Foresight Tests, December 1992- December 2000}

\begin{tabular}{lccc}
\hline Test & Return & $\begin{array}{c}\text { Cap-Weighted } \\
\text { Return }\end{array}$ & $\begin{array}{c}\text { Equal-Weighted } \\
\text { Return }\end{array}$ \\
\hline Top-down & & & - \\
TD-C & $6.3 \%$ & - & - \\
TD-S & 4.5 & - & - \\
TD-IG & 5.2 & - & \\
Bottom-up & & & - \\
Full BU & 13.6 & - & $11.8 \%$ \\
BU-C & - & $12.3 \%$ & 12.9 \\
BU-S & - & 13.2 & 9.3 \\
NBU-C & - & 10.8 & 9.7 \\
NBU-S & - & 10.1 & 9.4 \\
CELLS & - & 10.7 & \\
\hline
\end{tabular}


Table 2.2. Average Monthly Returns from Perfect-Foresight Tests by Country and Sector, December 1992-December 2000

\begin{tabular}{lcrlcc}
\hline Country & BU-C & NBU-C & Sector & BU-S & NBU-S \\
\hline Australia & $10.8 \%$ & $9.2 \%$ & Energy & $11.9 \%$ & $8.2 \%$ \\
Austria & 10.8 & 7.7 & Materials & 13.5 & 10.7 \\
Belgium & 8.2 & 5.8 & Industrials & 13.6 & 11.3 \\
Canada & 13.6 & 11.5 & Consumer discretionary & 14.2 & 11.9 \\
Denmark & 11.6 & 9.4 & Consumer staples & 12.6 & 9.3 \\
Finland & 13.5 & 7.7 & Health care & 12.8 & 9.6 \\
France & 11.5 & 9.7 & Financials & 17.5 & 13.4 \\
Germany & 11.8 & 9.8 & Telecommunication & 12.5 & 7.5 \\
Hong Kong & 13.7 & 11.7 & Utilities & 9.5 & 6.6 \\
Ireland & 12.0 & 8.3 & & & \\
Italy & 12.0 & 10.0 & & & \\
Japan & 12.2 & 11.5 & & & \\
Netherlands & 11.0 & 8.3 & & & \\
New Zealand & 11.2 & 7.4 & & & \\
Norway & 13.1 & 8.1 & & & \\
Singapore & 13.0 & 11.0 & & & \\
Spain & 11.5 & 9.5 & & & \\
Sweden & 11.8 & 8.6 & & & \\
Switzerland & 10.1 & 8.0 & & & \\
United Kingdom & 12.1 & 10.5 & & & \\
United States & 12.7 & 11.4 & & & \\
\hline
\end{tabular}

covariance of stocks are closely tied to the concept of breadth presented by Grinold and Kahn (1995) and are discussed in more detail in Chapter 3.

Another feature of Tables 2.1 and 2.2 is that they clearly show greater opportunity from unconstrained stock selection within sectors (BU-S) than within countries (BU-C). This outcome may also be related to the greater number of stocks within each sector, on average, than within each country, which provides more opportunity within a narrower number of sectors. Thus, the notion that more opportunity to add value through stock selection is available from orienting oneself to sectors rather than geography may be partially true. But it must be tempered by the fact that less opportunity is available across sectors from a top-down perspective, perhaps because there are fewer sectors.

We examined various combinations of test results to infer the relative opportunities of various strategies. Adding the bottom-up and top-down results together to determine proportional opportunity from each was a somewhat flawed test; the act of allocating to specific countries (top-down) 
affects the ability to implement the stock portfolios in each country (bottomup). Moreover, a practitioner cannot simultaneously allocate top-down to countries and sectors; one affects the other. For example, Japan's recent market structure has about 16 percent in financials versus about 25 percent in financials globally, so an underweight in Japan results in an overweight in financials. Nevertheless, by looking at combinations, one can gain a general sense of proportion.

In Figure 2.1, we show the proportions of opportunity available from three combinations that, theoretically, sum the total set of opportunities. In the first test, shown in Panel A, we summed the returns from perfect-foresight top-down country and sector investing (TD-C and TD-S) and the result from the CELLS tests (best versus worst stocks in each intersection of country and sector, or what would be left to stock selection after country and sector decisions were made). As mentioned, to assume that one could actually achieve both best top-down cases simultaneously is unrealistic because many of the country and sector positions are mutually exclusive. Thus, the proportion of opportunity attributable to CELLS (49 percent) is probably understated.

In Panel B of Figure 2.1, we show the proportion of opportunity available when top-down country selection is combined with country-neutral selection within sectors. Panel $\mathrm{C}$ shows the converse. In each case, the proportion of opportunity available to bottom-up investing (NBU-S or NBU-C) is 60-70 percent.

The assumption in all these tests was that we could buy the top half of each universe and "sell" the bottom half. Perhaps, lifting this constraint (so that we could, say, buy only the top quarter) would provide a greater advantage to bottom-up activities. Therefore, we carried out unconstrained bottom-up tests for a series of more narrowly focused stocks. Table 2.3 shows the resulting returns and risks (standard deviations). Although the return potential expands greatly, as one would expect, the standard deviations of the returns remain proportional. We believe the same characteristics are true for country and sector allocations, but an international portfolio constructed in a way to hold only the top five countries or top three sectors is highly unlikely, whereas most portfolios could hold only the top 100 stocks. Therefore, we suggest that the 60-70 percent of opportunity from bottom-up may be understated to the extent that managers hold a smaller subset of the universe.

\section{Summary}

Stock-specific information is incredibly abundant-stocks are many, and ways to assess the information are numerous-which is why the range of managers' success at stock selection is so broad. We are not trying to categorically state 


\section{Figure 2.1. Combinations of Tests to Derive the Relative Opportunity} from Bottom-Up Activities

A. Top-Down Country + Top-Down Sector + Bottom-Up Cells

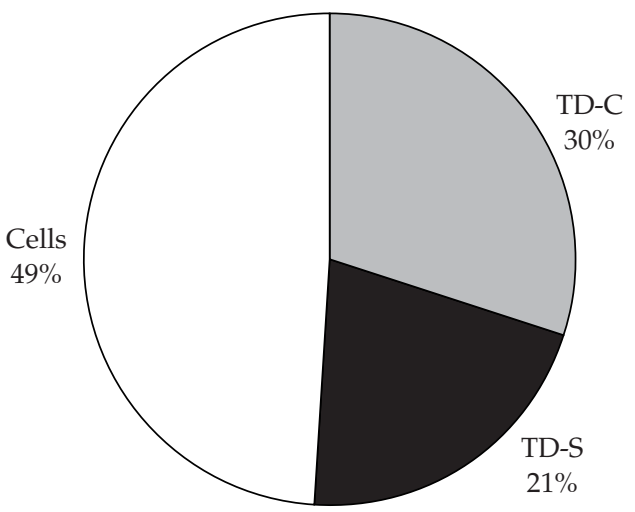

B. Top-Down Country + Country-Neutral Bottom-Up Selection by Sector

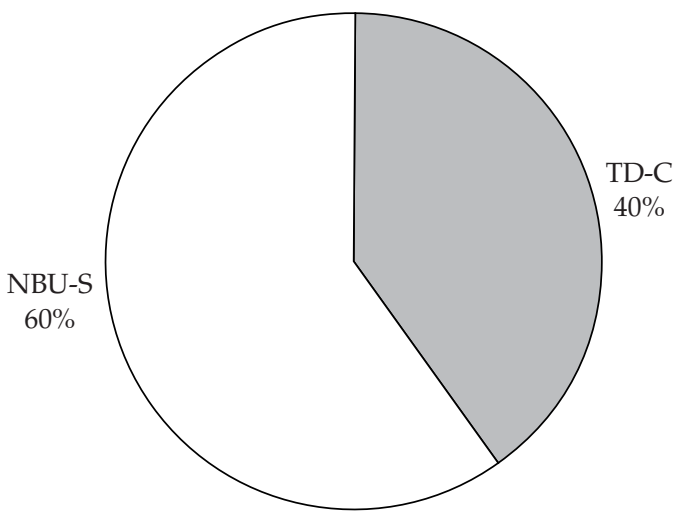

C. Top-Down Sector + Sector-Neutral Bottom-Up Selection by Country

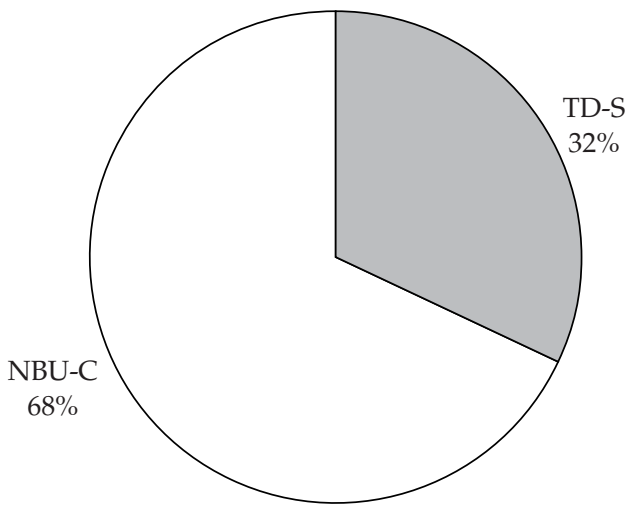




\section{Table 2.3. Range of Return and Risk for Pure Bottom-Up Tests for Various Sample Sizes}

\begin{tabular}{lcl}
\hline Sample & Return & Risk \\
\hline Top vs. bottom halves & $13.7 \%$ & $12.8 \%$ \\
Top vs. bottom 500 & 17.9 & 16.1 \\
Top vs. bottom 400 & 20.5 & 18.7 \\
Top vs. bottom 300 & 24.0 & 22.1 \\
Top vs. bottom 200 & 28.7 & 27.1 \\
Top vs. bottom 100 & 37.1 & 36.1 \\
Top vs. bottom 50 & 45.6 & 45.9 \\
\hline
\end{tabular}

that value is more likely to be added through stock selection than through top-down decisions. Indeed, we cannot say so from these results. What these tests did is provide, through perfect-foresight tests, a scale for adding maximum value through stock selection versus top-down forms of decisions. When decision rules are applied, such as value criteria or growth screens, the relative opportunities from stock selection may vanish or be severely diminished.

The idea that picking stocks within countries (neutralized for sector) should provide extensive opportunities is intuitive; we all know that companyspecific information translates into extreme intramonth gains and losses. The data in this chapter confirm that intuition. Lately, picking stocks within sectors (neutralized for country) has provided more opportunity than we have seen in recent history. 



\section{Countries, Sectors, and Stocks in Active Portfolio Management}

Our aim in this chapter is to estimate information coefficients (indicating the level of manager skill) for excess return and risk in stock selection, country selection, and sector selection. The ICs should indicate the relative efficiency of manager activities devoted to research in country, sector, and/or stock decisions. We will pursue this goal by first estimating information ratios (IRs) and breadth; from these ingredients, we will deduce the information coefficients.

According to Grinold and Kahn in Active Portfolio Management (1995), the IR depends on a combination of (1) the breadth of decisions made and (2) an information coefficient (IC). The IR is calculated by dividing a portfolio's return in excess of its benchmark return (its alpha) by its tracking error against the benchmark. The information ratio increases in proportion to the level of a manager's skill, as represented by the IC, and as a function of the square root of the breadth of opportunities. The formula is as follows:

$$
I R=I C \times \sqrt{\text { Breadth }} .
$$

\section{Breadth Considerations}

"Breadth of decisions" is easier to conceptualize than to quantify. Grinold and Kahn defined breadth as the number of independent forecasts of exceptional return made for each year. If we infer that the independence between two assets can be approximated by their correlations, the implication is that country and sector issues are important to breadth considerations. Indeed, the time-series tests in Chapter 1 showed that the correlations within certain countries and sectors can be quite high, which reduces the independence of decisions made within those countries and sectors. For example, choosing between two energy stocks, such as British Petroleum and Royal Dutch/Shell Group, carries a lower degree of independence than, say, choosing between Marks \& Spencer and Philips Electronics, two consumer discretionary stocks. In fact, we propose that breadth can be scaled by using the correlations we found in the "Time-Series Tests" section. We assume that a correlation of +1 
between two assets connotes complete dependence, amounting to effectively one decision. A correlation of 0 is complete independence (two decisions). The average correlation within a country or sector can be used, then, as a scaling factor for the degree of independence among the available stocks.

Furthermore, the breadth factor specifies that these independent forecasts must be made for "exceptional returns per year," which might be equated with excess returns. Thus, because the correlations that resulted from the time-series tests were based on excess returns for each stock against its respective market-weighted country and sector indexes (ex the stock in question), we were able to use the correlations directly without modification in our subsequent analyses.

Finally, for our purposes of comparing stock, country, and sector selection, we do not believe that the time horizon of decisions makes a great difference. We assumed that, for whatever time period applies, investors make the same number of decisions, whether top-down or bottom-up, for each asset. This assumption may not be the case for many investors, but our results are probably not biased greatly by this assumption. Therefore, in our analyses, we assumed a single unit of time, which was equivalent across the range of decisions.

To calculate the information ratio (or, rather, impute the information coefficients) for country, sector, and stock decisions, breadth must be calculated. The breadth calculation for the median manager of non-U.S. portfolios, with a total of $k$ countries in the universe, might be approximated in the following way:

$$
\text { Breadth }=\left(1-r_{C 1}\right)\left(N_{C 1}\right)+\left(1-r_{C 2}\right)\left(N_{C 2}\right) \ldots\left(1-r_{C k}\right)\left(N_{C k}\right),
$$
where

$r_{C j}=$ the market-weighted average correlation of stocks' excess returns within country $j$ (for $r<0$, we assumed 0 , so all assets were considered independent)

$N_{C j} \quad=$ the number of stocks in the index for country $j$

In our calculations, we used the final three-year average correlations of excess returns (each stock minus the global index return) for each stock relative to its country or sector ex itself.

Table 3.1 shows how the original number of stocks in the Morgan Stanley Capital International (MSCI) Global Index was reduced from 1,312 to 981 through the application of the breadth formula at the country level. The non-North American index, the Europe/Australasia/Far East (EAFE) Index, shrank from 905 to 616 when the same methodology was used. We applied this logic to sectors also, reducing the number of stocks in each sector in 
Table 3.1. Using Correlations to Determine Breadth

\begin{tabular}{|c|c|c|c|}
\hline Country/Sector & $\begin{array}{c}\text { MSCI } \\
\text { Number of } \\
\text { Stocks }\end{array}$ & $\begin{array}{l}\text { Average ex } \\
\text { Stock } \\
\text { Correlation }\end{array}$ & $\begin{array}{l}\text { Implied } \\
\text { Breadth }\end{array}$ \\
\hline \multicolumn{4}{|l|}{ Country } \\
\hline Australia & 57 & 0.26 & 42 \\
\hline Austria & 16 & 0.34 & 11 \\
\hline Belgium & 17 & 0.39 & 10 \\
\hline Canada & 71 & -0.04 & 71 \\
\hline Denmark & 21 & 0.33 & 14 \\
\hline Finland & 27 & 0.43 & 15 \\
\hline France & 53 & 0.22 & 41 \\
\hline Germany & 48 & 0.26 & 36 \\
\hline Hong Kong & 28 & 0.65 & 10 \\
\hline Ireland & 14 & 0.11 & 12 \\
\hline Italy & 40 & 0.50 & 20 \\
\hline Japan & 281 & 0.34 & 186 \\
\hline Netherlands & 23 & 0.14 & 20 \\
\hline New Zealand & 11 & 0.22 & 9 \\
\hline Norway & 24 & 0.46 & 13 \\
\hline Singapore & 30 & 0.49 & 15 \\
\hline Spain & 33 & 0.40 & 20 \\
\hline Sweden & 33 & 0.20 & 26 \\
\hline Switzerland & 36 & 0.33 & 24 \\
\hline United Kingdom & 113 & 0.19 & 91 \\
\hline United States & 336 & 0.12 & $\underline{294}$ \\
\hline Global & $\overline{1,312}$ & & $\overline{981}$ \\
\hline EAFE & 905 & & 616 \\
\hline \multicolumn{4}{|l|}{ Sector } \\
\hline Energy & 40 & 0.61 & 16 \\
\hline Materials & 152 & 0.46 & 83 \\
\hline Industrials & 278 & 0.08 & 257 \\
\hline Consumer discretionary & 238 & 0.08 & 219 \\
\hline Consumer staples & 101 & 0.47 & 54 \\
\hline Health care & 74 & 0.57 & 32 \\
\hline Financials & 204 & 0.40 & 122 \\
\hline Information technology & 134 & 0.42 & 77 \\
\hline Telecommunication services & 35 & 0.32 & 24 \\
\hline Utilities & 61 & 0.49 & 31 \\
\hline Global & $\overline{1,317}$ & & $\overline{914}$ \\
\hline
\end{tabular}


accordance with the correlations within sectors. Because our time-series sector data included North America, we could show a global implied breadth for sectors of only 914 , even lower than for countries.

The calculation of breadth at the country/sector level, compared with the calculation for stock selection, is further complicated by the way most portfolios are constructed. With 20 countries, 10 sectors, and 915 stocks in the EAFE Index as of December 31, 2000, we believed we could assume that a more overt set of decisions was being taken at the country and sector level than at the stock level. 1 That is, in a non-U.S. portfolio of, say, 100 stocks, we could assume that the manager expected positive exceptional returns for the overweight positions in the portfolio, but we could not assume that the manager necessarily expected negative exceptional returns from all of the 815 stocks excluded from the portfolio. We could reasonably assume, however, that the country and sector underweights reflected decisions based on expected negative relative returns. Applying this rationale to the implied breadth number of 616 for the EAFE universe might result in a further reduction of stock breadth by, say, half-to about 300.2

\section{IC Considerations}

Turning to the other key ingredient in the information ratio, recall that the information coefficient is defined as the relationship between an investor's forecasts and the actual outcome. As a general rule, ICs in the vicinity of 0.05 to 0.10 are considered to be quite good.

\footnotetext{
1 We used management of non-U.S., rather than global, portfolios because our analysis relied on universe data and other work that was based only on managers of non-U.S. portfolios. This focus is the result of the prevalence of non-U.S. mandates relative to global mandates in the U.S. institutional market. The greater number of managers in the non-U.S. universe gives better statistical evidence for the arguments presented than would be the case if we had used a global equity universe.

2 We would like to thank Roger Clarke for bringing this concept to our attention. Any vagueness in its application is strictly the authors'. The definition of breadth is the number of forecasts of exceptional returns a period. Because a portfolio of 100 stocks should signify close to 100 forecasts of positive exceptional returns, the question is how many of the remaining 800 or so stocks the manager made either positive or negative exceptional return forecasts for. On the one hand, a number close to 100 suggests that managers have a lot of gaps in their research. On the other hand, a number close to 800 assumes firm views on stocks that are probably screened out based simply on style biases. The answer depends on many factors and will be different for different managers. So, taking half is somewhat arbitrary. But it gives managers the benefit of the doubt. As will be seen later, the lower the breadth, the higher the IC for stock selection, which implies managers with more skill. Thus, a factor of one-half is generous to active managers.
} 
Because there is no repository of managers' stock return forecasts, ascertaining the universe's ICs directly was difficult. We could estimate ICs indirectly, however, by working backward from the actual information ratios generated by the investment industry. Specifically, we set out to gather IRs for the top-down and bottom-up elements of portfolio construction.

Calculating Information Ratios by Attribution. IRs measure the unit of excess return per unit of relative risk and are calculated as excess return divided by tracking error. To derive information ratios for investors' country, sector, and stock selections, we needed excess returns and tracking errors attributable to each element.

Excess returns. We used Intersec Research Corporation's global and non-U.S. manager databases of the performance of managers of approximately 100 tax-exempt pension funds. We believe Intersec's results are indicative of the results found in most other manager databases. Moreover, we could not find a database that provided universe attribution for a longer time period than from 1992. Figure 3.1 provides the compound annualized attributions for the performance of the Intersec institutional managers in the global universe (Panel A) and the EAFE universe (Panel B) for the eight years ending December 2000. The scale in the charts is the annualized percentage value added above the benchmark (MSCI World or EAFE). Thus, EAFE managers added a median of 1.30 percent value a year over the index from country selection and 1.47 percent a year from stock selection. The 25th percentile managers generated 2.23 percent and 2.03 percent a year from, respectively, country and stock selection. Note that all manager sector and stock selection shows up in the stock selection performance in Figure 3.1. Thus, one cannot distinguish between sector allocation and stock selection. ${ }^{3}$

Figure 3.1 shows that the median manager during this period added slightly more value from stock selection and sector selection combined than from country allocation. 4 Another important revelation of Figure 3.1, however, is the wide dispersion of results managers have had from their stock/sector selection activities, especially global managers (in Panel A). The best performers added much more value from stocks than even the best manager added from country allocation. The worst also gave up greater relative returns. The

\footnotetext{
3 We found no service that kept sector or industry level data on managers for a suitably long time period other than the information referred to in Lin (2000), which is discussed in connection with tracking error.

4 The algorithm used by Intersec and other performance measurement consultants forces the transaction costs into the stock selection category. Dividing transaction costs between the two attribution categories would slightly widen the gap between them.
} 


\section{Figure 3.1. Performance Attribution: Managers of Tax-Exempt Funds, December 1992-December 2000}

A. Global Universe

Excess Return (\%)

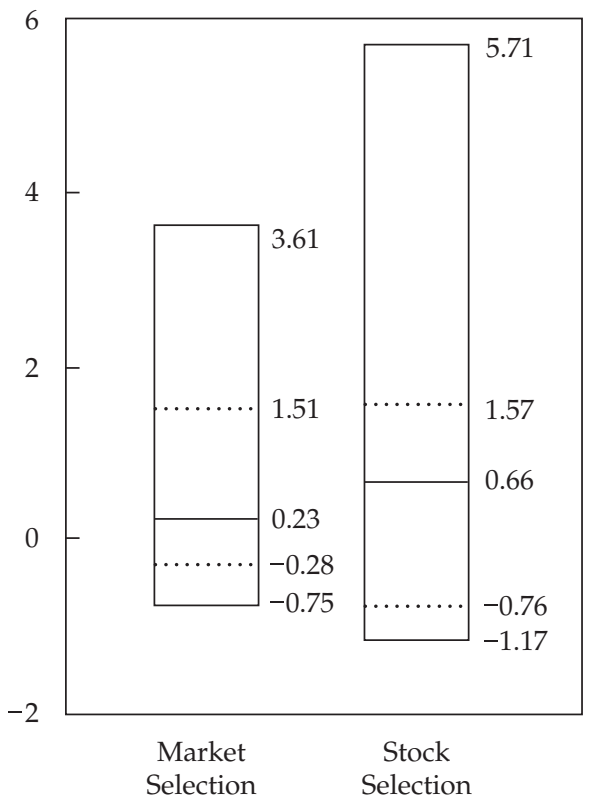

B. EAFE Universe

Excess Return (\%)

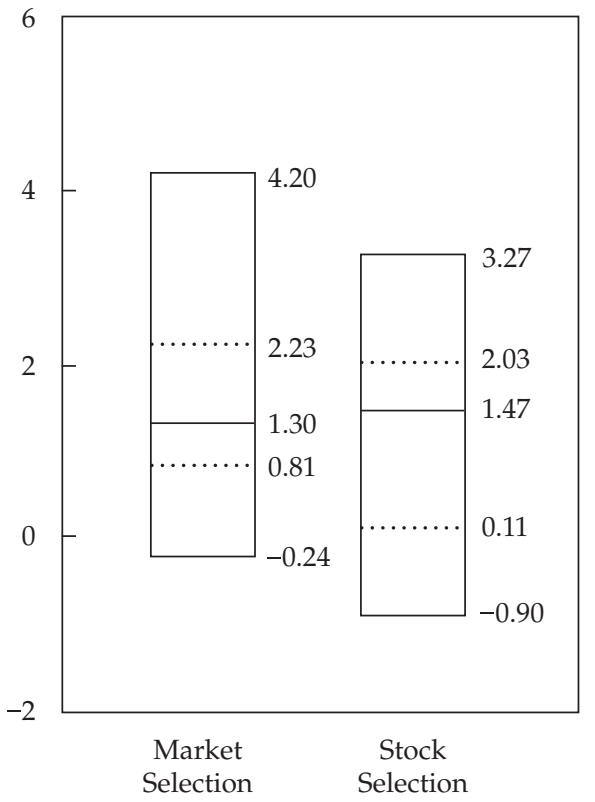

Note: Compound annual excess returns. The solid horizontal line identifies the excess return of the median manager; the solid line and the dotted horizontal lines identify the quartile breaks in the manager universe.

Source: Intersec.

performance of the global managers is consistent with the results of the perfect-foresight tests and indicates that the greater breadth available from stock/sector selection represents greater opportunity to either outperform or underperform. In the case of the EAFE universe (Panel B), the dispersion in returns for stock/sector selection is not much greater than for market selection (although it is wider for most short time periods).

A slightly different perspective on the median non-U.S. manager is provided in Figure 3.2. As can be seen, in only 3 of the 11 years covered did the median manager generate more relative return from stock (including sector) selection than from country selection. Because of the importance of the unprecedented sectoral influence on portfolios in 1999 (i.e., the new economy's strength), we can safely say that sector selection had a great deal to do with the compound eight-year "stock selection" median's outperformance in 


\section{Figure 3.2. Performance of Median Manager of Tax-Exempt Funds} versus EAFE, 1990-2000

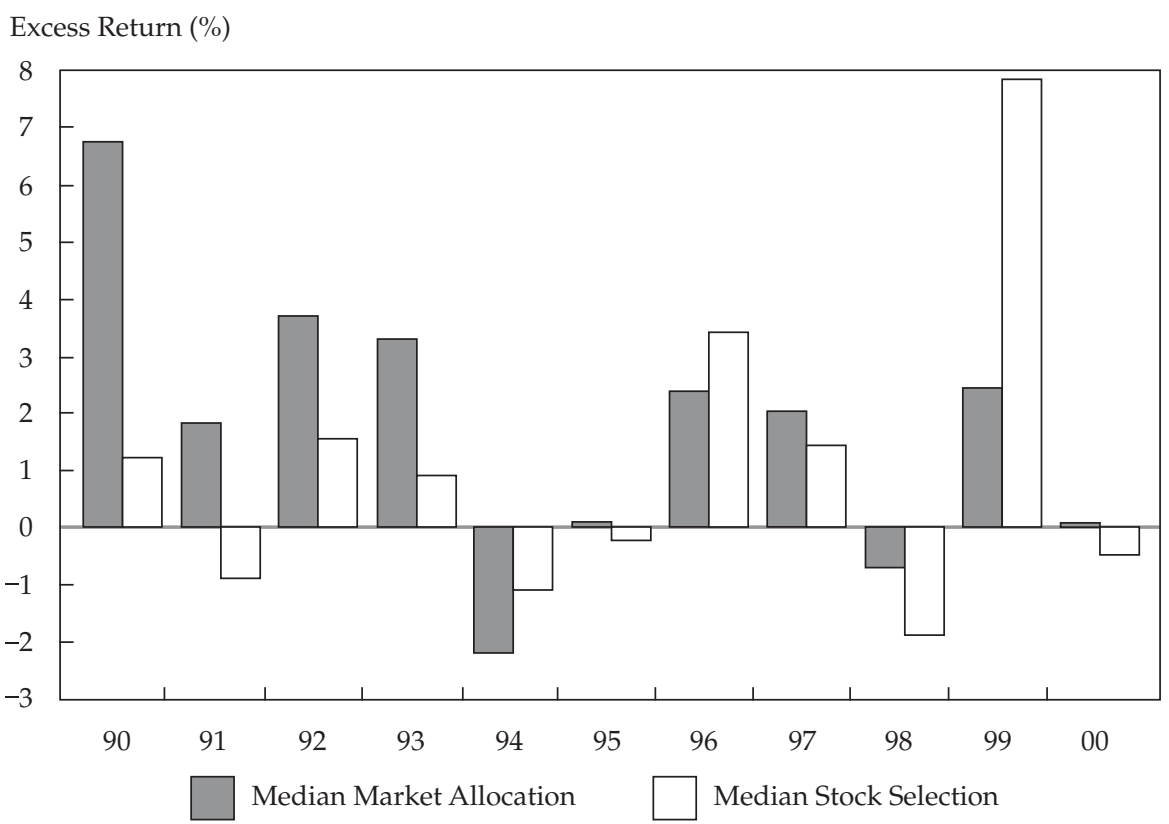

Note: Annual excess returns.

Source: Intersec.

Figure 3.1. We do not wish to diminish the importance of other elements of stock selection during this period; for example, the extreme returns of smallcap stocks in Japan also affected the compound 1999 results.

In the attribution structure postulated in Chapter 2, stock selection was defined as everything that was not country or sector allocation. Given the strength in sector allocation recently, the professional management universe has almost certainly added much less value from true stock selection in the past 10 years than from country allocation-especially in the case of managers with non-U.S. mandates, for whom the strong Japan effect boosted the attribution of value added from country selection.

Biases may affect any analysis based on the Intersec universe. In fact, it is hardly likely that a group of 100 or so pension asset managers operating in the United States is a good representation of international managers globally. Although laws of statistical properties suggest that the sample size is sufficient, biases may exist in regard to capitalization, value, or a host of other characteristics. Therefore, we also compared performances of offshore 
mutual funds against relevant regional or country indexes to see whether the retail universe would give a different result. Specifically, we looked at the performance of the median retail fund in each regional or country universe for December 1992 to December 2000, for which performance was calculated on an offer-to-offer basis in U.S. dollars from the Micropal database. We compare these medians with the relevant MSCI index in Table 3.2. As this table shows, in every case except Japan, the median managers underperformed the index. These results make the performance of the institutional managers look favorable in comparison and should alleviate concerns about downward biases in the Intersec data.

For managers with emerging market mandates, attribution analysis clearly shows the importance of country allocation. Figure 3.3 shows attribution for the emerging market universe relative to the MSCI Emerging Markets Free Index for a six-year period. Market allocation has clearly been the managers' leading source of alpha. And as with attribution for global and non-U.S. managers, dispersion in value added ascribed to stock/sector selection is wide.

Tracking errors. To analyze how much deviations from benchmark allocations contribute to managers' alphas, we started with the Intersec data on tracking error for the managers working with an EAFE Plus mandate. 5 Figure 3.4 shows the range of tracking errors (in percentage terms) for this non-U.S. universe. For the excess return analysis here, we used the median of 6.35 percent.

\section{Table 3.2. Performance of Median Offshore Mutual Fund by Region/Country, December 1992-December 2000}

\begin{tabular}{lcc}
\hline Region/Country & $\begin{array}{c}\text { Median Fund } \\
\text { Return }\end{array}$ & $\begin{array}{c}\text { MSCI Benchmark } \\
\text { Return }\end{array}$ \\
\hline Europe ex United Kingdom & $15.82 \%$ & $17.94 \%$ \\
Hong Kong & 11.50 & 12.38 \\
Japan & 2.87 & 2.53 \\
United Kingdom & 11.75 & 13.30 \\
United States & 15.57 & 17.40 \\
\hline
\end{tabular}

Source: Micropal. 5 EAFE Plus refers to portfolios that contain in addition to EAFE allocations a modest
opportunistic allocation to emerging markets. 


\section{Figure 3.3. Performance Attribution for Managers in the Emerging Market Universe, December 1994-December 2000}

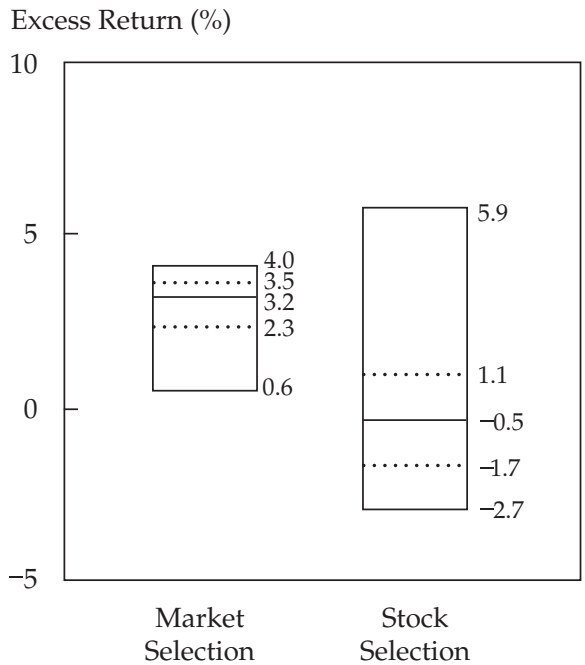

Note: Compound annual excess returns. The solid horizontal line identifies the excess return of the median manager; the solid line and the dotted horizontal lines identify the quartile breaks in the manager universe.

Source: Intersec.

We combined these data with work performed by Wenling Lin (2000) of Frank Russell Company. Using actual manager universe information for both global and EAFE mandates, Lin measured the degree to which managers' excess returns are driven by country versus sector exposures. She used a methodology very similar to the cross-sectional regressions we used in Chapter 1 (see Appendix B) but with data on managers' excess returns, their country weights, and their sector weights. (The sector classifications differed from the MSCI system we used.) As can be seen in Table 3.3, her tests showed that with EAFE as the benchmark, country allocation deviations explained 50 percent of excess returns for the second quarter (Q2) of 1993 to the first quarter (Q1) of 1998. She found that sector allocations explained 31 percent, and the combination of allocations based on countries and sectors explained a substantial 65 percent of excess returns. ${ }^{6}$ Note that this analysis is an explanation of what is driving managers' relative risk (as measured by

6 The implication is that 35 percent of managers' cross-sectional excess returns have been driven by stock selection in the "cells" sense, but remember that all of the noise in these regressions is contained in that 35 percent. 
Figure 3.4. Tracking Error for Managers of Tax-Exempt Funds in the EAFE Plus Universe, December 1994-December 2000

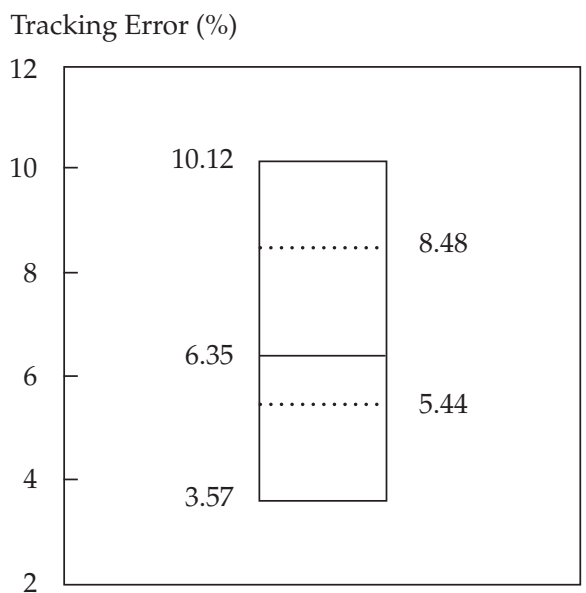

Note: The solid horizontal line identifies the tracking error of the median manager; the solid line and the dotted horizontal lines identify the quartile breaks in the manager universe.

Source: Intersec.

\section{Table 3.3. Explanatory Power of Country and Sector Selections in Excess Return Variations: EAFE as Benchmark, Q2 1993-Q1 1998}

\begin{tabular}{lccc}
\hline Measure & Country & Sector & $\begin{array}{c}\text { Country Plus } \\
\text { Sector }\end{array}$ \\
\hline $\begin{array}{l}\text { Average } R^{2} \\
\begin{array}{l}\text { Frequency of } \\
\text { significance }\end{array}\end{array}$ & $50 \%$ & $31 \%$ & $65 \%$ \\
\hline
\end{tabular}

Source: Lin.

tracking error) but does not deal with what has driven managers' long-term alpha, or excess return. Essentially, managers' country calls have had a greater impact on risk than have their sector calls.

Because the time frame for these tests was Q2 1993 to Q1 1998, the tests did not include the most recent two years, when sector effects strengthened. In conversations with the author, we confirmed that new data from Q1 1999 through Q2 2000, as yet unpublished, show much higher explanatory power for sector allocations (50-70 percent), with country allocation explaining 
slightly less than previously. The new data may indicate that the magnitudes of sector returns have become more important drivers than the sector weights chosen by managers in generating these factor returns. Because of this recent shift, we suggest that over the full time period, country effects explain something more like 45 percent than Lin's original 50 percent of tracking error.

Plugging the 45 percent of tracking error risk from countries back into the median tracking error figure of 6.35 percent for the EAFE universe from Figure 3.4, we conclude that country allocations, on average (median), account for a tracking error of approximately 2.9 percent and the combination of sector and stock selection accounts for the other 3.5 percent. (Exact figures are not important; we are trying to make a more general point.)

Estimated IRs. Now we can estimate information ratios for country allocation and stock selection, at least for managers in the non-U.S. equity universe. Taking the median eight-year alpha from country allocation of 1.3 percent (from Figure 3.1) and dividing by the 2.9 percent tracking error (45 percent of 6.35 percent median) gives an IR of 0.45 . For stock and sector selection combined, the IR is 1.5 percent $/ 3.5$ percent $=0.43$. We find, therefore, that country allocation has a slightly higher information ratio than sector and stock selection combined. That is, country allocation has been as efficient a use of managers' efforts as country/sector allocation, even if it has not been the highest-returning activity.

Implied ICs. From the foregoing analysis, we can now estimate information coefficients for country, sector, and stock selection by working backward. If

$$
I R=I C \times \sqrt{\text { Breadth }},
$$

then

$$
I C=\frac{I R}{\sqrt{\text { Breadth }}} .
$$

Substituting from the previous sections yields the following results:

Country allocation: $\frac{0.45}{\sqrt{20}}=0.10$;

Sector allocation (assuming all alpha comes from sector allocation): $\frac{0.43}{\sqrt{10}}=0.14$;

Stock selection (assuming all alpha comes from stock selection): $\frac{0.43}{\sqrt{300}}=0.02$. 
Clearly, even allowing for reduced breadth from stock selection, managers would have had to add considerably more value from stock selection than country selection activities to maintain even similar information coefficients. Given the greater opportunities available in stock selection, discussed in the "Perfect-Foresight Tests" section of Chapter 2, and the fact that managers' value added from stocks has been merely on a par with country selection (and perhaps even less than either country or sector allocation once stock and sector effects are separated), the IC estimates should be no surprise.

\section{Summary}

The information coefficient is the correlation of forecasts of excess return to actual outcomes. That stock selection activities have, on average, lower ICs than country (and probably sector) allocation activities, based on broad nonU.S. manager results for recent years, implies that stock selection is a more difficult activity in which to succeed. The size of the IC differentials suggests that individual stocks, in general, have a lower "signal-to-noise ratio" than stocks aggregated into countries and sectors. We propose that grouping stocks diversifies company-specific data and, in effect, reduces noise. Finally, such reduced information coefficients simply level the playing field for topdown and bottom-up activities. This statement does not imply that either activity has inherent advantages over the other. What country or sector selection may gain in efficiency, it gives up in breadth, and the opposite is true of company selection.

Such statements on the synthetic logic presented here require a number of caveats. First, the universe of managers with non-U.S. mandates may have been biased somehow. We believe that the Intersec data are broadly comparable to the data of the other leading performance services, but institutional managers operating in the U.S. markets may have certain characteristics that cause an emphasis on country allocation and some deficiency in stock management. The cost structure required to broadly cover the plethora of global companies certainly leads to less-efficient activities than organizing research on more top-down lines. Clearly, some managers in the top quartile of stock selection have added great amounts of value, however, through such effort.

The algorithms used to attribute performance present problems, in that (1) no distinction was made between stock selection and sector selection, and (2) transaction costs were assigned to stock/sector selection. We believe these issues are not severe enough to affect the general conclusions.

The time horizon over which this analysis was performed may have been slanted in favor of country allocation and against stock selection. The "Japan effect" was significant during this time period and contributed to the importance of country selection. But this effect might have been offset by the new economy 
effect in 1999, which led to median stock selection attributions of +7.4 percent for that year. Readers need to keep in mind that these results are time sensitive and that negating one-off effects poses significant risks.

\section{Further Research}

The magnitude of the difference between the estimated ICs for country selection (0.10) and stock selection (0.02) is such that the benefits of managing country indexes rather than picking stocks are hard to refute. Some avenues for research may provide a more direct assessment, however, of the relative degree of efficiency in devoting resources to the two strategies than these tests.

One interesting avenue of research is the investigation of the differences between top-down and bottom-up earnings forecasts. If we assume that the ability of analysts to predict earnings is indicative of the ability of investors to select stocks, then we can draw parallels between analysts' success in their estimates and likely successful stock picking. The analyst universe generates bottom-up earnings forecasts on companies and top-down forecasts for countries as a whole. There are some key differences in the way these forecasts are made. The top-down forecasts tend to be based more on economic analysis than on corporate financial data. Bottom-up forecasts have a well-known tendency to be optimistic early in the fiscal year and to drop as the year progresses. Some industry analysts have suggested that the reason is the particular motives analysts have to be optimistic about many of the stocks they cover. The motives include the desire to motivate customers to transact and the desire to avoid disappointing corporate banking clients or prospects. Topdown analysts, being primarily economists and strategists, do not have the same motives.

Darrough and Russell (1998) used bottom-up and top-down forecasts of U.S. (S\&P 500 Index) stocks to compare, among other things, forecast error. They aggregated company-level forecasts (bottom-up) and used strategists' top-down forecasts directly. They examined forecasts from 21 months ahead to 1 month after fiscal years ending 1987 through 1997. In assessing the error of each set of forecasts, they looked at the average of the mean absolute deviations of forecasts from actual outcomes through time. The forecast error for the bottom-up universe was about 15 percent at 21 months ahead and averaged 8.7 percent for the entire 23-month horizon. The figures for the topdown forecast were about 9 percent at 21 months and 8 percent over the entire period. Moreover, although the errors for the bottom-up universe tended toward zero after fiscal year ends, the top-down errors stayed high, presumably because (1) strategists are not looking at nonoperating accounting issues, which are at the discretion of management, and (2) they are less concerned about tidying up their old forecasts than looking ahead at future years. 
Given the differences in motivation and cognitive biases between these two groups, the result is not surprising. Yet, it does suggest that bottom-up forecasts are less correct, on average, than top-down forecasts, which supports the thesis we presented for the weaker information coefficient for stock selection. This area might be further explored in the future, especially in relation to the international markets.

Another supporting thesis comes from Peters (1991). Peters used rescaled range analysis to calculate Hurst coefficients on long time series in the capital markets. The Hurst coefficient can be viewed as an indicator of signal-to-noise; a value of 0.5 indicates true randomness, or Brownian motion. A series of data with this coefficient would be all noise. A figure greater than 0.5 indicates a tendency for persistence in the data, and a figure below 0.5 suggests antipersistence. Using monthly price series for individual U.S. stocks and the S\&P 500, Peters calculated a higher Hurst coefficient for the S\&P 500 than for any of the individual stocks. He concluded that the index exhibits less noise than the individual stocks, which is a product of the diversification that indexes provide. This area is also fertile for international research.

Finally, in unpublished research, Fishwick and McQueen (1996) showed that the information coefficient for stock selection within sectors is greater than for stock selection within countries. ${ }^{7}$ Their orientation toward organizational dynamics and design as reasons for this finding is presumptuous but instinctively compelling. First, they posited that ICs are a function of inefficiencies in markets. Next, they noted that because professional fund managers and securities firms have traditionally been established along geographical lines, research within countries has been more efficient than research within global sectors. Finally, they cited a shift (in 1996) toward more global sector orientation within securities firms. One might further infer, therefore, that the recent relative importance of sectors versus countries stems partly from a shift in the way investment firms operate.

A related but more practical and fundamental point of view recognizes sheer numbers. The MSCI World Index is divided into 22 countries, 10 sectors, 23 industry groups, and 1,206 companies. The research requirement at the stock level, especially given the idiosyncratic nature of stock data, is vastly greater than the requirement for countries and sectors, where exogenous variables may be more condensed (although not necessarily more predictable). Fund managers as a group may recognize the economy in devoting efforts to the aggregate levels and thus devote more resources, per decision, on top-down than on bottom-up decisions. This practical reason may explain the managerial universe's better record from top-down decisions.

7 They did not deal directly with the question of top-down allocation versus bottom-up selection. 


\section{Conclusions}

This research provides two primary insights. First, a recent rise has occurred in the importance of industry sectors in global investing. Second, globally, stock selection may not be an inherently more profitable area of focus for money managers than country or sector allocation.

\section{The Rise in Sector Importance}

A relatively significant shift appears to have recently occurred in the importance of global sectors and industries at the expense of geography in global investment strategies. Although this emphasis can and does shift through time, the rewards from global sector allocation, as well as organizing stock selection on sectoral lines, seem to justify allocating resources to sector research on an ongoing basis.

Many of the tests suggest that an industry group orientation (rather than the broader sector-level orientation) can add value, but the value added may not justify the additional resources or efforts. Focusing on smaller subgroups brings diminishing returns.

Among sectors, the information technology sector has the clearest distinction between its component industries-the technology hardware and equipment industry group, on the one hand, and the software and services industry group, on the other hand-and their distinction provides the clearest opportunity to add value. Other sectors that might be worthwhile because they exhibit some global homogeneity are utilities, health care, telecommunications, and to a lesser extent, finance. Investors appear to have less reason to focus on top-down calls in consumer discretionary, consumer staples, industrials, or materials sectors. Sector teams might still be useful, however, in assisting with stock selection decisions within the sectors with relatively good opportunities for producing alpha.

In policies for investing based on geography, managers should first focus their efforts on countries or regions that exhibit homogeneity. For the better part of the 1990s, such areas would have been Singapore, Hong Kong, and a few of the smaller European countries. As the cluster analysis shows, Europe now is probably better approached by a process that includes sectoral and geographical elements more holistically. An allocation decision to the United States, United Kingdom, or Canada should be secondary to the sector and stock biases in those countries. In other markets-such as Japan, Australia, 
and New Zealand-establishing allocation calls and stock selection strategies that will work in tandem may be prudent.

\section{Relative Power of Stock Selection}

The second insight has to do with the relative importance of stock selection. Clearly, based on the data we had, the opportunity for alpha from selecting a portfolio of stocks significantly outweighs the opportunity from country or sector selection. But managers as a group have not generally exploited that opportunity. The best stock selectors have added significant value; the worst have given up the same; and the average have added value at about the same level as country selection. Moreover, the data we had did not distinguish between sector allocation and stock selection; thus our tests could not make the distinction. In the future, we suspect attribution methods will begin to distinguish between these two activities, so stock selection will be viewed more in the cells context (i.e., selection within Japanese financials, European consumer staples, etc).

The relative advantages from stock selection activities are different for different countries and sectors. Stock selection is more important in the United States than in Hong Kong. It is also more important in the industrials and consumer discretionary sectors than in health care or information technology, where the sectoral influences are more global in scope.

A strong equalizing effect apparently exists between depth within countries and sectors and breadth across them. Selecting securities offers greater opportunity and scope but at a cost of having much greater information to sift and with greater noise. Allocating across sectors and countries offers less scope but better signals. At least the universe of managers with Europe/ Australasia/Far East mandates, and we believe also global managers, has found this situation to be true. Therefore, one might conclude that there really is more than one way to skin a cat and that no particular style has inherent advantages over the other. 


\section{Appendix A. MSCI Global Industry Classification Standard}

\section{Energy}

Equipment and services

Oil and gas drilling

Oil and gas equipment and services

Oil and gas

Integrated oil and gas

Exploration and products

Refining and marketing

\section{Consumer Staples}

Food and drug retailing

Drug retail

Food distribution

Food retail

Food, beverage, and tobacco

Brewers

Distillers and vintners

Soft drinks

Agricultural products

Meat, poultry, and fish

Packaged foods

Tobacco

Household and personal products

Household products

Personal products

\section{Materials}

Chemicals

Commodity chemicals

Diversified chemicals

Fertilizers and agriculture chemicals

Industrial gases

Specialty chemicals

Construction materials

Containers and packaging

Metal and glass containers

Paper packaging
Metals and mining

Aluminum

Diversified metals and mining

Gold

Precious metals and minerals

Steel

Paper and forest products

Forest products

Paper products

\section{Industrials}

Capital goods

Aerospace and defense

Building products

Construction and engineering

Electrical components and equipment

Heavy electrical equipment

Industrial conglomerates

Construction and farm machinery

Industrial machinery

Trading companies and distributors

Commercial services and supplies

Commercial printing

Data processing services

Diversified commercial services

Employment services

Environmental services

Office services and supplies

Transportation

Air freight and couriers

Airlines

Marine

Railroads

Trucking

Airport services

Highways and rail tracks

Marine ports and services 


\section{Consumer Discretionary}

Automobiles and components

Auto parts and equipment

Tires and rubber

\section{Automobiles}

Automobile manufacturers

Motorcycle manufacturers

Consumer durables and apparel

Consumer electronics

Home furnishings

Homebuilding

Household appliances

Housewares and specialties

Leisure products

Photographic products

Apparel and accessories

Footwear

Textiles

Hotels, restaurants, and leisure

Casinos and gaming

Hotels

Leisure facilities

Restaurants

Media

Advertising

Broadcasting and cable TV

Movies and entertainment

Publishing and printing

Retailing

Distributors

Catalog retail

Internet retail

Department stores

General merchandise stores

Apparel retail

Computer and electronic retail

Home improvement retail

Specialty stores

\section{Health Care}

Health care equipment and services

Health care equipment

Health care supplies

Health care distributors and services

Health care facilities

Managed health care
Pharmaceuticals and biotechnology

Pharmaceuticals

Biotechnology

\section{Utilities}

Electric

Gas

Multi-utilities

Water

\section{Information Technology}

Software and services

Internet software and services

IT consulting and services

Application software

Systems software

Technology hardware and equipment

Networking equipment

Telecommunications equipment

Computer hardware

Computer storage and peripherals

Electronic equipment and instruments

Office electronics

Semiconductor equipment

Semiconductors

\section{Financials}

Banks

Diversified financials

Consumer finance

Diversified financial services

Multisector holdings

Insurance

Insurance brokers

Life and health insurance

Multiline insurance

Property and casualty insurance

Reinsurance

Real estate

Investment trusts

Management and development

\section{Telecommunication Services}

Diversified telecom services

Alternative carriers

Integrated telecom services

Wireless telecom services 


\section{Appendix B. Regression Technique}

The regression used to determine the $K=21$ country and $J=10$ sector or 23 industry group factor returns was performed cross-sectionally for each month in the following format:

$$
R_{i}(t)=\alpha(t)+\sum_{j=1}^{J} \beta_{j}(t) I_{i j}+\sum_{k=1 \gamma k}^{K}(t) C_{i k}+\varepsilon_{i}(t),
$$

where

$R_{i}(t)=$ the return on stock $i$ at time $t$

$I_{i j} \quad=$ a dummy variable equal to 1 if security $i$ belongs to sector/ industry group $j$ and 0 otherwise

$\beta_{j}(t)=$ the country-neutral factor return for sector/industry group $j$ at time $t$

$C_{i k}=$ a dummy variable equal to 1 if security $i$ belongs to country $k$ and 0 otherwise

$\gamma_{k}(t)=$ the sector/industry group-neutral factor return for country $k$ at time $t$

$\alpha(t)=$ the common factor associated with the global market at time $t$

$\varepsilon_{i}(t)=$ the residual for stock $i$ at time $t$

The variables $\alpha(t), \beta_{j}(t)$, and $\gamma_{k}(t)$ were found for each period $t$ by minimizing

$$
\sum_{i=1}^{N(t)} w_{i}(t) \varepsilon_{i}(t)^{2}
$$

subject to the following constraints:

$$
\sum_{j=1}^{J}\left[\sum_{i=1}^{N(t)} w_{i}(t) I_{i j}\right] \beta_{j}(t)=0
$$

and

$$
\sum_{k=1}^{K}\left[\sum_{i=1}^{N(t)} w_{i}(t) C_{i k}\right] \gamma_{k}(t)=0,
$$


where $N(t)$ is the number of companies in the MSCI World Index at time $t$. The $w_{i}(t)$ 's correspond to the weight of stock $i$ in the index at time $t$ and were derived from the stocks' free market capitalizations. In the equally weighted regressions, the $w_{i}(t)$ 's were replaced with $1 / N(t)$ in the minimization function and by $N_{j}(t) / N(t)$ and $N_{k}(t) / N(t)$ in the constraints. 


\section{Appendix C. Explanatory Power Statistic}

Following Beckers, Connor, and Curds (1996), we used two types of statistics to measure the degree to which country and industry group/sector factors explain the variation in stock returns. The first was the usual $R^{2}$, which is defined as

$$
R^{2}=1-\frac{\sum_{i=1}^{N(t)} w_{i}(t) \varepsilon_{i}(t)^{2}}{\sum_{i=1}^{N(t)} w_{i}(t)\left[r_{i}(t)-\sum_{i=1}^{N(t)} w_{i}(t) r_{i}(t)\right]^{2}}
$$

We adjusted the $R^{2}$ for the number of degrees of freedom and then averaged through time, as described in Chapter 1. Typically, we dealt with 36-month moving averages of this measure.

We also used an explanatory power (EP) statistic. Whereas the $R^{2}$ is derived from the amount of variance explained by the model across all companies at time $t$, the EP statistic is based on per stock data. For any stock $i$,

$$
E P_{i}=1-\frac{(1 / T) \sum_{t=1}^{T} \varepsilon_{i}(t)^{2}}{(1 / T) \sum_{t=1}^{T}\left[r_{i}(t)-(1 / T) \sum_{t=1}^{T} r_{i}(t)\right]^{2}}
$$

where time $T$ is usually chosen to be 36 months. The per stock EPs are then averaged across stocks by using stock weights derived from the average stock weight over the period $t=1, T$.

In the equally weighted regressions, the operator was replaced by for the $R^{2}$ case. A straight average of $E P_{i}$ was used for the explanatory power statistic in the equally weighted case.

The difference between the $R^{2}$ and EP statistics derives from the $\alpha(t)$ term in the regression. This global factor return is an important driver of stock returns. Because it is the same for all stocks at time $t$ (and so has no crosssectional variance), its contribution to explaining stock returns is not measured by the $R^{2}$. The $R^{2}$, therefore, does not capture all the model's contributions. But because $\alpha(t)$ does vary through time, the EP statistic captures it on a per stock level. Consequently, the EP provides a more complete description than does the $R^{2}$ of the model's degree of fit with the data. 



\section{Appendix D. Average Characteristics of Countries and Sectors Used in Weighting}

\begin{tabular}{|c|c|c|c|c|}
\hline \multirow[b]{2}{*}{ Country/Sector } & \multirow{2}{*}{$\begin{array}{c}\text { Average Number } \\
\text { of Stocks }\end{array}$} & \multicolumn{3}{|c|}{ Market Cap as Percent of Total } \\
\hline & & Average & Minimum & Maximum \\
\hline \multicolumn{5}{|l|}{ Country } \\
\hline Australia & 53 & $1.5 \%$ & $1.1 \%$ & $1.9 \%$ \\
\hline Austria & 21 & 0.2 & 0.1 & 0.3 \\
\hline Belgium & 17 & 0.7 & 0.3 & 1.0 \\
\hline Canada & 80 & 2.4 & 1.9 & 2.9 \\
\hline Denmark & 23 & 0.5 & 0.4 & 0.6 \\
\hline Finland & 22 & 0.6 & 0.0 & 1.7 \\
\hline France & 67 & 4.2 & 3.6 & 5.6 \\
\hline Germany & 64 & 4.5 & 3.6 & 5.9 \\
\hline Hong Kong & 36 & 1.7 & 0.8 & 3.3 \\
\hline Ireland & 13 & 0.2 & 0.1 & 0.3 \\
\hline Italy & 57 & 1.8 & 1.1 & 2.6 \\
\hline Japan & 301 & 20.2 & 10.0 & 32.6 \\
\hline Netherlands & 23 & 2.5 & 1.9 & 3.2 \\
\hline New Zealand & 9 & 0.2 & 0.0 & 0.3 \\
\hline Norway & 24 & 0.2 & 0.2 & 0.3 \\
\hline Singapore & 32 & 0.3 & 0.2 & 0.6 \\
\hline Spain & 34 & 1.3 & 1.0 & 1.8 \\
\hline Sweden & 31 & 1.2 & 0.8 & 1.7 \\
\hline Switzerland & 42 & 3.3 & 2.5 & 4.3 \\
\hline United Kingdom & 137 & 10.5 & 9.2 & 11.9 \\
\hline United States & 305 & 42.0 & 32.3 & 52.5 \\
\hline Total & 1,389 & $100.0 \%$ & & \\
\hline
\end{tabular}




\begin{tabular}{lcccc}
\hline & & \multicolumn{3}{c}{ Market Cap as Percent of Total } \\
\cline { 3 - 5 } Country/Sector & $\begin{array}{c}\text { Average Number } \\
\text { of Stocks }\end{array}$ & Average & Minimum & Maximum \\
\hline Sector & & & & \\
Energy & 48 & $5.3 \%$ & $4.4 \%$ & $6.1 \%$ \\
Materials & 192 & 7.0 & 2.9 & 10.3 \\
Industrials & 321 & 12.5 & 9.2 & 15.0 \\
Consumer discretionary & 241 & 14.3 & 12.7 & 15.8 \\
Consumer staples & 124 & 9.5 & 5.1 & 12.9 \\
Health care & 62 & 9.2 & 6.6 & 12.3 \\
Financials & 234 & 20.8 & 15.8 & 23.5 \\
Information technology & 70 & 10.2 & 4.5 & 23.7 \\
Telecommunication services & 27 & 6.4 & 4.0 & 12.0 \\
Utilities & 70 & 4.8 & 2.8 & 6.7 \\
$\quad$ Total & 1,389 & $100.0 \%$ & & \\
\hline
\end{tabular}




\section{References}

Beckers, Stan, Gregory Connor, and Ross Curds. 1996. "National versus Global Influences on Equity Returns.” Financial Analysts Journal, vol. 52, no. 2 (March/April):31-38.

Beckers, Stan, Richard C. Grinold, Andrew Rudd, and Dan Stefek. 1992. "The Relative Importance of Common Factors Across the European Equity Markets.” Journal of Banking \& Finance, vol. 1, no. 16 (February):75-95.

Cavaglia, Stefano, Christopher Brightman, and Michael Aked. 2000. "The Increasing Importance of Industry Factors.” Financial Analysts Journal, vol. 56, no. 5 (September/October):41-53.

Connor, Gregory. 1995. "The Three Types of Factor Models: A Comparison of Their Explanatory Power.” Financial Analysts Journal, vol. 51, no. 3 (May/ June):42-46.

Darrough, Masako N., and Thomas Russell. 1998. "A Behavioural Model of Earnings Forecasts: Top Down versus Bottom Up.” Working paper, University of California, Davis and Santa Clara University (July).

Drummen, Martin, and Heinz Zimmermann. 1992. "The Structure of European Stock Returns.” Financial Analysts Journal, vol. 48, no. 4 (July/ August):15-26.

Fishwick, Edward, and Jason McQueen. 1996. "The Global vs. Local Debate and the Design of Active Equity Strategies.” Unpublished presentation.

Griffin, John M., and G. Andrew Karolyi. 1998. "Another Look at the Role of Industrial Structure of Markets for International Diversification Strategies." Journal of Financial Economics, vol. 50, no. 3 (December):351-373.

Grinold, Richard C., and Ronald N. Kahn. 1995. Active Portfolio Management. Chicago, IL: Richard D. Irwin.

Grinold, Richard C., Andrew Rudd, and Dan Stefek. 1989. "Global Factors: Fact or Fiction?” Journal of Portfolio Management, vol. 16, no. 1 (Fall):79-88.

Heckman, Leila, Singanallur R. Narayanan, and Sandeep A. Patel.2000. "Country and Industry Importance in European Returns.” Working paper, Salomon Smith Barney (March). 
Heston, Steven L., and K. Geert Rouwenhorst. 1994. "Does Industrial Structure Explain the Benefits of International Diversification?” Journal of Financial Economics, vol. 36, no. 1 (August 1994):3-27.

—_. 1995. "Industry and Country Effects in International Stock Returns." Journal of Portfolio Management, vol. 21, no. 3 (Spring):53-58.

Lin, Wenling. 2000. "Controlling Risk in Global Multimanager Portfolios." Financial Analysts Journal, vol. 56, no. 1 (January/February):44-53.

Peters, Edgar E. 1991. Chaos and Order in the Capital Markets. New York: John Wiley \& Sons.

Roll, Richard. 1992. "Industrial Structure and the Comparative Behavior of International Stock Market Indexes.” Journal of Finance, vol. 47, no. 1 (March):3-41.

Rouwenhorst, K. Geert. 1999. "European Equity Markets and the EMU.” Financial Analysts Journal, vol. 55, no. 3 (May/June):57-64. 